\title{
Prevention of home-related injuries of pre-school children : behavioural research on safety education for parents
}

Citation for published version (APA):

Wortel, E. (1994). Prevention of home-related injuries of pre-school children : behavioural research on safety education for parents. [Doctoral Thesis, Maastricht University]. TNO Preventie en Gezondheid. https://doi.org/10.26481/dis.19940921ew

Document status and date:

Published: 01/01/1994

DOI:

10.26481/dis.19940921ew

Document Version:

Publisher's PDF, also known as Version of record

Please check the document version of this publication:

- A submitted manuscript is the version of the article upon submission and before peer-review. There can be important differences between the submitted version and the official published version of record.

People interested in the research are advised to contact the author for the final version of the publication, or visit the DOI to the publisher's website.

- The final author version and the galley proof are versions of the publication after peer review.

- The final published version features the final layout of the paper including the volume, issue and page numbers.

Link to publication

\footnotetext{
General rights rights.

- You may freely distribute the URL identifying the publication in the public portal. please follow below link for the End User Agreement:

www.umlib.nl/taverne-license

Take down policy

If you believe that this document breaches copyright please contact us at:

repository@maastrichtuniversity.nl

providing details and we will investigate your claim.
}

Copyright and moral rights for the publications made accessible in the public portal are retained by the authors and/or other copyright owners and it is a condition of accessing publications that users recognise and abide by the legal requirements associated with these

- Users may download and print one copy of any publication from the public portal for the purpose of private study or research.

- You may not further distribute the material or use it for any profit-making activity or commercial gain

If the publication is distributed under the terms of Article 25fa of the Dutch Copyright Act, indicated by the "Taverne" license above, 


\section{Prevention of home-related injuries of pre-school children}

Behavioural research on safety education for parents

Edith Wortel 


\section{CIP-GEGEVENS KONINKLIJKE BIBLIOTHEEK, DEN HAAG}

\section{Wortel, Edith}

Prevention of home-related injuries of pre-school children : behavioural research on safety education for parents / Edith Wortel. - Leiden : TNO Preventie en Gezondheid Also publ. as thesis Maastricht. - With ref. - With summary in Dutch.

ISBN 90-6743-327-6

Subject headings: home-related injuries ; pre-school children ; prevention / safety education. 


\section{Prevention of home-related injuries of pre-school children}

Behavioural research on safety education for parents

\section{PROEFSCHRIFT}

ter verkrijging van de graad van doctor aan de Rijksuniversiteit Limburg te Maastricht, op gezag van de Rector Magnificus, Prof.dr. H. Philipsen, volgens het besluit van het College van Dekanen, in het openbaar te verdedigen op woensdag 21 september 1994 om 16.00 uur

door

Edith Wortel

geboren te Leeuwarden op 2 januari 1960 


\section{Promotores}

Prof.dr. G.J. Kok

Prof.dr. C.M.J. van Woerkum (Landbouwuniversiteit Wageningen)

\section{Beoordelingscommissie}

Prof.dr. J.W. van Ree (voorzitter)

Prof.dr. H. Philipsen

Prof.dr. G. Parcel

Dr. E.J.J. de Leeuw

Dr. W.H.J. Rogmans (Stichting Consument en Veiligheid, Amsterdam)

Dr. R. Jonkers (Rescon, Haarlem) 


\section{Contents}

1. General introduction

2. Lessons learned from a one-year community campaign on child safety in the Netherlands

3. Volunteers as safety educators in a community campaign on child safety

4. Injury control in pre-school children: a review of parental safety measures and the behavioural determinants

5. Prevention of home-related injuries of pre-school children: safety measures taken by mothers

6. Behavioural determinants of mothers' safety measures to prevent injuries of pre-school children

7. General discussion and conclusions

SUMMARY

SAMENVATTING

DANKWOORD 


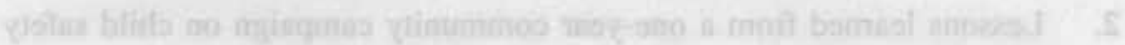
r

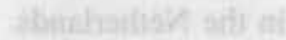

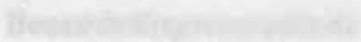

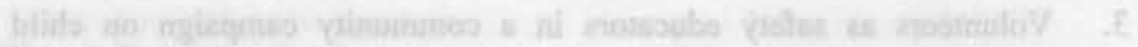
Ty

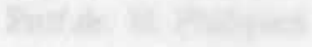

wishe

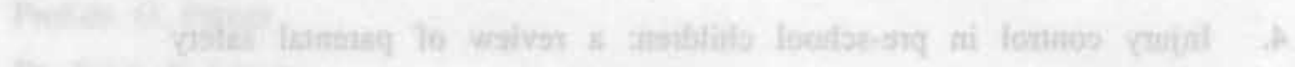

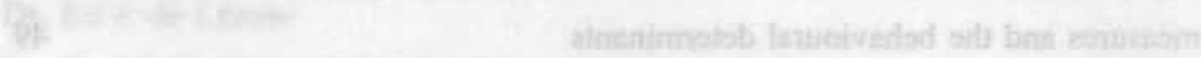

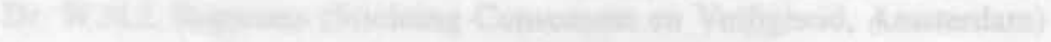

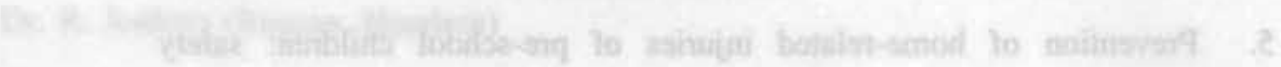
?at:

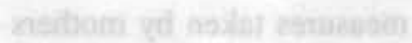

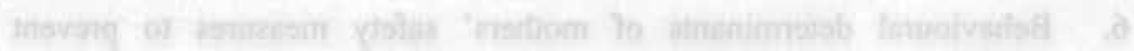
E0I

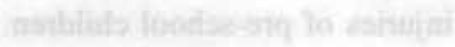




\section{General introduction}

Home-related injuries are a major cause of mortality and morbidity in pre-school children. In the Netherlands this is the main cause of death in the age-group 1-4 years (CBS, 1986-1988). About 50,000 children have to be treated in hospital yearly (PORS, 1986-1988). Moreover, about 5,500 children in the age group 0-4 years have to be admitted to hospital yearly. Childhood injuries may have long term physical and psychological consequences for the child. Obviously, accidents cause suffering and frequently crises in the family too.

There are three strategies that can be used to prevent injuries: (1) persuade and educate individuals to change their behaviour, (2) require individuals to change their behaviour through legislation or regulation and (3) modify the product or environment to provide passive, automatic protection to the individual (Grossman and Rivara, 1992). Although passive strategies seem to be most effective (Baker, 1981), often a combination with active strategies, like health education, is necessary. In the case of home-related injuries of pre-school children there are many risk situations that can only be avoided by means of changing parental safety behaviour through safety education. Therefore, safety education directed at parents is a main strategy in child accident prevention.

This dissertation was meant to contribute to the effectiveness of safety education directed at parents of pre-school children. It is based on a research project that was carried out from 1986 to 1991 by the TNO Institute of Preventive Health Care. The initiative for the research project was the start of a one-year community campaign on child safety in Nijmegen. This campaign was set up as a consequence of a successful Swedish community campaign on safety (Schelp, 1987). Therefore, the Dutch Consumer Safety Institute together with the Ministry of Welfare, Health and Cultural Affairs decided to develop a community campaign in the Netherlands. The overall goal of the campaign was twofold: to reduce home-related injuries of children by $20 \%$ (a political goal) by means of safety education and to stimulate cooperation between local organizations to maintain the attention to child safety in the long term in Nijmegen. 
The TNO Institute of Preventive Health Care was asked to start a research project in order to evaluate the campaign and to take an advisory role in the campaign development. The Ministry of Welfare, Health and Cultural Affairs was partly supporting the research project. Apart from the evaluation study of the campaign, three other studies were carried out. These studies can be characterized as behavioural research with regard to the development of safety education directed at parents of pre-school children. To give an insight into the status of the five studies that were carried out, the guidelines to set up health education activities will be presented.

In general, in setting up potentially effective health education activities, it is of utmost importance that they are systematically planned. This planning needs to be done by means of four steps which can be formulated as the following questions (Green and Kreuter, 1991; Kok, 1988):

1. What is the seriousness of the health problem and what are the behaviours involved (behavioural diagnosis)?

2. Which behavioural determinants have to be influenced (educational diagnosis)?

3. Which behavioural intervention (educational methods and strategy) has to be chosen?

4. What are the effects of the intervention and what are the reasons for its success or failure (evaluation)?

The first three steps are related to the development of educational activities and the fourth step is related to the activities' evaluation.

Clearly, the initiative for the present research project was related to the fourth step: a process and effect evaluation of a community campaign on child safety. In the very beginning of the project it was clear that only limited information on the behavioural and educational diagnosis related to children's home-related injuries was available. Therefore, the TNO Institute carried out a pilot study to explore the safety behaviour of parents of children aged 0-12 years and the possible behavioural determinants (Wortel and Ooijendijk, 1988). The results of this pilot study, where possible, were used for the campaign development on the one hand and for the construction of a 
written questionnaire to assess the campaign effects on parental safety measures and behavioural determinants on the other.

Moreover, the pilot study made clear that parents of 5-12-year-old children were less able to take safety measures at home, because their children's safety was more related to outdoor places like school, street and sport facilities. Therefore, it was decided to direct the evaluation of the campaign only at parents of pre-school children.

The third question on effective health education is related to choosing the intervention strategy. There was no intention to base the answer to this question on research since the Consumer Safety Institute had already decided to provide parents of preschool children with safety education as part of a community campaign. The campaign became more detailed as it developed. A main guideline in this development was the use of a multimedia approach in which interpersonal communication was essential. Except for safety education given through professional intermediaries in the community, volunteers were brought into the campaign. The development of the activities for volunteers and their educational efforts themselves can be considered as a mini-project, called the Voluntary Safety Educators Project (VSEP). In chapter 2 the results of the process and effect evaluation of the community campaign are described, whereas in chapter 3 the Voluntary Safety Educators Project is highlighted.

The third, fourth and fifth studies of this thesis were carried out more or less simultaneously to the evaluation of the campaign. From the viewpoint of effective health education planning these studies should have been carried out before the start of the campaign (Green and Kreuter, 1991), but for practical reasons we were not able to do so. Nevertheless, the results of these last three studies may contribute to the empirical basis needed for effective child safety programmes in the future.

In the scope of the evaluation study we consulted a lot of literature. This information was further completed by a systematic review of the literature on the behavioural and educational diagnosis on child safety. This review can be considered as the first additional study in the research project and is presented in chapter 4. 
In the context of the effect evaluation data were gathered on parental safety measures and the underlying behavioural determinants by means of the above mentioned written questionnaire. At the pretest in Nijmegen (intervention community) the questionnaire was completed by 1129 mothers with pre-school children. This also gave us the opportunity to study the taking of safety measures and the underlying behavioural determinants in a quantitative way (Wortel et al., 1991). As during the development of the campaign only the small scale explorative study was carried out, these two additional studies can be considered as a further elaboration of the pilot study. Chapter 5 describes the study on parental safety measures and chapter 6 presents the study of behavioural determinants. Finally, in chapter 7 the general discussion, conclusions and recommendations are presented.

\section{REFERENCES}

BAKER SP. Childhood injuries: the community approach to prevention. J Publ Health Pol 1981;2:235-46.

CENTRAAL BUREAU VOOR DE STATISTIEK. Overledenen naar doodsoorzaak, leeftijd en geslacht in het jaar 1985-1987. Voorburg: CBS, 1986-1988. Series Al.

GREEN LW, KREUTER MW. Health promotion planning, an educational and environmental approach. Mayfield: Mountain View, 1991.

GROSSMAN DC, RIVARA FP. Injury control in childhood. Pediatr Clin Am 1992;39:47185 .

KOK GJ. Health motivation: health education from a social psychological point of view. In: Maes S, Spielberger CD, Defares PB, Sarasen IG, eds. Topics in health psychology. New York: Wiley, 1988:295-300.

PRIVÉ ONGEVALLEN REGISTRATIE SYSTEEM (PORS). Jaaroverzicht Privé-Ongevallen Registratie Systeem, 1985-1987. Amsterdam: Stichting Consument en Veiligheid, 1986-1988.

SCHELP L. Community intervention and changes in a rural Swedish municipality. In: Epidemiology as a basis for evaluation of a community intervention programme on accidents. Sundbyberg: Karolinska Institute, 1987. Paper 5. 
WORTEL E, OOIJENDIJK WTM. Preventie van privé-ongevallen bij kinderen: onderzækek naar preventief gedrag van ouders en gedragsdeterminanten. (Prevention of home-rclated accidents of children: research on parental preventive behaviour and behavioural determinants). Leiden: NIPG-TNO, 1988. 


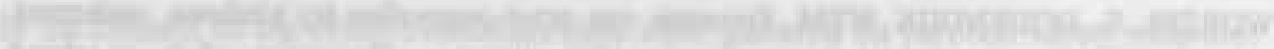

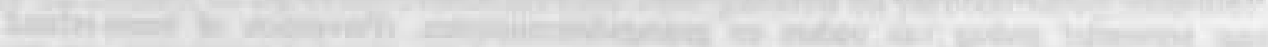

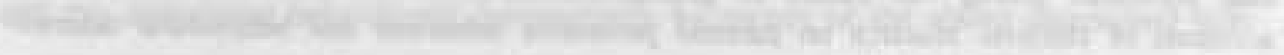

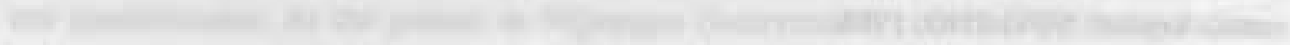

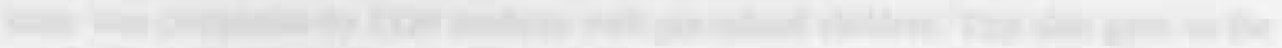
-

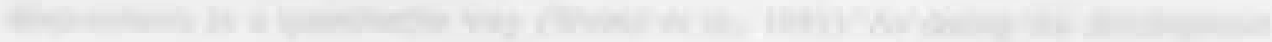

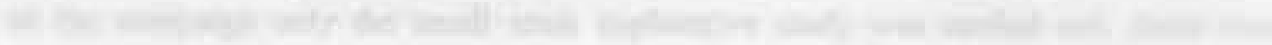

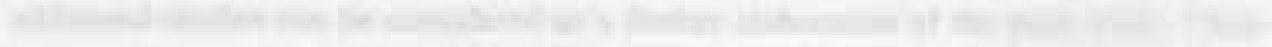

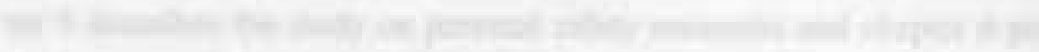

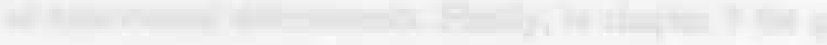
(1)

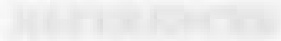

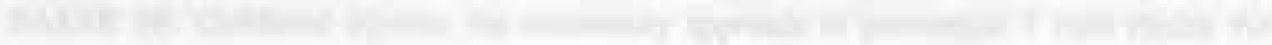

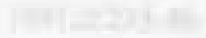

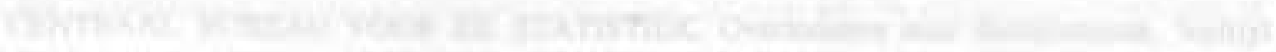

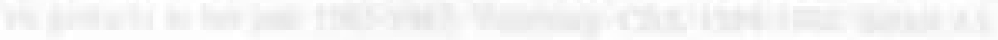

(20)

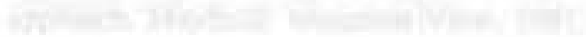




\section{Lessons learned from a one-year community campaign on child safety in the Netherlands*}

Edith Wortel, Hein de Vries, Gerard H. de Geus

\section{ABSTRACT}

A one-year community campaign was carried out in the Netherlands in order to reduce home-related injuries of pre-school children by $20 \%$. Since health education directed at parents of pre-school children was a main instrument in this campaign, several guidelines on behalf of effective health education were taken into account in the campaign development.

However, the campaign did not show the expected effects on parental knowledge, their beliefs nor on their adoption of safety measures. In this paper the campaign development and implementation are described in detail in order to spread light on the 'no-effect' results. This may help future campaigns to overcome the failures incurred in the present campaign.

\section{INTRODUCTION}

In the Netherlands, as in most industrialized countries, home-related injuries of pre-school children represent a major health problem. They are the main cause of death in the age group 1-4 years (CBS, 1986-1988). Moreover, about 50,000 children have to be treated in hospital yearly (PORS, 1986-1988).

In Sweden a community campaign on safety was successful in reducing injuries (Schelp, 1987). In this campaign local organizations were brought together in order to provide the community with safety education. Although detailed information on this campaign

\footnotetext{
* Submitted for publication.
} 
was not available, the Dutch Consumer Safety Institute (CSI) was inspired by its success. In September 1987 the CSI in cooperation with the Ministry of Welfare and Social Affairs started a community campaign on child safety for the period of one year. The campaign was held in Nijmegen, a university city with 145,000 inhabitants which is situated in the east of the Netherlands.

The overall goals of the community campaign were to reduce home-related injuries of children by $20 \%$ (a political goal) by means of safety education directed at parents and to stimulate collaboration between local organizations to provide and to maintain safety education activities in the community*. The TNO Institute of Preventive Health Care had an advisory role during the campaign development, and evaluated the campaign for pre-school children.

\section{Involvement of organizations}

The goal of the CSI was to create a multi-sectoral collaboration by involving local organizations as well as regional and national organizations operating at the local level. Although no theoretical approach was used for the involvement of organizations, in retrospect the CSI had chosen a procedure that has similarities with the linkage approach (Dijkstra et al., 1993; Orlandi et al., 1990). According to the linkage approach, effective implementation of an innovation depends on the collaboration of two systems: the resource system and the user system. The resource system consists of researchers, developers, trainers, consultants, services, products and materials. The user system consists of individuals, organizations, agencies, groups and networks which are the potential adopters of the innovation. Representatives of the user and resource system form the 'linkage system' to bridge the gap between users and providers in an innovation process. The committee in the present campaign was meant to link the CSI and the TNO Institute to

* It should be noted that the goals set, might in retrospect be considered as too ambitious in relation to the campaign means and implementation period. 
the local organizations to enhance the adoption and maintenance of safety education activities in these organizations.

\section{Safety education as intervention instrument}

Health education was chosen as the intervention instrument of the community campaign. Important steps in the planning of the health education process are the behavioural diagnosis (the seriousness of the health problem and the behaviours related to the health problem), the educational diagnosis (the behavioural determinants related to the problem behaviours), and the development and evaluation of the intervention (Green and Kreuter, 1991; Bracht, 1990).

Epidemiological research in the Netherlands indicated that safety messages aimed at parents of pre-school children had to be directed at the prevention of poisoning, burns, falls, suffocation, drowning and pinching injuries (PORS, 1986-1988; CBS, 1986-1988). However, information on the behavioural and educational diagnosis was scarcely available. Therefore, a small scale, explorative pilot study was carried out in another town (Wortel and Ooijendijk, 1988).

In this pilot study parents of pre-school children filled in a self-completion questionnaire, and with some of them personal interviews were conducted. Parents' reasons for not adopting safety behaviour (supervising and educating the child, and taking safety measures; see also Wortel and De Geus; 1993) were assessed by the Attitude - Social Influence Self-Efficacy model (Ajzen, 1988; De Vries et al., 1988). The ASE model (see figure 1) states that a person's behaviour is influenced by three determinants: a person's attitude towards the behaviour, the social influence a person experiences from other persons and the extent to which a person feels that he/she will be able to perform the behaviour (selfefficacy expectations). Moreover, the actual performance of the behaviour leads to a feedback process that in turn influences these determinants.

The pilot study revealed that the adoption of safety measures to structure the child's home environment in particular needed to be improved and, consequently, had to receive substantial attention in the campaign. These measures had to be directed at the agents 
that are related to serious injuries among Dutch 0-4-year-old children. Furthermore, the pilot study indicated which reasons parents had for not taking safety measures. Therefore, safety messages had to try to influence the weighting of the pros and cons in favour of taking safety measures. It was further recommended that safety messages had to influence parents' knowledge of the susceptibility and seriousness of the child safety problem and their knowledge of the relation between the child's development and certain injuries.

Figure 1 Model of behavioural delerminants

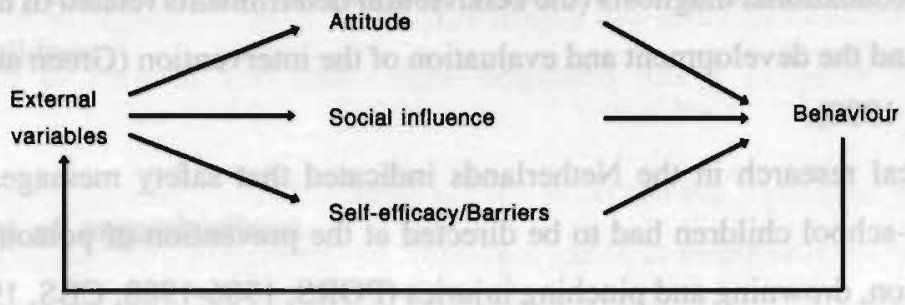

Furthermore, a multimedia approach was advocated since this approach has the greatest potential to realize behaviour change (Rogers, 1983; Bettinghaus, 1986): this approach was characterized by a combination of mass media methods and interpersonal communication utilizing both professionals and paraprofessionals. Paraprofessionals may have the advantage that they are more easily accepted by their peers in the community. Moreover, training members of a community will enhance ownership and continuation of an intervention in a community (Bracht and Tsouros, 1990; Kok and De Vries, 1989).

\section{Campaign evaluation}

Evaluation of community programmes may include process evaluation to analyse which campaign elements were developed and implemented, and their reach of and acceptance by the target group, while effect evaluations assess the impact of the campaign on changes in knowledge, beliefs and behaviour (Green and Kreuter, 
1991). The combination of both qualitative and quantitative methods may imply a better understanding of the results (Basch et al., 1985; De Vries et al., 1992).

The goal of the present paper is to describe the effect and process evaluation of the community campaign on child safety in Nijmegen. The effect evaluation focused on changes in parental knowledge, their beliefs and the taking of safety measures; the process evaluation was meant to provide an insight into the involvement of local (operating) organizations, the participation of intermediaries in training sessions, the safety education implemented during the campaign through mass media and interpersonal channels and parents' exposure to and appraisal of the campaign.

\section{METHOD}

\section{Effect evaluation}

\section{Design and sample}

The effectiveness of the campaign on parental knowledge, beliefs and safety measures was studied by means of a pre-test-post-test control design with four separate groups (Cook and Campbell, 1979). If the same groups had been used at the pretest and post-test, this would have resulted in a loss of respondents.

Nijmegen was chosen to be the experimental community mainly because the CSI was known to the local organizations that were concerned with children's affairs. Nijmegen had about 4,500 families with pre-school children. The control city was Woerden, a small city in the middle of the Netherlands, with 900 families with pre-school children. Woerden was chosen for reasons related to a part of the effect-evaluation that is not the focus of this paper, namely the assessment of changes in childhood injuries.

In both cities a random stratified sample was taken from the population register before and after the campaign. In order to represent all ages in similar sized groups, the children were stratified according to age. To avoid dependent data only one pre- 


\section{Chapter 2}

school child was chosen per family. For practical reasons the sample contained only families of Dutch nationality. The sample size in Nijmegen and Woerden was 1,500 and 300 families with pre-school children respectively.

\section{Data gathering method}

A self-completion questionnaire using short categorical scales was constructed. This questionnaire was pretested among 24 mothers to assess its 'face validity' and subsequently adjusted. The questionnaire was sent to mothers/female carers with preschool children and was collected personally by research assistants. The structured and pre-coded questionnaire contained questions about parental safety measures to prevent risk situations related to poisoning, burns, falls, choking, drowning and injuries due to doors and bicycles, questions on behavioural determinants (e.g. knowledge, beliefs), demographic variables and injury data.

The selection of evaluated safety measures was done on the basis of 1 . the agents that are responsible for serious injuries (hospital visit or death) among Dutch 0-4year-old children, 2. the feasibility of applying the measures taking account of children's age, housing and family situation, and 3. the recommended safety measures by the Consumer Safety Institute.

For the selection of determinants of parental safety measures the ASE model was used with the inclusion of some variables from the Health Belief Model (Janz and Becker, 1984) and the Protection Motivation Theory (Rippetoe and Rogers, 1987). A pilot study assessed which variables were relevant for inclusion in the quantitative questionnaire (Wortel and Ooijendijk, 1988).

First, all relevant safety measures were explained for each type of accident (see table 1). Second, for each safety measure the mothers had to indicate their attitude (familiarity, instrumentality, inconvenience, necessity, susceptibility and seriousness), their partners' opinion and self-efficacy (see table 2). Finally, mothers had to answer questions on their actual safety behaviour. 
Table 1 Safely measures related to poisoning, bums/scalds, falls, choking, drowning and pinching injuries with corresponding age group*

Poisoning (6 months -4 years):

- storing household products in a cupboard at a height of at least $1.5 \mathrm{~m}$

- storing do-it-yourself products in a cupboard at a height of at least $1.5 \mathrm{~m}$

- storing medicines in a locked cupboard at a height of at least $1.5 \mathrm{~m}$

- keeping cosmetics out of reach

- keeping alcoholic drinks out of reach

- keeping smoking articles out of reach

- removing poisonous plants from the house

Bums/scalds:

- not taking the child on the lap while drinking tea or cofiee (0-4 years)

- keeping the tea or coffee can out of reach (9 months-4 years)

- keeping the child out of the kitchen during cooking (9 months-4 years)

- keeping matches and lighters out of reach (12 months-4 years)

- applying a topguard on the cooker (9 months-4 years)

- protecting the oven window with a safety screen (9 months-4 years)

- protecting the oven door with a salety mechanism ( 9 months-4 years)

Falls:

- applying a stairgate at the top and bottom of stairs ( 9 months-2.5 years)

- protecting sharp corners and edges by means of protective material (6 months-4 years)

- applying window guards on windows (18 months-4 years)

- applying anti-slip material in bath and/or shower (9 months-4 years)

Choking:

- keeping little toys that can be swallowed out of reach ( 3 months- 1.5 years)

- checking toys for parts that may come loose (3 months-1.5 years)

- keeping plastic bags out of reach (9 months-4 years)

- keeping hard sweets out of reach (9 months -4 years)

Drowning:

- screening off the garden from adjacent water

- putting pressure on the community to screen off community water

Pinching injuries due to bicycles ( $0-4$ years):

- fastening a child's saddle

- fastening a saddle spring-guard

- fastening spoke-guards

Pinching injuries due to doors ( 9 months-4 years):

- lastening a door when it is open for a while (e.g. by means of a door spring)

- The corresponding age groups were not mentioned in the questionnaire. 
Table 2 Measurement of the determinants of the safety measures

\begin{tabular}{|c|c|}
\hline Determinants & Question" \\
\hline famillarity*" & $\begin{array}{l}\text { Which of the above mentioned safety measures did you not know or have you never } \\
\text { thought of before? } \\
\text { if the mother did not know the measure, this had to be ticked }\end{array}$ \\
\hline instrumentality & $\begin{array}{l}\text { To what extent do you think these measures will be instrumental in preventing your } \\
\text { child from getting poisoned/burned/injured due to a fall? } \\
\text { very instrumental, a bit instrumental, not instrumental }\end{array}$ \\
\hline inconvenience & $\begin{array}{l}\text { How inconvenient do you find it (or do you think it will be) to take these measures? } \\
\text { very inconvenient, moderately inconvenient, not inconvenient }\end{array}$ \\
\hline necessity & $\begin{array}{l}\text { Do you find these safety measures necessary according to the age of your child? } \\
\text { necessary; not necessary, too old; not necessary, too young; never necessary }\end{array}$ \\
\hline susceptibility & $\begin{array}{l}\text { How big is the chance that your child in your home will: } \\
\text { - drink from washing-up liquid, iodine and shampoo? } \\
\text { get bumed from a cup of hot tea, a pan with hot gravy while you are cooking and } \\
\text { contact with the oven window while it is in use? } \\
\text { - fall from the stairs, against a sharp corner and in the shower or bath? } \\
\text { very big, moderately big, not big }\end{array}$ \\
\hline seriousness & $\begin{array}{l}\text { - How poisonous do you think the following products can be for your child: washing- } \\
\text { up liquid, turpentine, iodine, shampoo, aspirin, cigarettes, gin and dieffenbachia? } \\
\text { very poisonous, moderately poisonous, not poisonous } \\
\text { - Which kind of bums/scalds do you think your child can get from: a cup of tea, a } \\
\text { pan with hot gravy and contact with the oven window? } \\
\text { first degree burns, second degree bums, third degree bums } \\
\text { - How serious do you think the injury will be if your child falls from the stairs, against } \\
\text { a sharp corner and in the shower or bath? } \\
\text { very serious, moderately serious, not serious }\end{array}$ \\
\hline partner's opinion & $\begin{array}{l}\text { Do you think your partner finds these measures necessary for your child? } \\
\text { certainly yes, I think so, I think not, certainly not }\end{array}$ \\
\hline self-efficacy & $\begin{array}{l}\text { How often do you think you will succeed in taking these measures? } \\
\text { always/often, regularly, sometimes/never }\end{array}$ \\
\hline
\end{tabular}

- All questions, except familiarity, had a category 'no idea'.

" With respect to safety measures related to choking, drowning and pinching injuries only the familiarity with the measure was asked.

In order to assess the impact of safety group sessions organized by volunteers, parents visiting a safety group session received a pre-coded questionnaire that, among others, was meant to assess parents' reported improvement in their safety knowledge and safety behaviour. This questionnaire had to be sent to the TNO Institute. 


\section{Response}

The response rate for the four research groups was $79 \%$ or higher and was considered representative for mothers with pre-school children in Nijmegen and Woerden (see figure 2).

The comparability of the four research groups was assessed by means of the mothers' level of education, selected as an indicator of the mothers' socio-economic status, and by checking whether the child was first-born or not. It appeared that the intervention community had more highly educated mothers than the control community (chi-square=29.60; $<<.01$ ). Moreover, the intervention community compared to the control community had more mothers with a first-born child and within the intervention community more mothers from the post-test group had a first-born child than those of the pre-test group (chi-square $=126.80 ; p<.05$ ). Therefore, these variables were included in the statistical analysis as confounders.

Figure 2 Response rate for the pre- and post-lest in Nijmegen (intervention community) and Woerden (control community)

\begin{tabular}{lccc}
\hline & pre-test & post-test \\
Nijmegen: & $\begin{array}{c}84 \% \\
(n=1129)\end{array}$ & campaign & $\begin{array}{c}79 \% \\
(n=1118)\end{array}$ \\
& & & \\
Woerden: & $86 \%$ & - & $\begin{array}{c}88 \% \\
(n=254)\end{array}$ \\
\hline
\end{tabular}

In order to calculate the response rate, the number of questionnaires returned from mothers in Nijmegen at the pre- and post-test had to be corrected. By mistake some lamilies had received more than one questionnaire and in the case of the post-test some families had to be left out because they already had filled in a questionnaire at the pre-test.

Moreover, the response to the questionnaire on self-reported effects was $89 \%$ ( $n=637$ ) and may be considered representative for the parents participating in group sessions organized by volunteers. 


\section{Statistical analysis}

Effect analyses were conducted by logistic regression analyses since the variables were measured at a categorical level. Variables included in the regression model were: (1) 'community'- the differences in the pre-test scores between the intervention and control community (2) 'measurement'- the difference between the pre-test and post-test scores in the control community; (3) interaction 'community and measurement'- the difference between effects in the intervention community and control community; (4) level of education, and (5) having a first-born child or not.

All analyses were age-specific (see table 1 for the age groups) and conducted for those mothers for whom the safety measures were relevant according to their housing and family situation. For each safety measure and each determinant, effects of the campaign were assessed on changes between categories. The answers on each safety measure were categorized as 'safe', 'moderately safe' or 'unsafe' behaviour (Wortel and De Geus, 1993). To analyse relevant behavioural changes 48 regression analyses on 30 safety measures were done. As the frequencies of most determinants were not equally divided over the categories, all determinants were reduced to two categories (e.g.: not/bit instrumental versus very instrumental). For assessing the effects on determinants 149 analyses were done. Because there were indications that the measurement of the perceived susceptibility was invalid, effects on this variable are not presented.

\section{Process evaluation}

Process evaluation data were gathered throughout the whole project and were centred around the involvement of organizations, the participation of intermediaries in the training, the safety education implemented during the campaign both via mass media and interpersonal channels, and parents' exposure and appraisal of safety education activities. 
Involvement of local (operating) organizations

To evaluate the involvement of local (operating) organizations in the campaign, the CSI consultant was interviewed, internal reports of the CSI were analysed, observations were made of committee meetings, the minutes of these meetings were used and a personal interview was held with all committee members after the end of the campaign.

\section{Participation of intermediaries in the training}

Participation in the training on individual safety education was mandatory for district and maternity nurses; their participation rate was $100 \%$. The voluntary participation of day-care providers was assessed comparing the number of day-care centres present in Nijmegen and the number of day-care centres that were represented in the training; their level of participation was assessed by comparing it with participation levels on voluntary training courses on other subjects. Furthermore, the administration of the CSI consultant and of committee members was used to assess the number of training sessions held for professional workers.

A report of the CSI consultant was used to evaluate the recruitment of volunteers to be trained. After the training volunteers completed a questionnaire, among others, on their personal characteristics, like level of education, sex and having children.

\section{Implementation of safety education}

The implementation of safety education via mass media channels was registered by the CSI, district nurses and volunteers. Safety education implemented by professional intermediaries was assessed by short semi-structured questionnaires (before their training and at the end of the campaign) which also assessed their motivation, their appraisal of the training and barriers confronted in educating parents. In addition, information provided by committee members was used to gain insight into safety education implemented by professional intermediaries. Registration forms were used to assess the number of group sessions organized by district nurses and volunteers. The volunteers completed a written questionnaire on their training; their evaluation on conducting group sessions was assessed by a short telephone interview. 
Parents' exposure to and appraisal of safety education

Parents' reported exposure to different campaign activities was assessed by the questionnaire that was used at the post-test in Nijmegen on behalf of the effect evaluation which also measured parents' appraisal of the campaign. Furthermore, parents' attendance at safety group sessions held by professional workers (district nurses and day-care providers) as well as volunteers was based on their administration. Comparing the number of participating families with the total number of families with preschool children resulted in the participation rate at the community level.

Characteristics of parents participating in group sessions organized by volunteers, parents' appraisal of the group session and of the volunteer were assessed by means of the same written questionnaire used to assess their reported effects on their knowledge and behaviour (see also the method of the effect-evaluation). To determine. whether participating parents were representative of the parents in the community their characteristics were compared with characteristics of the parents derived from the pre-test in Nijmegen by means of chi-square tests $(p<.05)$.

\section{RESULTS}

\section{Effect evaluation}

Effects on parental knowledge, beliefs and safety measures

The campaign showed the following effects $(O R \neq 1 ; p<.05)$ : after the campaign more mothers in the intervention community compared with mothers in the control community were familiar with the application of a saddle spring guard, found the installation of stairgates at the top and bottom necessary at this age of the child, indicated that their partner found it necessary to keep do-it-yourself products out of reach, to avoid taking the child on the lap while drinking tea or coffee and to install stairgates, more mothers thought that a pan with hot gravy may cause third degree burns, and more mothers kept medicines out of reach. Contrary to what might be expected, 
fewer mothers from the intervention community found the application of anti-slip in the bath-tub instrumental, fewer mothers put anti-slip in their bath-tub and fewer mothers thought that they would succeed in keeping matches and lighters out of reach.

\section{Parents' self-reported effects}

Most parents who visited a safety group session reported an improvement in their knowledge about safety measures related to all six types of accidents: percentages varied from 81-90. Behavioural changes were also reported: $97 \%$ talked with their partner about the safety group session, $56 \%$ proposed changes in their house, $37 \%$ inspected their home for unsafe places and of these parents $88 \%$ intended to alter these places.

\section{Process evaluation}

Most data methods used to obtain information for the process evaluation resulted in reliable observations. However, the data gathered on ideas and activities of maternity nurses at the end of the campaign had to be interpreted carefully because the number of nurses that responded was rather small. Moreover, the data on day-care providers could not be used because very few responded.

\section{Involvement of organizations}

One year before the campaign started, the CSI formed a linkage system (see figure 3): representatives from local (operating) organizations took part in a committee together with the CSI consultant and a researcher from the TNO Institute.

The organizations approached for participation were the local and regional district nursing care, the maternity care, the local foundation for day-care centres and the national foundation for child play and education. All but one organization had a repre- 
sentative who participated in the committee. The maternity care was willing to cooperate, but due to lack of personnel had no representative available (during the campaign they gave advice on ad hoc basis). Furthermore, the representative of the local foundation for day-care centres participated a few months later than the other representatives due to changes in the personnel of the foundation.

Figure 3 Linkage system for a community campaign on child safety in the Netherlands

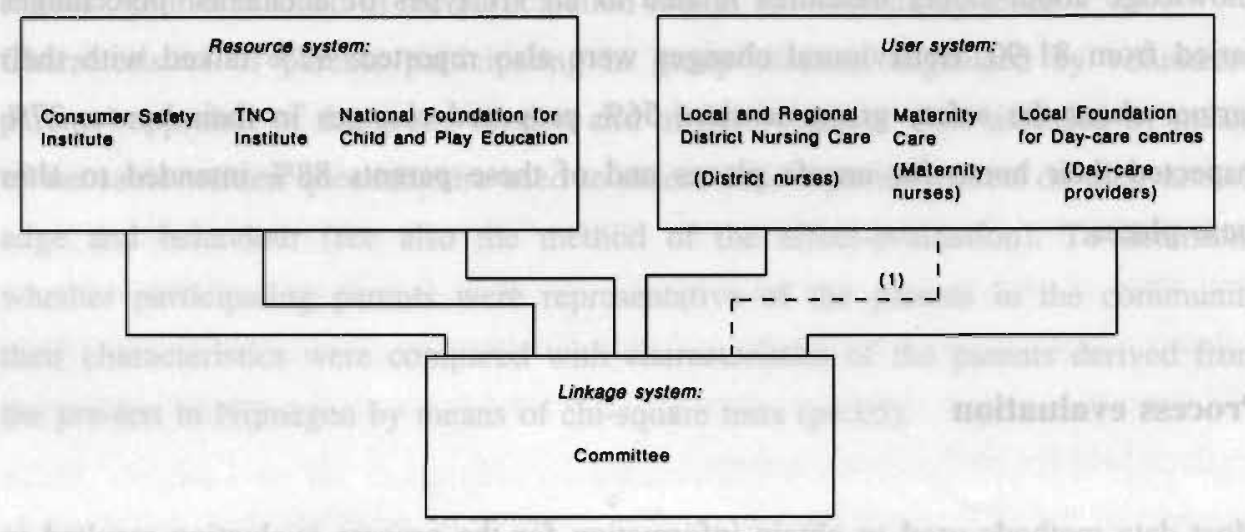

(1) Cooperation on ad hoc basis.

The main task of the committee was to prepare professional intermediaries to give safety education to parents. In order to do this the committee members had plenary meetings but participated also in small study groups. The CSI consultant initiated and coordinated all these activities. The committee members from local organizations formed a link on behalf of their management as well as of intermediaries (district nurses, maternity nurses and day-care providers). The representative from the local foundation on child play and education had an advisory role. The researcher's role was to observe the activities, to fit the research methods to the activities of the committee and to give advice.

For intermediaries' activities the CSI had a rough plan available. This plan was intended to be elaborated with local organizations. However, an unforeseen factor for 
the CSI was that most local committee members had little time to spend while there was a lot of work to be carried out (e.g. the development and giving of trainings courses, the development of training aids, educational tools and scenarios). The CSI consultant and her project assistant carried out most of the work on behalf of the professional intermediaries.

Furthermore, it appeared that the number and intensity of the contacts of professional intermediaries with parents were not sufficient to reach most families in the community with elaborate interpersonal education. The CSI, more than the local organizations, felt committed to reach the campaign goal. Therefore, the CSI decided to bring in volunteers to give interpersonal education to parents. Although this had the approval of the participating organizations, the unforeseen work needed for volunteers was largely carried out by the CSI consultant and her project assistant.

Time pressure and the pressure to reach the campaign goal were disadvantages experienced by the local committee members as well as by the CSI consultant (see also table 3). Since the CSI was the main executor of the committee's activities, consequently, cooperation between local organizations was hardly realized and only a few activities were continued in the local organizations after the end of the campaign.

\section{Intermediaries' participation in the training}

\section{Participation of professional intermediaries}

The training developed for professional intermediaries was mainly directed at improving their safety knowledge and on the use of educational aids/tools. All district nurses $(n=69)$ and maternity nurses $(n=77)$ participated in a two-hour, compulsory training session in communicating child safety during individual contact with parents. In total, six groups of district nurses and 10 groups of maternity nurses were trained. In addition, some of the district nurses $(n=13)$ followed a one-day training in organizing safety group sessions for parents on a voluntary basis. These nurses already had some experience of health education activities. Day-care providers were asked via the 
foundation of day-care centres to participate in a training programme on a voluntary basis to organize safety group sessions. It appeared that 50 day-care providers followed the training, the same as that developed for district nurses, in two groups. They represented less than half of all day-care centres in Nijmegen $(n=70)$ : this participation level was comparable to that of voluntary training programmes on other subjects.

\section{Participation of volunteers}

It was calculated that approximately 30 volunteers had to be recruited to reach as many parents as possible in the community (Wortel et al., 1991). Volunteers had to follow a three-day training programme and have pre-school children themselves to create credibility and attractiveness in the eyes of parents, respectively. To reach as many parents as possible they had to be willing to hold 25 group sessions.

Recruitment occurred via advertisements in local newspapers and via district nurses at the child health centres. Since this recruitment was not very successful, a second recruitment was started in which the volunteer was asked to conduct at least 12 sessions and to have experience with children. This procedure resulted in 20 volunteers who were recruited and trained; they were mostly female, had children of preschool age, followed a secondary or higher education while nearly half of them had experience in working with groups. Five volunteers abandoned for varying reasons.

Volunteers' training focused on the enlargement of their knowledge, providing them skills to conduct safety group sessions, using educational aids and in inviting parents to participate. After the training the majority found themselves capable of educating parents about different aspects of child safety, but half of them indicated that they had insufficient skills to lead a group session. 
Safety education implemented during the campaign

\section{Mass media channels}

Safety messages given through (local) mass media channels included an information market in the town hall to open the campaign, leaflets distributed via child welfare centres and via volunteers, temporary exhibitions at the courthouse, the library and at all child health centres and a few announcements in the regional paper and in neighbourhood papers. Posters designed to announce the campaign were present in nearly all child health and day-care centres. Moreover, district nurses provided parents systematically with 'safety cards' each time they visited the child health centre. (These cards address safety in relation to the child's development and are intended to be distributed via each child health centre in the Netherlands).

Moreover, during the campaign the CSI developed a new leaflet on child safety in addition to existing leaflets. This leaflet was based on the pilot study on parental safety behaviour and behavioural determinants mentioned in the introduction (Wortel and Ooijendijk, 1988). The leaflet was pre-tested among 59 parents with pre-school children living in Leiden (Wortel and De Geus, 1988). Parents who visited a safety group session organized by a volunteer received this leaflet.

\section{Interpersonal channels}

An overview of the safety education implemented by interpersonal channels and the barriers that were signalled is presented in table 3 and will be discussed.

District nurses indicated that they only rarely used their educational aids, specially developed for giving safety education during individual contact with parents. Moreover, at the end of the campaign one-third found it difficult to discuss safety with parents. Furthermore, they mentioned that they had too little time during their consultation ( $8 \mathrm{~min}$. per consultation) to bring up the subject. In addition, district nurses conducted 11 group sessions on child safety. Barriers they mentioned were the large time investment needed for the preparation and organization mainly due to the lack of a manual they should have received from the committee. Moreover, although 


\section{Chapter 2}

these district nurses had experience with health education, difficulties were experienced in giving education to groups of parents.

Table 3 Realization and barriers of the community campaign on child safety in the Netherlands: involvement of local organizations and implementation of safety education

\begin{tabular}{ll}
\hline & Barriers \\
\hline I. Involvement of local (operating) organizations & - rough campaign plan \\
- low participation & - little manpower \\
& - time pressure \\
\hline
\end{tabular}

II. Implementation of safely education

\section{Mass media channels}

- information markel lown hall, exhibitions in courthouse, library and child health centres, announcements regional and neighbourhood papers, posters, saiety cards, leallets, new leaflet

\section{Interpersonal channels}

a. district nurses:

- limited education in one to one contact

- too little time

- 11 group sessions

- difflicult to bring up the subject

- lack of manual

- dificult to conduct group sessions

b. maternity nurses:

- limited education in one-to-one contact

- difficult to discuss safety

- not their duty

c. day-care providers:

- difficult to conduct group sessions

-9 group sessions

d. volunteers:

-139 group sessions

- difficult to conduct group sessions

- too much time

- loss of motivation

- too little guidance

With respect to the maternity nurses there was an indication that they gave no structural attention to safety during their visits to the home of parents with newborn children. Since at the end of the campaign, the majority found that it was not their duty and one-third found it difficult to discuss child safety with parents. 
Day-care providers organized 9 safety group sessions. According to the committee member representing the day-care providers, this was mainly due to a general lack of skills in providing education to parents.

Volunteers organized 139 safety group sessions ranging from three to 33 group sessions per volunteer. Although most volunteers liked to give safety education, they also experienced shortcomings, like difficulties in holding a group session, too much time was needed too organize a session (recruitment, preparation), too little support from the CSI consultant and a loss of motivation because parents did not always turn up.

\section{Parents' exposure to and appraisal of the campaign}

Exposition at the community level

Of the mothers who completed the questionnaire at the post-test in Nijmegen $(n=1,118) 72 \%$ were aware of the campaign. The main channels through which they heard about the campaign were the papers $(37 \%)$, child health centre $(35 \%)$, volunteers $(30 \%)$, and posters $(25 \%)$. However, of these mothers $70 \%$ indicated that they have noticed either not much or nearly nothing of the campaign activities. Nevertheless, the majority found that the campaign was (very) informative $(65 \%)$ and (very) important to be held in another city $(76 \%)$.

\section{Group sessions held by professional intermediaries}

About 90 parents, mainly women $(85 \%)$, participated in safety group sessions organized by district nurses. Consequently, the participation rate at the community level was $2 \%$. The number of parents reached by day-care providers was unknown as they did not complete the written report of all group sessions. District nurses reported that participating parents were a selective group since they were very interested and already doing a lot to improve their child's safety. 
Group sessions held by volunteers

Of the 4,500 families with pre-school children volunteers invited more than 2,800 parents to participate in a safety group session of whom 713 actually participated. The participation rate was $25 \%$ resulting in a participation rate at the community level of $16 \%$. Most parents were women with a secondary or higher education level. Compared to a prior study in Nijmegen, the mothers who participated in a safety group session were significantly more highly educated and thus were a selective group (Wortel et al., 1991). The majority of parents (69\% or more) were satisfied with the volunteer as safety educator, with the group session as such and with the things they have learned. However, only $15 \%$ mentioned that they obtained much new information (see for more details, Wortel et al., 1991).

\section{CONCLUSIONS AND IMPLICATIONS}

The one-year community campaign showed a few effects at the community level on parents' safety knowledge, their beliefs and the adoption of safety measures. However, these effects also could be expected due to chance because of multiple testing. Hence, it can be concluded that the campaign did not result in significant changes in the intervention community (Wortel et al., 1992).

The process evaluation demonstrated that the lack of effect on parental beliefs at the community level can be attributed to the small percentage of parents exposed to safety messages given through interpersonal communication (18\%). Besides, these parents were relatively highly educated and may possibly be seen as the so-called 'early adopters' (Rogers, 1983). Consequently, the majority of parents in the intervention community received little or no child safety information which is also evidenced by the fact that $28 \%$ of the mothers were unaware of the campaign. In addition, of the mothers who were aware of the campaign, $70 \%$ had noticed very little of campaign activities.

The low exposure and participation of parents were due to an implementation failure (Orlandi et al., 1990): the limited activities of professional intermediaries in combina- 
tion with the short implementation period (less than 1 year). Professional intermediaries did not integrate safety education in their regular contacts with parents and organized only few safety group sessions. In turn, these poor efforts are related to the functioning of the linkage system; in other words, the committee that was responsible for the activities of intermediaries did not operate well. This is related to the cooperation between the CSI and local organizations.

First, the CSI had no detailed strategy to cooperate with local organizations. No plan was available in which the time investment and responsibilities of the local organizations were specified resulting in a low participation level of representatives of local organizations in the committee. Second, at the start of the campaign the CSI had no training programmes and only few educational materials/tools for professional intermediaries available. Therefore, in combination with the limited manpower, all kind of materials were not ready at the start of the implementation period. Consequently, professional intermediaries were not sufficiently prepared and equipped to give high quality safety education to parents. Third, intermediaries' activities were hampered also by structural barriers from their organization. Some intermediaries were motivated but experienced no support from their organization such as little time available for child safety. Others considered safety education not as a part of their task which was probably related to their job description as was formulated by their organization. Hence the local organizations created no structural basis that was sufficient to lead their personnel to hold safety education activities.

When it became clear that professional intermediaries would not be able to reach many parents in the community, the CSI decided to bring volunteers into the campaign in order to try to reach the campaign goal. Indeed, volunteers conducted most of the safety group sessions which, according to parents, showed positive effects on their knowledge and safety measures. However, due to the short implementation period the volunteers did not reach enough parents in the community with safety education activities and participating parents' were a selective group; they were more highly educated parents. The latter may be related to the fact that less well educated parents may be less interested in the issue of child safety as such (Laidman, 1987), highly educated volunteers may have been unappealing for lower 
educated parents and the strategy of organizing safety group sessions may not be attractive for less well educated parents (see also Wortel et al., 1991).

Since the CSI developed and carried out most of the committee's activities, collaboration between local organizations and continuation of safety education activities after the end of the campaign was only realized to a limited extent.

\section{Implications for future community campaigns on child safety}

To enhance the success of a Dutch community campaign on child safety it seems advisable for the CSI to change their role when participating in a community campaign. Their role as a resource system must be stricter in the sense that they have to provide resources to local organizations, like injury data, educational materials and training programmes for intermediaries. Moreover, the CSI has to fit in with the existing needs of a community, e.g. with respect to the need to start a campaign on child safety.

In general, all key participants in a community campaign have to agree on the goals to be reached. This may create commitment in reaching these goals and to induce a sense of 'community ownership'. The latter may enhance the possibility that the campaign activities will maintain in the community (Bracht and Tsouros, 1990; Orlandi et al., 1990).

The higher the campaign goals - for instance changing parental safety behaviour - the more time is needed for a thorough development of high standard activities of which pre-tests of activities have to be a necessary part. Moreover, the need of an adequate implementation period is stressed. To observe measurable effects at the community level enough parents have to come into contact with both mass media messages and interpersonal education activities.

For interpersonal safety education at the community level professionals are very important; when they incorporate safety as a part of their duties the continuation of safety education activities in the community may be guaranteed (Bjärås, 1991). Professional workers need a proper training and guidance. Moreover, they need educational tools to bring up the subject child safety something that seems to be difficult for intermediaries (Laidman, 1987). An example of an educational tool is an age-ap- 
propriate questionnaire which is filled in by the educator and the parent during each visit to the child health centre (Kelly et al., 1987).

Besides professionals, volunteers may be important in providing the community with safety education because they may substitute and/or complement the educational efforts of professional intermediaries. Obviously, the need for volunteers depends on the organization of the local child health in a community. However, the role of volunteers has to be thoroughly prepared, among other things, by means of pre-tests. Since educating parents in group sessions put heavy demands upon volunteers, home visits may be more suitable because they require probably fewer skills from volunteers. Consequently, it may be easier to recruit volunteers from all segments of the community and therefore the chance will be greater to reach a more representative group of parents in the community.

Furthermore, we like to focus on two other aspects that may further improve the impact of child safety education in a community campaign. A community campaign often uses a multimedia approach (Kok and De Vries, 1989). In general, mass media may have the function of enhancing awareness of the problem by giving information on the magnitude of the problem (susceptibility and seriousness). With respect to child safety this is very essential because there are indications that the threat parents experience of childhood injuries seems to be insufficiently present (Wortel et al, 1994). Moreover, mass media channels may be used to inform parents on the safety measures available, in particular on the safety equipment available. In this way mass media may support interpersonal education activities.

Finally, a multifaceted approach in which other strategies strengthen the influence of safety education may be more powerful. As in some other community campaigns on child safety (Spiegel and Lindaman, 1977; Gallagher et al., 1985), it would be better to use a combination of strategies, like education together with the distribution and installation of safety devices in the home. For instance, safety equipment may be more available for parents when local shops sell safety products and when local health centres set up a loan scheme. 


\section{ACKNOWLEDGEMENTS}

We would like to thank Louisa Bosker for the coordination of the campaign, Wil Ooijendijk for his cooperation in the research project and Jan Radder for his advice on the statistical analysis.

\section{REFERENCES}

AJZEN I. Attitude, personality and behavior. Milton Keynes: Open University Press, 1988.

BASCH CE, SLIEPCEVICH EM, GOLD RS, et al. Avoiding type 111 errors in health education program evaluations: a case study. Health Educ Quart 1985;12:315-31.

BETTINGHAUS EP. Health promotion and the knowledge-attitude-behavior continuum. Prev Med 1986;15:475-91.

BJÄRÅS G. Can a community development model be used for health programmes in an industrialized country? Int J Health Planning Managem 1991;6:209-19.

BRACHT N, TSOUROS A. Principles and strategies of effective community participation. Health Prom Int 1990;5:199-207.

CENTRAAL BUREAU VOOR DE STATISTIEK. Overledenen naar doodsoorzaak, leeftijd en geslacht in het jaar 1985-1987. Voorburg: CBS, 1986-1988. Series A1.

COOK TD, CAMPBELL DT. Quasi-experimentation. Chicago: Rand McNally, 1979.

DIJKSTRA M, VRIES H de, PARCEL GS. The linkage system applied to a school-based smoking prevention program in the Netherlands. J School Health 1993;63:339-42.

GALLAGHER SS, HUNTER P, GUYER B. A home injury prevention program for children. Pediatr Clin North Am 1985;32:95-112.

GREEN LW, KREUTER MW. Health promotion planning, an educational and environmental approach. Mayfield: Mountain View, 1991.

JANZ NK, BECKER MH. The health belief model: a decade later. Health Educ Quart 1984; 11:1-47. 
KELLY BK, SEIN C, MCCARTHY PL. (1987) Safety education in a pediatric primary care setting. Pediatr 1987;79:818-24.

KOK GJ. Health motivation: health education from a social psychological point of view. In: Maes S, Spielberger CD, Defares PB, Sarasen IG, eds. Topics in health psychology. New York: Wiley, 1988:295-300.

KOK G, VRIES H de. Primary prevention of cancers: the need for health education and intersectoral health promotion. In: Heller T, Davey B, Bailey L, eds. Reducing the risk of cancers. London: Hodder and Stoughton, 1989:99-111.

LAIDMAN P. Health visiting and preventing accidents to children. London: Child accident prevention trust, 1987. Research report no.12.

McGUIRE WJ. Attitudes and attitude change. In: Lindzey G, Aronson E, eds. Handbook of social psychology. 3rd ed. New York: Random House, 1985:233-346.

ORLANDI MA, LANDERS C, WESTON R, HALEY N. Diffusion of health promotion innovations. In: Glanz K, Lewis FM, Rimer B, eds. Health behavior and health education: theory, research and practice. San Francisco: Jossey-Bass, 1990:288-313.

PRIVÉ ONGEVALLEN REGISTRATIE SYSTEEM (PORS). Jaaroverzicht privé-ongevallen registratie systeem, 1985-1987. Amsterdam: Stichting Consument en Veiligheid, 1986-1988.

RIPPETOE PA, Rogers RW. Effects of componenets of protection-motivation theory on adaptive and maladaptive coping with a health threat. J Pers Soc Psychol 1987;52:596-604.

ROGERS EM. Diffusion of innovations. New York: The Free Press, 1983.

SCHELP L. Community intervention and changes in a rural Swedish municipality. In: Epidemiology as a basis for evaluation of a community intervention programme on accidents. Sundbyberg: Karolinska Institute, 1987. Paper 5.

SPIEGEL CN, LINDAMAN FC. Children can't fly: a program to prevent childhood morbidity and mortality from window falls. Am J Publ Health 1977;12:1143-7.

VRIES $H$ de, DIJKSTRA M, KUHLMAN P. Self-efficacy: the third factor besides attitude and subjective norm as predictor of behavioral intentions. Health Educ Res 1988;3:273-82.

VRIES $\mathrm{H}$ de, WEIJTS W, DIJKSTRA M, KOK G. The utilization of qualitative data for health education program planning, implementation, and evaluation: a spiral approach. Health Educ Quart 1992;19:101-15. 


\section{Chapter 2}

WORTEL E, OOIJENDIJK WTM. Preventie van privé-ongevallen bij kinderen: onderzoek naar preventief gedrag van ouders en gedragsdeterminanten. (Prevention of home-related accidents of children: research on parental preventive behaviour and behavioural determinants). Leiden: NIPG-TNO, 1988.

WORTEL E, GEUS GH de. Pretest van de folder 'Kinderveiligheid'. Leiden: NIPG-TNO; Amsterdam, Stichting Consument en Veiligheid, 1988.

WORTEL E, GEUS GH de. Prevention of home related injuries of pre-school children: safety measures taken by mothers. Accepted for publication in Health Educ Res 1994;

WORTEL E, OOIJENDIJK WTM, STOMPEDISSEL I, GEUS GH de. Volunteers as safety educators in a community campaign on child safety. Health Prom Int 1991;6:173-80.

WORTEL E, OOIJENDIJK WTM, BOSKER L, GEUS GH de. Proces- en effectevaluatie van de lokale kinderveiligheidscampagne 'Nijmegen staat op veilig'. Leiden: NIPG-TNO, 1992. 


\section{Volunteers as safety educators in a community campaign on child safety*}

Edith Wortel, Wil T.M. Ooijendijk, Gerard H. de Geus, Iris Stompedissel

\section{ABSTRACT}

In 1987 the Dutch Consumer Safety Institute initiated a 1 year community campaign to reduce home-related injuries of children in Nijmegen. The Voluntary Safety Educators Project (VSEP), a main part of this community campaign, was directed at parents with pre-school children. The VSEP was meant to educate parents in most families in the community through group sessions to improve their safety behaviour.

The aim of the present paper is to describe the development of the VSEP and to assess its success. Data were gathered about the recruitment of volunteers, their training and experiences as safety educators, parents' participation in the VSEP, their appraisal of the VSEP and the effects of the VSEP on their knowledge and behaviour related to child safety.

The main finding was that far more parents received safety education through interpersonal channels than would have been the case if volunteers had not been brought into the community campaign. However, the objective, to educate parents in most families in the community, was not achieved. Moreover, participating parents were relatively highly educated.

One reason underlying this result is that the small number of volunteers that worked for the VSEP was not able to invite parents in all families during the 1 year period of the campaign. The other reason is that the participation was selective. This was probably due to components of the educational approach itself: the involvement in child safety as such, the characteristics of the volunteers and/or the educational method used.

* In: Health Promotion International 1991;6(3):173-80. 
In developing the VSEP too little attention was given to the recruitment of volunteers and to whether the educational approach was suitable for parents in the community. It seems worthwhile to develop a new role for volunteers in the promotion of child safety at the community level. Suggestions are given for filling this role and the need for a thorough pretest is stressed.

\section{INTRODUCTION}

In the Netherlands, as in most of the industrialized countries, childhood injuries due to accidents in and around the home represent a major health problem. Inspired by the success of a community campaign on safety in Sweden (Schelp, 1987) the Consumer Safety Institute (CSI) initiated in 1987 a community campaign to reduce home-related injuries of children. This campaign was carried out during 1 year in Nijmegen (population 145000 ). Nijmegen is a university town which is situated in the eastern part of the Netherlands at the borders of the river Rhine. The main sources of employment are: light industries, services, health care and tourism. The unemployment is relatively high, almost $20 \%$.

A main objective of the Dutch community campaign was to educate parents with pre-school children on child safety in order to change their safety behaviour. According to communication guidelines this implied that parents had to be reached by mass media as well as through interpersonal communication activities (Rogers, 1983; Bettinghaus, 1986). In this campaign, however, interpersonal safety education had to be given mainly by volunteers, because professionals who had regular contact with parents were not able to fulfil this task. The Voluntary Safety Educators Project (VSEP) was therefore started. The aim of the VSEP was twofold: (i) to recruit and train volunteers; (ii) to let volunteers educate parents in most families with preschool children in the community in order to improve their safety behaviour.

The aim of this paper is to describe the VSEP and to assess to what extent it succeeded in achieving its objectives. Therefore, the following questions had to be answered. 
- Was the number of recruited volunteers sufficient, were volunteers able to fulfil their educational activities after undergoing training and did they have positive work experiences?

- Did parents in most families in the community participate?

- Did participating parents appraise the VSEP positively?

- Did participating parents report effects of the VSEP on their knowledge, behavioural intentions and behaviour related to child safety? It was expected that parents with only one child (often first born child), as opposed to parents with more children, would profit more from the VSEP because they were the least experienced parents. These two groups of parents were therefore compared with each other.

\section{METHOD}

\section{Development of the Voluntary Safety Educator Project (VSEP)}

\section{Number of volunteers required}

To restrict the number of volunteers required, parents had to be educated in groups. Enough room for interaction could probably be created if volunteers were to organize group sessions of about 2 hours with a maximum of six parents. For practical reasons parents living in the same neighbourhood were to be asked to participate in the same safety group session.

The population register indicated that there were $\sim 4500$ families with pre-school children living in Nijmegen. If a parent in each family was willing to participate, it was found that 30 volunteers had to be recruited if each volunteer organized 25 group sessions with six persons each. 


\section{Chapter 3}

\section{Characteristics of volunteers}

According to communication guidelines, persuasive educators have to be perceived as credible and attractive by their receivers (McGuire, 1985). An educator's credibility can be created by giving him/her expertise. To create expertise volunteers had to follow a 3-day training course in conducting safety group sessions. An important factor of an educator's attractiveness is similarity. It was assumed that volunteers would be most similar to parents if they had pre-school children themselves.

\section{Training of volunteers}

A CSI consultant and a consultant of the Dutch Health Education Centre organized the training. The training course was given twice. Role play sessions and video presentations were used as training aids.

The training was meant to enable volunteers to educate parents on the main homerelated accidents that threaten pre-school children, the risk situations leading to these accidents, their relation to the child's development and the safety behaviour needed for prevention. Attention had to be given to the pros and cons of three forms of parental safety behaviour that can be distinguished: supervising the child, educating the child and making the child's environment, the home, safe. The training was furthermore aimed at teaching volunteers communication skills, the use of communication aids (pictures, fly-sheets) and how to invite parents to participate. In addition, volunteers received a written guide and support from the CSI consultant in order to organize and carry out the group sessions.

\section{Framework for carrying out a safety group session}

The framework for carrying out a safety group session consisted of four parts.

- Part 1: a general introduction ( $20 \mathrm{~min})$. The volunteer introduces her/himself and asks parents to introduce themselves. The volunteer explains the objective, content and procedure of the safety group session by means of a fly-sheet.

- Part 2: introduction of 'child safery in and around the home' (30-40 min). The volunteer shows pictures with children in a hazardous situation and asks each parent to react. The volunteer continues with a presentation of the number and 
severity of home-related injuries of pre-school children. Thereafter, the main risk situations are mentioned and related to children's development. Again pictures are used for demonstration.

- Part 3: elaboration of the subject ( $60 \mathrm{~min})$. The volunteer shows parents some pictures with a hazardous situation. Each parent is asked to indicate what he/she would do to prevent this situation. The volunteer writes down the safety actions parents mentioned on a fly-sheet while placing them in one of three categories of parental safety behaviour. The most ideal combination of safety actions is discussed in terms of pros and cons.

- Part 4: closing the session (10 min). The volunteer sums up the things that have been said and thanks parents for their participation.

This framework was tried out only once by the CSI consultant. This try-out was done with a few parents who were willing to cooperate; they were satisfied with the chosen framework.

\section{Invitation to parents for participation}

Volunteers had to send each family a (standard) letter. The volunteer introduced her/himself to the parents as being their Voluntary Safety Educator. The volunteers made clear that a community campaign on child safety was going on in Nijmegen because of the high incidence of childhood injuries in the community. It was explained that the VSEP was especially developed for parents with children aged 0-4 years and that she/he was specially trained to educate parents in their neighbourhood. The letter made clear that VSEP was a joint venture of the Consumer Safety Institute together with local professional organizations. Furthermore, it was explained that the safety group sessions with about six parents was aimed at exchanging experiences and at learning about child safety. The volunteer ended the letter with the intention of making an appointment by telephone a week later. A second letter with an invitation was sent when there was no telephone. The safety group sessions were conducted in a child health centre in the quarter in which the parents were living. 


\section{Data collection materials and analysis}

In Table 1 an overview is given of the data collection materials used.

Table 1 Methods of data collection for the study on the VSEP related to subject and data source

\begin{tabular}{|c|c|c|}
\hline Subject & Data source & Data collection method \\
\hline Volunteers' recruitment & CSI consultant & Report \\
\hline Volunteers' training & Volunteers & Written questionnaire \\
\hline Volunteers' experiences & Volunteers & Interview by telephone \\
\hline Parents' participation, reasons for non-participation & Volunteers & Administration \\
\hline $\begin{array}{l}\text { Parents' characteristics, appraisal of the VSEP and reported } \\
\text { effects }\end{array}$ & Parents & Written questionnaire \\
\hline
\end{tabular}

\section{Volunteers' recruitment, training and experiences}

A report of the CSI consultant was used to assess the recruitment of volunteers. The recruitment procedure was compared with the number of volunteers actually recruited. The quality of the training was measured by means of a written questionnaire in which the volunteers were asked about various aspects of their training. After the volunteers had completed their work, their experiences were collected by means of telephone interviews.

\section{Participation of parents}

The participation rate at the community level was assessed by the number of participating parents registered by the volunteers and the total number of families with preschool children in the community. The participation rate of the parents invited was based on the administration of the volunteers.

\section{Parents' characteristics, their appraisal of the VSEP and reported effects}

A written questionnaire was constructed for parents who participated in the VSEP to measure their characteristics, their appraisal of the VSEP and effects on their knowledge, behavioural intention and behaviour related to child safety. Parents received the 
questionnaire from the volunteer after the group session and were asked to send the completed questionnaire to the TNO Institute of Preventive Health Care.

Characteristics measured were: sex, level of education, number of children and information on child safety received earlier. To assess whether participating parents were representative of the parents in the community, their characteristics were compared with characteristics of parents derived from a prior random sample of mothers in Nijmegen (response rate: $84 \% ; n=1129$; Wortel et al., 1990). Chi-square tests were used to analyse differences between the characteristics of the two groups.

Parents' appraisal of the VSEP was assessed in detail by their opinions about the volunteer, the group process and the benefits of education in a group.

To determine the volunteer's credibility parents were asked whether they found the volunteer qualified to give safety education and whether they got clear answers to their questions. The attractiveness of volunteers could not be measured in terms of similarity, because it seemed unrealistic to ask parents how similar they found the volunteer to themselves. Instead parents were asked whether they found the volunteers' presentation pleasant.

Important factors of the group process were the opportunity to ask questions, to react to other parents, to talk about their own child(ren) and to meet parents with children both of the same age and of an age different to that of their own children. Benefits of education in a group were measured by asking parents if they learned a lot from other parents' opinions on child safety and if they got solutions and tips from other parents. Differences in these benefits experienced by parents with one child and parents with more children were assessed with chi-square statistics.

A more direct evaluation of the VSEP was measured by asking parents how they would like to be educated on child safety if they were to be educated for the first time (alternatives: a folder, personal contact or both), how they would like personal contact (alone, in a small or a large group) and from whom (a volunteer or a professional).

Immediate effects of visiting a safety group session were measured by asking parents to what extent the information they received was new and to what extent they learned about safety measures, if they talked with their partner about the safety group 
session and whether they proposed to do something for their child's safety. Furthermore, we asked them if they inspected their home for unsafe places and had the intention to alter these places. Differences in effects on parents with one child and parents with more children were analysed by chi-square statistics.

\section{RESULTS}

\section{Volunteers' recruitment, training and work experiences}

Volunteers were recruited by means of advertisements in local papers and via the nurses of the child health centre. It appeared that volunteers were hard to recruit. The criteria for selection were therefore altered. Instead of the 25 group sessions intended, the volunteer had to conduct at least 12 group sessions. Besides, it was not required that volunteers had children themselves; experience with children was desired.

After a few months 20 volunteers were recruited and trained. After the training course 18 volunteers filled in the questionnaire. It appeared that 13 volunteers had children of pre-school age. Most volunteers were women $(n=16)$ and all volunteers had a secondary or higher education level; nearly half of them $(n=8)$ had experience with working in groups. Most volunteers $(n=16)$ thought they were able to contact and invite parents. Half of the volunteers $(n=9)$ indicated that they did not have enough skills to lead a group session but the majority found themselves capable of educating parents about the different aspects of child safety ( $\mathrm{n}$ varied for the subjects from 13 to 17). Nearly all volunteers were satisfied with the communication aids which had to be used during the group session (n varied for the aids from 14 to 17).

Actually 15 volunteers started work. Of these volunteers four worked in pairs. The volunteers who quitted after the training course had very diverse reasons for doing so. Because not all families could be reached with 15 volunteers, it was planned that the 15 volunteers already recruited would recruit new volunteers from the participat- 
ing parents. However, only two new volunteers were recruited during the implementation of the VSEP.

Volunteers organized 139 safety group sessions; the range varied from three to 33 group sessions per volunteer. Although most volunteers liked to give safety education to parents, they signalled some shortcomings: difficulties in leading a group session, too much time needed to organize a group session, too little supervision from the CSI consultant and loss of motivation because some parents did not turn up although they had promised to do so.

\section{Participating parents}

During 1 year more than 2800 parents living in different urban districts, were invited to participate in a safety group session. Of these parents 713 actually participated. Thus, the participation rate at the community level was $\sim 16 \%$ whereas the participation rate to the volunteers' invitation was $25 \%$. The main reasons for non-participation were that parents: were not interested in the subject, were sufficiently informed about child safety or were not able to participate (lack of time, no one to look after the children).

The response to the questionnaire constructed for participating parents was $89 \%$ ( $n=$ $637)$ and could be considered representative for all parents who participated. Most parents were women $(84 \%)$ with a secondary or higher education level $(83 \%)$. Mothers participating in the VSEP $(n=522)$ had, compared with mothers from the prior study in Nijmegen $(n=1097)$, significantly more often a secondary or higher education level (chi-square $=27.73 ; \mathrm{df}=2 ; \mathrm{p}<0.01$ ); $17 \%$ of the participating mothers had a low level of education compared with $29 \%$ of the mothers in the other research group. In the VSEP group nearly $50 \%$ of all parents had only one child and $77 \%$ had already received some information about child safety before they participated in a safety group session; these percentages were the same as found in the representative sample. 


\section{Parents' appraisal of the VSEP}

The majority of parents found the volunteer qualified (72\%), his/her answers clear $(80 \%)$ and his/her presentation pleasant $(93 \%)$. The mean group size was five parents, whereas the range varied from one to 12 parents. In Table 2 the results related to the group process are presented.

Table 2 Parents' appraisal of the group process

\begin{tabular}{lcc}
\hline The group session gave enough opportunity for parents to* & Percentage & (n) \\
\hline Ask questions & $91 \%$ & $(570)$ \\
React to other parents & $90 \%$ & $(565)$ \\
Talk about own child & $89 \%$ & $(552)$ \\
Meet parents with children of the same age as their child(ren) & $69 \%$ & $(431)$ \\
Meet parents with children of a different age to their child(ren) & $80 \%$ & $(498)$ \\
\hline
\end{tabular}

- These statements were formulated in a negative way to try and prevent socially desirable answers.

The large majority of parents agreed with the statements that there was enough opportunity to ask questions, to react to other parents and to talk about their own child(ren). Most parents agreed that there were enough parents with children of the same and of different ages to their own child(ren).

With regard to the group benefits parents reported the following: nearly half of the parents learned a lot from the opinion of other parents (49\%) and got many tips and solutions from other parents (45\%). Significantly more parents with one child compared with parents with more children reported these benefits: $55 \%$ of parents with one child learned a lot from the opinion of other parents compared with $44 \%$ of the parents with more children (chi-square $=7.80$; df $=1 ; p<0.01$ ) whereas $54 \%$ of the parents with one child got many tips from other parents compared with $37 \%$ of the parents with more children (chi-square $=17.96 ; \mathrm{df}=1 ; \mathrm{p}<0.01$ ).

Finally, where parents had to be informed about child safety for the first time, most parents preferred a combination of a folder and personal contact $(86 \%)$ and preferred personal contact in a small group $(80 \%)$. Moreover, the majority $(61 \%)$ wanted safety education given by a volunteer. 


\section{Reported effects}

Table 3 shows the results with respect to the effects parents reported. Few parents heard a lot of new information about safety measures. However, most parents indicated they learned (a bit) more about safety measures related to six types of childhood accidents. Almost all parents talked with their partner about the safety education group and more than half of them proposed to their partner to do something in favour of their child's safety. Less than half of the parents had inspected their home for unsafe places; the majority intended to change some or all unsafe places. Clearly, compared with parents with more children, parents with one child showed stronger positive responses to nearly all of the items on knowledge and behaviour.

Table 3 Effecls reported by parents after the safely group session; differences between parents with one child and parents with more children

\begin{tabular}{|c|c|c|c|c|}
\hline \multirow{2}{*}{ 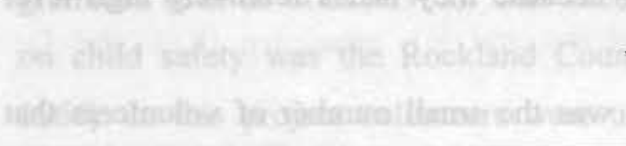 } & \multicolumn{2}{|c|}{ Total } & \multicolumn{2}{|c|}{ Parents with: } \\
\hline & Percentage & (n) & One child & $\begin{array}{l}\text { More } \\
\text { children }\end{array}$ \\
\hline Heard a lot of new information & $15 \%$ & (631) & $17 \%$ & $13 \%$ \\
\hline $\begin{array}{l}\text { Learned (a bit) more about environmental measures } \\
\text { to prevent: }\end{array}$ & & & & \\
\hline drowning & $81 \% *$ & (623) & $85 \%$ & $77 \%$ \\
\hline - suffocation & $90 \% "$ & (617) & $93 \%$ & $87 \%$ \\
\hline - poisoning & $90 \%$ & (616) & $92 \%$ & $88 \%$ \\
\hline - burns & $89 \% \%^{*}$ & (616) & $92 \%$ & $86 \%$ \\
\hline - falls & $88 \%{ }^{*}$ & (618) & $91 \%$ & $85 \%$ \\
\hline - injuries due to doors and bicycles & $88 \% \%^{\circ}$ & (616) & $92 \%$ & $84 \%$ \\
\hline Talked with partner about safety group session & $97 \%$ & (612) & $98 \%$ & $96 \%$ \\
\hline Proposed changes to partner & $56 \% \%^{*}$ & (594) & $65 \%$ & $49 \%$ \\
\hline Inspected home for unsale places & $37 \% *$ & (630) & $42 \%$ & $32 \%$ \\
\hline Intend to alter unsafe places & $88 \% *$ & (514) & $94 \%$ & $82 \%$ \\
\hline
\end{tabular}

- chi-square test; $d f=1 ; p<0.05$. 


\section{Chapter 3}

\section{DISCUSSION}

In the community campaign on child safety far more parents received safety education through interpersonal channels than would have been the case if volunteers had not been brought into the community campaign.

On the whole parents participating in the Voluntary Safety Educators Project (VSEP) have given the VSEP a positive appraisal. Moreover, these parents reported some positive effects on their knowledge and behaviour related to child safety; parents with only one child reported stronger effects compared with parents with more children and thus have profited more from the VSEP. These positive effects are only an indication of the VSEP's impact, because no appropriate research design was used in assessing these effects. However, the VSEP objective to educate parents in most families in the community was not achieved. Besides, participating parents were not representative of parents in the community because they had a relatively high level of education.

One reason for not reaching most families was the small number of volunteers that worked for the VSEP in combination with the 1 year campaign period. The number of volunteers that worked for the VSEP was not sufficient to invite and educate the parents in most families within a year. A more active recruitment and a longer campaign period might have made it possible to educate a larger number of parents.

But, more volunteers probably would not have led to a higher and a more representative participation of parents. It seems likely that this can be attributed to components of the educational approach: the involvement in child safety as such, the volunteer's characteristics and/or the educational method that was used. It may be that the involvement in child safety has inhibited the participation of parents with a low level of education. Especially parents in lower socio-economic groups, reported safety as a particularly low priority (Laidman, 1987). In relation to poorly educated parents, volunteers' characteristics may have been insufficiently similar. The educational level of the volunteer may be of equal or even greater importance than being a parent. Furthermore, the chosen educational method, group sessions, may not fit into the lifestyle of parents with a lower educational level. From nurses of child health centres it 
is known that group sessions organized at the centre are often visited by highly educated parents.

The overall conclusion is that in the development of the VSEP too little attention was given to the recruitment of volunteers on the one hand and the chosen educational approach in relation to its suitability for the target group on the other. A thorough pretest might have unfolded the shortcomings of the VSEP.

\section{The future role of volunteers in child accident prevention at the commun-} ity level

In general the role of volunteers in patient education programmes is very well recognized. Less common, however, are examples of volunteers directing primary programmes (DePue et al., 1987). One such experience in primary prevention activities on child safety was the Rockland County Child Injury Project (Schlesinger et al., 1966). In this project volunteers were used to organize small neighbourhood meetings in developmental homes. However, from this study no participation rates are known nor the number of volunteers working for this project and their precise activities.

In order to reach parents in the community with safety education through interpersonal channels volunteers must play an important role because professional educators themselves are not able to educate parents intensively on child safety. Contrary to some other countries where the profession of 'health visitor' is common, in The Netherlands no such profession exists.

The experiences with the VSEP suggest that another educational method has to be chosen to improve community participation of parents. Cooke and Meyers (1983) found that, in the case of blood pressure screening by volunteers, door-to-door screening compared with central site screening resulted in a higher participation rate. Safety education during home visits may also respond more to the preferences of parents with a low level of education and may therefore put an end to the problem of 'the self selecting audience'. Moreover, Colver et al. (1982) showed that, of severely 
disadvantaged families who were given safety advice during home visits, $60 \%$ at least made one change to make their home safer.

Child safety in and around the home lends itself very well to an individual method of communication by means of home visits. In relation to volunteers, home visits may have some advantages compared with group sessions. They certainly will make the task of the volunteer less extensive; the organizational part of the VSEP especially, the effort and time needed to recruit parents for a group session, was experienced negatively by the volunteers. Second, skills for leading a group session, which put heavy demands upon volunteers, are no longer required.

When home visits require less effort and skills from volunteers, it will not only be easier to recruit volunteers, but probably also to select them from all segments of the community. Selecting volunteers from the community with an influential position in quarters of the city appeals more to the idea of working with para-professionals. Using para-professionals as a source has proven to be an effective way of reaching 'difficult' groups, like people with low income and low education (Kok and De Vries, 1989).

A disadvantage of home visits can be the time consuming aspect. This may be minimized by reducing the target group to parents with a first born child because, as the results showed, they can profit more from safety education than more experienced parents. Parents with a first born child compared with parents with more children will probably more easily adopt advice on safety behaviour because they have not yet developed a fixed pattern of safety behaviour that may be difficult to change (Van Rijn et al., 1991).

Volunteers' activities should at least be linked to professional local health centres as was done in the North Karelia Project, a cardiovascular community programme in a norther province of Finland (Neittaanmäki et al., 1980). Co-operation with, for instance, child health centres may create a framework for the volunteers' work which can give it more support, status and continuity.

In conclusion it seems worthwhile to develop a new role for volunteers in the promotion of child safety at the community level. However, before the new 'safety educa- 
tors' start on a large scale, their recruitment and education activities must be pretested thoroughly.

\section{ACKNOWLEDGEMENTS}

We thank Martin Schuurman, Hein de Vries and Ellen Bergsma for their useful comments on earlier drafts of this paper.

\section{REFERENCES}

BETTINGHAUS EP. Health promotion and the knowledge-attitude-behaviour continuum. Prev Med 1986;15:475-91.

COLVER AF, HUTCHINSON PJ, JUDSON EC. Promoting children's home safety. Brit Med J 1982;285:1177-80.

COOKE CJ, MEYERS A. The role of community volunteers in health interventions: a hypertension screening and follow-up program. Am J Publ Health 1983;73:193-4.

DEPUE JD, WEELS BL, LASATER TM, CARLETON RA. Training volunteers to conduct heart health programs in churches. Am J Prev Med 1987;3:51-7.

KOK G, VRIES H de. Primary prevention of cancers: the need for health education and intersectoral health promotion. In: Heller T, Davey B, Bailey L, eds. Reducing the risk of cancers. London: Hodder and Stoughton, 1989:99-111.

LAIDMAN P. Health visiting and preventing accidents to children. London: Child Accident Prevention Trust, 1987. Research report no. 12.

McGUIRE WJ. Attitudes and attitude change. In: Lindzey G, Aronson E, eds. Handbook of social psychology: vol. 2. Special fields and applications. 3rd edn. New York: Random House, 1985:233-346.

NEITTAANMÄKI L, KOSKELA K, PUSKA P, McALISTER AL. The role of lay workers in community health education: experiences of the North Karelia Project. Scand J Soc Med 1980;8:1-7. 


\section{Chapter 3}

RIJN OJL van, MEERTENS RM, KOK GJ, BOUTER LM. Determinants of behavioural risk factors for bum injuries. Burns 1991;17:364-70.

ROGERS EM. Diffusion of innovations. New York: The Free Press, 1983.

SCHELP L. Community intervention and changes in accident pattern in a rural Swedish municipality. In: Epidemiology as a basis for evaluation of a community intervention programme on accidents. Sundbyberg: Karolinska Institute, 1987. Paper 5.

SCHLESINGER ER, DICKSON DG, WESTABY J, et al. A controlled study of health education in accident prevention: the Rockland County child injury project. Am J Diseases Children 1966;3:490-5.

WORTEL E, STOMPEDISSEL I, OOIJENDIJK WTM. Preventie van privé-ongevallen bij 04 jarigen: preventieve maatregelen van moeders, kennis en opvattingen, mogelijkheden voor gedragsbeïnvloeding via voorlichting. (Safety measures taken by mothers, their knowledge and opinions.) Leiden: NIPG-TNO, 1990. 


\section{Injury control in pre-school children: a review of parental safety measures and the behavioural determinants*}

Edith Wortel, Gerard H. de Geus, Gerjo Kok, Cees van Woerkum

\section{ABSTRACT}

Safety education directed at parents of pre-school children may be an important tool in reducing injuries of pre-school children at home. However, many studies on educational programmes directed at parents have shown little evidence of success in terms of changes in parental safety behaviour and childhood injuries. These programmes may have been affected, among other factors, by a typical kind of 'programme failure' due to a lack of empirical information on at risk behaviour and the determinants of that behaviour prior to the educational development of programmes. We tried to get an indication of the possibility that previous safety educational programmes had for grounding their activities in an empirical basis. Therefore, a review of literature was carried out on empirical studies on 1. parental safety measures, the form of parental safety behaviour that is supposed to be very important in preventing injuries to pre-school children and 2. the behavioural determinants of those safety measures. It appeared that information on these topics is scarce and this suggests that previous programmes may indeed have suffered from such programme failure. Recommendations are made for enlarging the body of knowledge essential for the development of effective safety education directed at parents of pre-school children. Finally, some recommendations are presented for safety practitioners.

* In: Health Education Research 1994;9(2):201-13. 


\section{INTRODUCTION}

Home-related accidents are a major threat to pre-school children in most of the industrialized world. In the Netherlands these accidents are the major cause of death in the age group 1-4 years (Centraal Bureau voor de Statistiek, 1986-1988). Moreover, about 50,000 Dutch children have to be treated in a hospital yearly for these accidents (Privé Ongevallen Registratie Systeem, 1986-1988): nationally that is 6\% of all children aged 0-4 years. The main types of home-related accidents that threaten pre-school children are falls, poisonings, burns, drownings, suffocations and 'trapping' or crushing injuries. Most of these accidents happen in and around the parental home.

Passive strategies, like legislation and structural measures that require no response from parents or children, are recognized as the most effective (Baker, 1981). However, many risk situations that affect pre-school children can only be avoided by the behaviour of their parents. This stresses the need for effective health education activities in order to improve parental safety behaviour. However, most evaluation studies that used parental safety behaviour and/or childhood injuries as outcome measures have shown little evidence of success. Significant changes in parental safety behaviour and/or childhood injuries were either partially found (Dershewitz, 1979; Thomas et al., 1984; Bass et al., 1985; Kelly et al., 1987; Guyer et al., 1989), or were not found at all (Schlesinger et al., 1966; Dershewitz and Williamson, 1977; Fergusson et al., 1982; McLoughin et al., 1982; O'Connor, 1982; Minchom et al., 1984; Webne et al., 1989). Many different factors may have influenced the 'noeffect' conclusions of these studies: these range from programme failure or implementation failure (Basch et al., 1985) to problems in evaluation methodology.

Our purpose is to focus on a typical kind of programme failure that, among others, may have affected the quality of previous safety education programmes in advance: i.e. health education programmes that are not strongly grounded in previous epidemiological and social psychological research are more likely to be ineffective (Kok and Green, 1990). More specifically, in developing potentially effective education programmes, the first conditions to be met are that those activities are based on 
(1) the behaviours related to the health problem (i.e. behavioural diagnosis) and on

(2) the determinants of behaviour (i.e. educational diagnosis) (Green and Kreuter, 1991). When insufficient empirical information on these subjects was available for previous safety education programmes, these programmes in advance may have been directed at the wrong behaviours and/or wrong behavioural determinants.

The focus of this paper is to assess the extent to which the empirical basis for the development of goal-directed safety education programmes is present. Therefore, studies on parental safety measures (behavioural diagnosis) and the underlying behavioural determinants (educational diagnosis) were reviewed and, where possible, indicators of parents' socio-economic status (SES) have also been presented. Since the literature is not conclusive about the relation of SES and childhood injuries (Wortel and De Geus, 1993), the relationship between SES indicators on the one hand, and safety measures and behavioural determinants on the other has been explored.

\section{METHOD}

To meet the above mentioned goal, we reviewed empirical studies on parental safety measures and on the behavioural determinants of these safety measures. Literature for this study was obtained in different ways.

First, relevant articles, reports and other literature were obtained from the reading list of the Consumer Safety Institute. Second, a systematic literature search of all English language articles listed in Index Medicus from 1966 and listed in Psyc Info (from the American Psychological Association) from 1967 was conducted. This was done by means of a group of key words related to 'safety', 'accidents' and 'wounds and injuries' on the one hand in combination with 'pre-school' on the other hand. Moreover, because the Journal of Safety Research was not included either in Index Medicus or in Psyc Info, we reviewed this journal from the first volume until the present day. 


\section{Chapter 4}

In order to present the results of the studies a general theoretical framework is used for parental safety measures and one for behavioural determinants. These frameworks may provide an insight into the individual contribution of the studies reviewed.

\section{STUDIES ON PARENTAL SAFETY MEASURES}

To develop goal-directed safety education activities, we need to know which behaviours should be recommended to parents. In other words: 'Which parental safety behaviours need to be changed?'.

In general, for formulating the educational goals on the behaviour to be changed, health educators have to rely on the epidemiological literature identifying the behaviour involved. In the case of safety behaviour to prevent home-related injuries of preschool children very few epidemiological studies have examined the relation between childhood injuries and parental safety behaviour. Gustafsson (1977) analyzed the situations leading to children's accidents (1-6 years of age). Clearly identifiable risk factors in the environment could be connected with $52 \%$ of the accidents, whereas some deficiency in supervision was noted in $20 \%$ of cases. Two case-control studies on storage and accessibility of poisons showed no difference between the homes of poisoned and control children (Baltimore and Meyer, 1968; Sobel, 1969). In a casecontrol study on burns of pre-school children, only three behaviours were significantly $(\mathrm{p}<10)$ related to an increased risk: having an oven window that gets hot while in use, storing hot drinks in their original flasks and, contrary to what was expected, cooking on an electric stove compared with cooking on gas (Van Rijn et al., 1991a). Thus, the epidemiological evidence on parental safety behaviour at risk is not yet available.

However, many risk situations affecting pre-school children can only be avoided by the behaviour of their parents, which often makes their behaviour the key factor in the accident-injury process of pre-school children (Roberts et al., 1984). Figure 1 illustrates how four forms of parental safety behaviour are related to the stages of 
this process: educating the child, supervising the child, making the child's environment safe (safety measures) and giving first aid after the accident has happened.

Flgure 1 Accident-injury process of pre-school children related to parental safely behaviour (Wortel and De Geus, 1993)

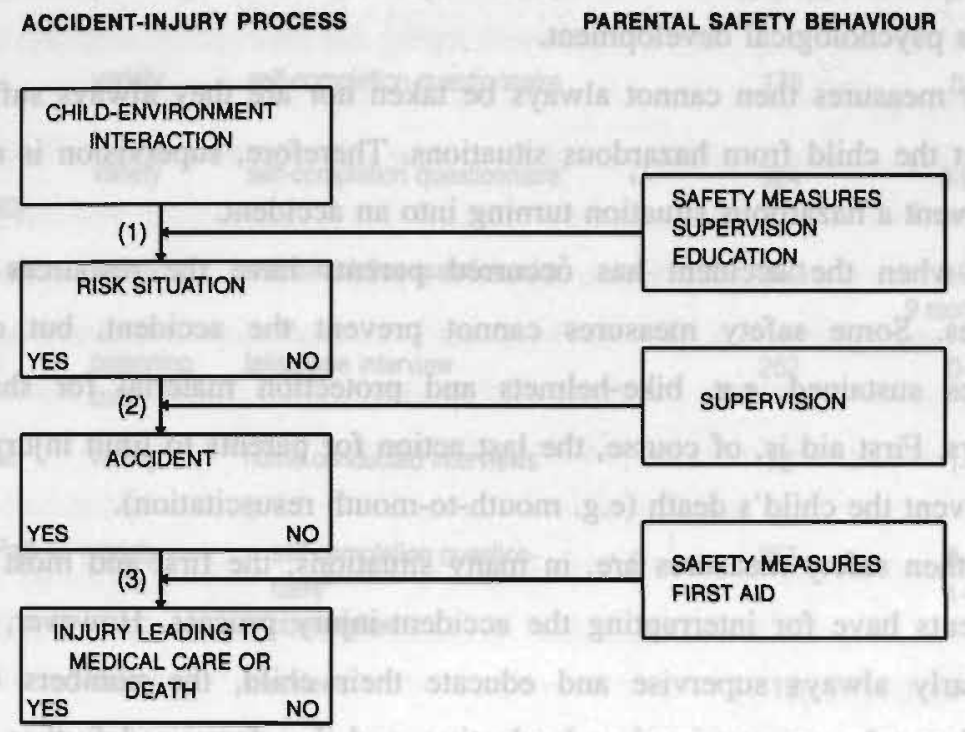

1. To prevent a child-environment interaction turning into a situation at risk, parents can take three courses of action: (i) adopt safety measures, (ii) supervise and (iii) educate their children.

Although often all three forms of parental safety behaviour are necessary, safety measures should be taken whenever possible. This is because, first of all, safety measures may remove sources of accidents ['single action' safety measures (e.g. applying a topguard on the cooker) have this quality even more than safety measures that require frequency actions (e.g. keeping household products out of reach)]. Second, education and supervision have some shortcomings that make them not always effective in regulating the child-environment interaction. The effects of education are dubious, especially for very young children. Most of these children are not yet able to understand and calculate the risks that are 
threatening them. Parents often overestimate the child's maturity which makes education often an improper strategy (Laidman, 1987). The effects of supervision (not leaving the child alone) can be affected by changing circumstances, such as parental stress, illness, fatigue and sudden telephone calls. Moreover, constant supervision is not realistic and may not be appropriate in terms of the child's psychological development.

2. Safety measures then cannot always be taken nor are they always sufficient to protect the child from hazardous situations. Therefore, supervision is necessary to prevent a hazardous situation turning into an accident.

3. Even when the accident has occurred parents have the resources to limit injuries. Some safety measures cannot prevent the accident, but can limit injuries sustained, e.g. bike-helmets and protection material for sharp table corners. First aid is, of course, the last action for parents to limit injury or even to prevent the child's death (e.g. mouth-to-mouth resuscitation).

It is clear then safety measures are, in many situations, the first and most effective means parents have for interrupting the accident-injury process. However, although parents nearly always supervise and educate their child, the numbers of safety measures they take are restricted and selective, and therefore need further improvement (Wortel and Ooijendijk, 1988). Taking safety measures probably is not as natural as education and supervision which seem to happen intuitively. Thus, health education designed to foster the adoption of safety measures should be a priority and for that reason the present review has concentrated on this aspect of prevention.

There have been relatively few studies which have examined the proportion of parents adopting specific safety measures (table 1). Three studies used the same selfcompletion questionnaire (Framingham Safety Survey) of which two were comparable and will be discussed. 
Table 1 Studies on parental safely measures

\begin{tabular}{|c|c|c|c|c|}
\hline Authors & $\begin{array}{l}\text { Type of } \\
\text { accident }\end{array}$ & Measurement & $\begin{array}{l}\text { Number of } \\
\text { respondents }\end{array}$ & $\begin{array}{l}\text { Children's } \\
\text { age }\end{array}$ \\
\hline $\begin{array}{l}\text { Berfenstam and } \\
\text { Beskow (1962) }\end{array}$ & poisoning & observation & 206 & $1-2$ years \\
\hline $\begin{array}{l}\text { Maisel et al. } \\
\text { (1967) }\end{array}$ & poisoning & self-completion questionnaire & $604 ; 1129$ & pre-school \\
\hline $\begin{array}{l}\text { Adair et al. } \\
(1980)\end{array}$ & variety & self-completion questionnaire & 178 & $0-5$ years \\
\hline $\begin{array}{l}\text { Bass and } \\
\text { Mehta (1980) }\end{array}$ & variety & self-completion questionnaire ${ }^{2} \quad+/-$ & 924 & $\begin{array}{l}0-9 \text { months } \\
9 \text { months- } 5 \text { years }\end{array}$ \\
\hline $\begin{array}{l}\text { Halperin et al. } \\
\text { (1983) }\end{array}$ & variety & self-completion questionnaire ${ }^{2}+1-$ & 1493 & $\begin{array}{l}0-9 \text { months } \\
9 \text { months- } 5 \text { years }\end{array}$ \\
\hline $\begin{array}{l}\text { Woolf et al. } \\
\text { (1987) }\end{array}$ & $\begin{array}{l}\text { poisoning } \\
\text { cuts }\end{array}$ & telephone interview & 262 & $0-5$ years \\
\hline $\begin{array}{l}\text { Gärling et al. } \\
\text { (1989) }\end{array}$ & variety & home conducted interviews & 72 & $1-3$ years \\
\hline $\begin{array}{l}\text { Gofin and Palti } \\
(1991)^{3}\end{array}$ & variety & $\begin{array}{l}\text { - seli-completion question- } \\
\text { naire }^{2} \\
\text { - observation }\end{array}$ & 357 & $\begin{array}{l}0-1 \text { years } \\
1-2 \text { years }\end{array}$ \\
\hline $\begin{array}{l}\text { Santer and } \\
\text { Stocking } \\
\text { (1991) }\end{array}$ & variety & interviews & 118 & $0-5$ years \\
\hline $\begin{array}{l}\text { Glik et al. } \\
\text { (1993) }\end{array}$ & variety & self-completion questionnaire & 1247 & pre-school \\
\hline
\end{tabular}

I : a positive relation with SES was found.

0 : no relation with SES was found.

$+/:$ : lor some safety measures a positive relation with SES was found, for others a negative relation.

2The so-called 'Framingham Safety Survey', a series of developmentally oriented safety survey.

${ }^{3}$ This sludy was based on a relatively highly educated population.

- This study was based on a low income population.

In the age group 0-9 months Bass and Mehta (1980) found three 'at risk' safety measures from more than $40 \%$ of the parents whereas Halperin et al. (1983) found two 'at risk' safety measures in this age group. These two 'at risk' safety measures, 'no fire extinguisher in the house' and 'placing the child in the front seat of the car', were also found in the Bass and Mehta study. In the age group 9 months to 5 years Bass and Mehta found 12 'at risk' safety measures from more than $40 \%$ of the par- 
ents; Halperin et al. found 7 'at risk' safety measures of which the following six were comparable with the at risk safety measures of the Bass and Mehta study: no fire extinguishers in the house, the use of electrical appliances in the bathroom, no safety plugs on all unused electrical outlets, no Ipecac (a syrup that provokes vomiting) in the house, not always checking safety hazards in homes of friends or relatives where the child may play, and not always keeping the child in an enclosed area when alone and unsupervised.

The remaining studies presented in table 1 were difficult to compare, because they often differed in the safety measures selected for examination, the children's age group and in the research population they were based on. In all, the studies reviewed had one feature in common: they showed that measures adopted by large numbers of parents happen to be selective and insufficient. Moreover, the studies did not provide a basis for making inferences on the role of SES.

\section{STUDIES ON BEHAVIOURAL DETERMINANTS OF PARENTAL SAFETY MEASURES}

In addition to understanding which parental safety measures have to be changed, we need information about why parents do or do not perform the desired safety measures. Recently, determinants of behaviour have been measured according to the Attitude - Social influence - Self-efficacy/barriers (ASE) model (Ajzen, 1988, 'the model of planned behaviour'; De Vries et al., 1988; Kok et al., 1991). Therefore, this model will be used as a framework for discussing the results found with respect to the determinants of parental safety behaviour. It states that a people's behaviour is influenced by their attitude towards the behaviour, the social influence they are experiencing with respect to that behaviour and the self-efficacy and barriers they are confronted with when performing the behaviour. External variables, such as demographic variables, are considered to influence behaviour via these three determinants. An attitude of health-related behaviour is the weighting of all perceived advantages and disadvantages of performing that behaviour. Health advantages, in this case the 
child's safety, probably are the main advantages of taking a safety measure. A disadvantage of some measures may be their inconvenience.

Social influence refers to the influence of others, either directly or indirectly. In the case of child safety, the partner of a parent is probably the main person next to family and friends who may or may not give social support for taking safety measures. Self-efficacy/barriers refers to the extent to which a person thinks he/she will be able to perform the (desired) behaviour. Self-efficacy is an estimate of the ability to cope with barriers inside or outside the person (Bandura, 1986). Examples of internal barriers are: no knowledge of where to buy safety equipment or not knowing how to apply certain safety devices. Examples of external barriers are: insufficient time to take a measure or lack of money for buying safety devices.

We specifically included some variables into the ASE model that may be useful in the context of determinants of parental safety behaviour. As parental safety behaviour can be considered as a health behaviour, we also included some variables from the Health Belief Model (Janz and Becker, 1984) and the Protection Motivation Theory (Rippetoe and Rogers, 1987).

The first variable to be included was the 'threat' that is formed through a person's perception of susceptibility and seriousness of diseases or injuries. The second variable that was included was 'response-efficacy'. Response-efficacy is the extent to which a person believes the recommended behaviour can reduce the risk to be confronted; in other words this is the belief about the instrumentality of the behaviour. Both level of threat and response-efficacy can be considered as parts of overall attitude (Ajzen, 1988; De Vries et al., 1988).

Furthermore, as was stated in the introduction, in the case of childhood injuries an external variable that may be of importance is parents' socio-economic status (SES). 
Table 2 Studies on behavioural determinants

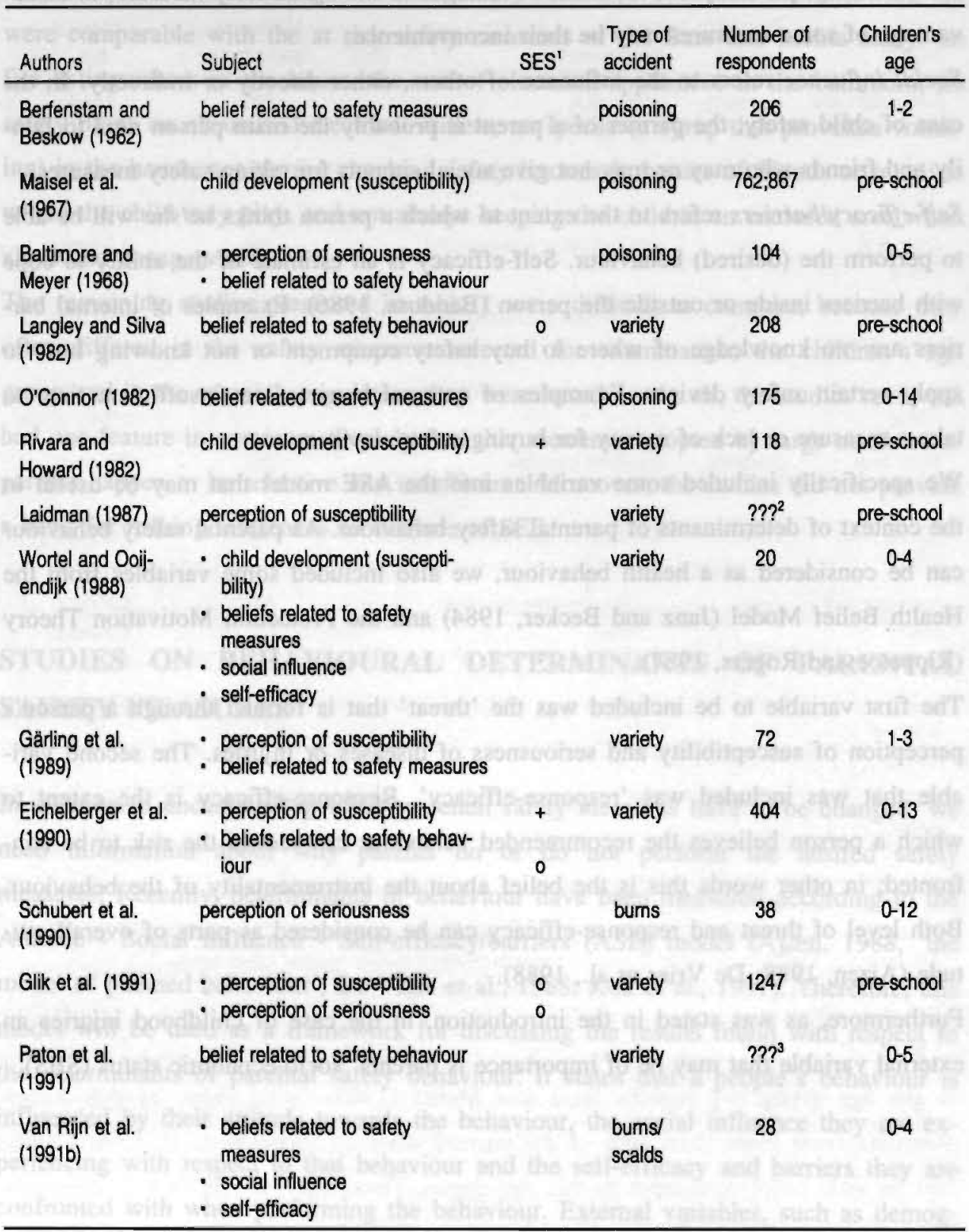

1 t: a positive relation with SES was found.

o: no relation with SES was found.

2 The number of respondents was not given.

${ }^{3}$ Only the response-rate was presented. 
Most of the studies reviewed (see table 2) did not use any kind of theoretical model for the measurements of determinants. Findings were clarified in terms of the ASE model mentioned above.

\section{Attitude aspects related to the threat parents experience of childhood injuries}

How parents perceive the threat of childhood injuries depends on the extent to which they believe their child is susceptible to injuries, and how serious these injuries might be. Except for one study, the studies reviewed did, in fact, examine concepts related to either parents' perception of the susceptibility or their perception of the seriousness of childhood injuries.

\section{Perceived susceptibility}

Parents' belief in susceptibility is related to their understanding of the child's development - each developmental stage makes the child vulnerable to specific risk situations (Jordán and Valdes-Lazo, 1991) - and to their knowledge of risk situations.

In the context of a study on child safety Rivara and Howard (1982) assessed parental knowledge of child development and concluded that their knowledge of this subject was low. Different SES indicators, insurance status and level of education, were also significantly related to parental knowledge of the child's development: the lower parents' SES the less they knew about child development.

Maisel et al. (1967) observed that many parents stored toxic products in places that were accessible to their children while believing that they were, in fact, inaccessible. Parents do not appear to be aware of the mobility of their children and of the risks that confront them.

In an explorative study Wortel and Ooijendijk (1988) asked parents of children aged 0-4 years why they did not implement safety measures appropriate for their child's age. Parents thought either that their child was too young to be confronted with the 
risk situation or thought their child was too old for the measure because parents supposed the child was able to cope with the risk situation.

Parents, in fact, misperceived their child's development and the latter two studies suggest that this may contribute to their not taking the safety measures appropriate to their child's age. The following studies give an insight into parents' knowledge of risk situations.

Gärling et al. (1989) investigated how mothers with children aged 1-3 years perceived dangers for their children in the home. They were asked how likely they thought their unsupervised child was to have an accident in the kitchen, bathroom, living room and the child's bedroom. Mothers perceived the kitchen and bathroom as the most dangerous places and that their need for supervision and safety measures was felt to be the strongest for these rooms. This study showed that mothers discriminate between locations in the home that may be risky to their children. Unfortunately, whether these perceptions were right could not be concluded from this study because the authors were unable to relate these perceptions to statistical data on injuries.

Eichelberger et al. (1990) examined parents' knowledge of injury risks for children aged 0-13. Parents demonstrated a better understanding of automobile injury risk and prevention than other types of injury. Although scalds are the most common type of burns (Van Rijn et al., 1991b), half of these parenis believed that 'most burns children receive are from fires:. However, parents of younger children had more accurate perceptions, as did parents with a higher SES.

Glik et al. (1991) demonstrated that mothers of pre-school children underestimated the risk of some hazards and injuries and overestimated the risks of others: mothers may underestimate the likelihood of burns, poisoning, head injuries and broken bones for their children as well as the likelihood of hazards like hot water, electrical appliances, electrical outlets and bath tubs.

Laidman (1987) also found that mother's knowledge of accident situations was limited and often the priorities drawn between accident types were inappropriate.

These studies unanimously indicated that parents' knowledge of risk situations is insufficient. This may imply that parents' perception of the likelihood of their child 
being confronted with home-related injuries is incomplete or even wrong. Furthermore, although two studies showed a positive relation with parents' SES, these studies cannot provide a basis for making inferences on the role of SES.

\section{Perceived seriousness}

Parents' belief in the seriousness of childhood injuries will be influenced by their knowledge of possible consequences of risk situations.

Glik et al. (1991) showed that mothers had a good understanding of the seriousness of different types of injuries. A study by Baltimore and Meyer (1968) demonstrated that the overall quality of mothers' knowledge of the toxicity of medications and common household products was good. However, Schubert et al. (1990) found that many parents of children who were burned by hot oil or grease indicated they were unaware of the hazards of these substances.

The studies carried out so far with respect to parents' perception of the seriousness of childhood injuries are not conclusive. This may be because the Schubert study was based on the responses of parents whose children had injuries as these parents may make other attributions because of feelings of guilt.

\section{Perceived threat}

In the study by Glik et al. (1991) the perceived threat (i.e. risk perception) was measured and analyzed according to the Health Belief Model in which the perception of the threat is based on the perceived susceptibility and seriousness. This study revealed that the perceived threat of childhood injuries and hazards was insufficient and that this was mainly due to the underestimation of the susceptibility to certain injuries and hazards. While parents seem to have a good understanding of the seriousness of certain risks, they have more difficulty in estimating probabilities. These findings seem to be in agreement with the former studies presented on mothers' perception on the susceptibility and seriousness of injuries. 
Attitude aspects related to safety measures, social influence and self-efficacy/barriers

The first studies to be presented give an insight into the extent to which parents may regard their own behaviour as instrumental in preventing childhood injuries in and around the home without specifying the type of behaviour.

Langley and Silva (1982) demonstrated that only $39 \%$ of the parents of a child who had an accident during the pre-school age changed their safety behaviour afterwards to prevent a recurrence. Most parents who did not take measures after the accident thought that the accident was not preventable (63\%). Berfenstam and Beskow (1962) and O'Connor (1982) found comparable results: even after the occurrence of poisoning most parents did not make any effort to improve the safety in their home. Moreover, Baltimore and Meyer (1968) showed that both mothers with poisoned children and the comparison group attributed careless behaviour as a major cause of poisoning, but mothers of poisoned children made only minor or no changes in their home storage after the accident.

The results of the last two studies to be discussed in this context were based on the beliefs of parents with children without an injury history. Eichelberger et al. (1990) showed that $87 \%$ of the parents agreed with the statement that most accidents are avoidable. Furthermore, $70 \%$ believed that more than half of all serious injuries or accidents could be prevented. Paton et al. (1991) found that $84 \%$ of parents with children less than 2 years old considered injuries to be usually preventable or preventable with effort. For different locations (e.g. home, playground) fewer parents with children between 2 and 5 years old than parents with younger children believed injuries could always or usually be prevented. These studies affirm the findings of Baltimore and Meyer that parents regard childhood injuries as preventable.

In all, the results of these studies are not conclusive with respect to how parents judge their own behaviour as instrumental in preventing childhood injuries (responseefficacy). Eichelberger et al. (1990) tried to be more specific in the sense that they also gave parents' opinion on one form of parental safety behaviour, 'supervising the child'. They found that parents of children aged 0-13 years hold the mistaken belief 
that 'caution and vigilance are effective means to protect their children from injuries'. This may indicate that parents consider safety measures as unimportant in avoiding accidents.

The following studies concern one or more behavioural determinants of specific safety measures that are related to the taking or not taking of these measures. Gärling et al. (1989) examined the relation between the belief about the instrumentality of specific safety measures (i.e. response-efficacy) and the taking of specific safety measures. They found that whether a safety measure was implemented in the home or not, was related to the extent to which mothers perceived the measure as instrumental to the child's protection. For instance, equipping the bathroom with an antislip mat was considered instrumental, whereas the protection of sharp corners was not.

The last two studies to be presented were explorative studies on salient beliefs, important reference persons and barriers in terms of the ASE model. Wortel and Ooijendijk (1988) found that salient beliefs mentioned by parents of pre-school children for not taking safety measures were: unfamiliarity with a measure, rejection of the necessity of the measure according to the child's age (too young or too old) or for other reasons, inconvenience, impracticability and difficulty of applying the measure. Where safety equipment was concemed, parents also mentioned as a reason for not applying this that they disliked its appearance. It appeared that the partner can be regarded as the main reference person when preventive actions are concerned.

Van Rijn et al. (1991c) asked a group of Dutch and Turkish parents with pre-school children to implement nine safety measures for two weeks to prevent scalds and burns. Main reasons mentioned for non-compliance were: unfamiliarity with the measure and difficulty in applying the measure. Other reasons mentioned were: visitors did not adopt this behaviour (a social influence especially mentioned by Turkish parents), by making the child's environment safe the child does not learn how to handle dangerous situations and parents doubted if the safety measure indeed improved the child's safety (instrumentality).

Thus, in general parents may not be aware that taking safety measures is an effective way to avoid childhood injuries. Moreover, an insight was provided into salient 
beliefs parents may link to safety measures in terms of pros and cons, their ability to take the measures (self-efficacy) and into reference persons that influence their decision making on safety measures (social influence). However, none of the previous studies assessed the relationship between the taking or non-taking of specific safety measures on the one hand and a set of behavioural determinants on the other. This kind of information is necessary in order to get the right information for the 'educational diagnosis' and thus the information developers need to set the education goals of a safety education programme.

\section{CONCLUSIONS AND DISCUSSION}

In this paper we have tried to gain insight into the body of knowledge that must be present in order to develop potentially effective safety education activities. The main conclusion to be made is that the knowledge essential for the development of effective safety messages directed at parents is far from complete. As too little information is available on the parental safety measures that need to be changed and the determinants underlying these safety measures, it is of no surprise that educators often had to develop their safety education activities on the basis of common sense and intuition (Roberts et al., 1984). Hence, these activities may a priori have suffered from 'programme failure'. Moreover, it may be that many evaluation studies have tried to assess changes at a level which their programmes were inappropriate to effect. Therefore, on the basis of these studies it was mistakenly concluded that health education does not work.

In the following section we shall discuss the conclusions in more detail and we will suggest how future research could bridge gaps in the knowledge on child safety as far as it concerns educational activities aimed at promoting parental safety measures. 


\section{Parental safety measures}

A first step in formulating safety measures to be recommended to parents is to assess the safety measures 'at risk'. However, this review has shown that there is a lack of epidemiological studies that included parental safety measures as a risk factor. This seems to be related to the predominant use of the classical epidemiological model that describes the etiology of childhood injuries by means of the host (e.g age, sex, family backgrounds), agent (e.g. tea/coffee, poisons) and environment (e.g. time, place) in which the behavioural component is overlooked (Gärling, 1985; Peterson et al., 1987; Vilardo, 1988). Therefore, epidemiological studies are needed in which parental safety measures are examined as a risk factor.

Case-control studies are mostly used to assess causal relations between accidents and risk factors (cases are the injured children; controls are uninjured children). However, the case-control design may not be appropriate for studying the role of parental safety measures since it is vulnerable to several methodological pitfalls like recall bias (Kopec and Esdaile, 1990), cases and controls overreporting or underreporting risk behaviours, and the adaption of behaviour after the accident. A more appropriate way of studying behaviour at risk is the use of a prospective model, e.g. by means of process analysis: analysis of a series of behaviours that can result into injury or nearinjury (Peterson et al., 1987). Unfortunately, this only gives us information in the long term because serious injuries are relatively rare events. Moreover, large populations have to be followed over a long period (Scheidt, 1988).

Actually, for tracing parental safety measures to be improved less complex and less labour intensive research seems to be more suitable. The analysis of the circumstances of childhood injuries that have already occurred may also reveal the parental safety measures that should have been taken. For instance, Jackson et al. (1968) assessed how poisons were kept by parents with children with accidental poisoning. They concluded that poisons were often kept in an inappropriate place. Langley et al. (1981) found that scalding incidents involving children could often be related to hazards in the environment of the child. From these kind of studies the safety measures at risk can be assessed and consequently the safety measures desired can be derived. 
A second step in formulating safety measures to be recommended to parents is to gather information on the parental safety measures present in a representative population. Thus far, only a few, difficult to compare, studies have been carried out in order to assess the percentage of parents that adopted and did not adopt specific safety measures needed according to their child's development. Thus, except for the knowledge that parents' safety measures need improvement, little is known of the specific safety measures that should be given priority in safety education.

In order to compare the results from future studies, consensus has to be reached on the formulation of safety measures and on the developmental period where the measure is considered to be necessary for the child. Foundations and trusts may be helpful in this formulation.

\section{Determinants of parental safety measures}

Although the control of a child's safety is largely in the hands of the parents, little literature is available on why parents do not adopt recommended safety measures. Only a few attempts have been made to study determinants of parents' safety measures and even fewer studies tried to do this by means of a model of planned behaviour. When studying these determinants, a model of planned behaviour with the inclusion of attitude aspects related to how parents perceive the threat of childhood injuries may be useful. This perceived threat may indicate parents' need to cope with the child safety problem which may give an insight into the parents' stage of preventive thinking.

First, as this paper demonstrated, parental perception of threat of childhood injuries, derived from perceived susceptibility and seriousness, seems to be insufficiently present. Although previous information on the perceived susceptibility was conclusive, more research is needed on the specific risk situations/hazards parents do not know. Since very little information on the perceived seriousness of injuries was available, studies on parents' knowledge of the seriousness are also needed. In general, in studying perceived susceptibility to and seriousness of childhood injuries it may be 
useful to differentiate between perceptions related to injuries (like falls, burns and suffocation), on the one hand, and perceptions of hazards (like stairs, hot coffee and plastic bags) on the other (Glik et al., 1991).

Second, studies carried out so far have not made clear whether parents consider their own behaviour in general as a remedy to avoid childhood injuries. More information on this topic is needed. Since parents whose child had an injury may make other attributions with respect to their own behaviour to protect themselves from feelings of guilt, it seems preferable to gather this kind of information from parents of children without an injury history. In particular, an insight is needed into parents' estimation of the relative importance of the four forms of safety behaviour (see figure 1). This gives an idea of the possible resistance they might have towards safety measures as a coping strategy.

Third, more information on determinants of specific safety measures (e.g. keeping out of reach the tea/coffee pot) is necessary. This means that salient beliefs about costs and benefits of safety measures and self-efficacy beliefs as well as the influence of main referent persons (social influence) have to be related to taking or not taking specific safety measures. However, assessing the behavioural determinants of all specific safety measures that parents of pre-school children are supposed to take is a very labour intensive job. Therefore, it is seems more feasible to look for the determinants that influence specific safety measures most. For instance, safety measures can be categorized according to the type of accident (e.g. poisoning, suffocation) they have to prevent, the frequency with which action is required from parents (one action measures versus more action measures) and the financial consequences they require when safety equipment (e.g. stair gates) is involved.

\section{Parental SES}

The studies reviewed provided too little evidence for making inferences on the relation between SES indicators at the one hand and safety measures and behavioural determinants on the other. Since assessment of these relations may be helpful to 


\section{Chapter 4}

identify groups that need more intensive or other guidance future research should pay more attention to the role of parents' SES.

\section{PRACTICAL IMPLICATIONS}

Although the information available for safety practitioners is not complete, some useful recommendations can already be given. In developing the content of safety messages for parents, it may be helpful to work according to the following questions: 1. Which parental safety behaviours have to be recommended? 2. Which determinants underlie these behaviours and how can parents be convinced to comply with these behaviours?.

First, safety practitioners have to advocate taking safety measures rather than educating and supervising the child - something most parents already do. However, as too little information is available on the safety measures that need to be changed, it is difficult to set priorities with respect to the advocating of specific measures. The best way of limiting the number of safety measures to be advocated is to discuss those measures necessary to the child's developmental stage.

Second, in trying to convince parents to comply with recommended safety measures it is necessary to assess the stage which parents have reached in their preventive thinking on child safety. The first step is to assess if parents perceive the threat of childhood injuries. Educators need to explain to parents how the child's developmental process makes each child vulnerable to the same risk situations. By explaining this to parents, they may mitigate parental unrealistic optimism (Weinstein, 1984), a belief that an accident will not happen to their child(ren). Kelly et al. (1987) developed a method that may be helpful in discussing the child safety problem. This method consists of an age-appropriate, developmentally-oriented questionnaire to be completed by the parents and paediatrician. The parents' responses to the questionnaire serve as a basis for a parent-paediatrician dialogue. By means of this strategy, active participation of the parent is stimulated, which is useful to assess parents' knowledge of their child's development, in combination with risk situations present 
in their homes. Moreover, educators may explain the most serious type of hazards to parents that may affect their children in certain developmental stages. Parents need to know that many risk situations may have only mild consequences or no consequences at all for their children, but also can badly injure their child or even lead to the child's death. Naturally, to enhance parents' perception of the threat is only allowed when safety measures are available to reduce this threat.

Once they perceive the threat and thus the need to cope with child safety is apparent, the next step is to introduce safety measures as a coping strategy. The educator has to check parents' attitude towards safety measures as opposed to supervising and educating the child as remedies to prevent injuries. Therefore, safety educators have to advocate the advantages of safety measures compared with supervision and education. Except for the child's safety, another advantage of taking safety measures is the rest the parent and the child will get when the child is moving in a safe home environment.

The last step is to convince parents to take specific safety measures. The educator has to create a positive trade-off between the reduction in injury risk and the costs of taking the safety measure. At least parents have to be convinced of the instrumentality of the safety measure in reducing the risk situation, they need to have social support from their partner and other important persons (social influence) and they need to have the feeling to be able to take the safety measure themselves (self-efficacy).

\section{ACKNOWLEDGEMENTS}

We would like to thank Susan Brink, Guy Parcel, Hein de Vries and Ellen Bergsma for their useful comments on earlier drafts of this article. 


\section{REFERENCES}

ADAIR D, CHARLTON A, FLOOD M, et al. A project on home accidents. Health Visitor 1980;53:158-60.

AJZEN I. Attitude, personality and behavior. Milton Keynes: Open University Press, 1988.

BAKER SP. Childhood injuries: the community approach to prevention. J Publ Health Pol $1981 ; 2: 235-46$.

BALTIMORE CL, MEYER RJ. A study of storage, child behavioral traits, and mother's knowledge of toxicology in 52 poisoned families and 52 comparison families. Pediatrics 1968;42:312-7.

BANDURA A. Social foundations of thought and action: a social cognitive theory. Englewood Cliffs, NJ: Prentice Hall, 1986.

BASCH CE, SLIEPCEVICH EM, GOLD RS, et al. Avoiding type III errors in health education program evaluations: a case study. Health Educ Quart 1985;12:315-31.

BASS JL, MEHTA KA. Developmentally-oriented safety surveys: reported parental and adolescent practices. Clin Pediatr 1980;19:350-6.

BASS JL, MEHTA KA, OSTROVSKY M, HALPERIN SF. Educating parents about injury prevention. Pediatr Clin North Am 1985;32:233-42.

BERFENSTAM R, BESKOW J. Storage of poisons in the homes of families with small children. Brit J Prev Soc Med 1962;16:123-9.

CENTRAAL BUREAU VOOR DE STATISTIEK. Overledenen naar doodsoorzaak, leeftijd en geslacht in het jaar 1985-1987. Voorburg: CBS, 1986-1988. Series A1.

DERSHEWITZ RA. Will mothers use free household safety devices? Am J Diseases Childr 1979;133:61-4.

DERSHEWITZ RA, WILLIAMSON JW. Prevention of childhood household injuries: a controlled clinical trial. Am J Publ Health 1977;67:1148-53.

EICHELBERGER MR, GOTSCHALL CS, FEELY HB, et al. Parental attitudes and knowledge of child safety. Am J Diseases Childr 1990;144:714-20. 
FERGUSSON DM, HORWOOD LJ, BEAUTRAIS AL, SHANNON FT. A controlled field trial of a poisoning prevention method. Pediatr 1982;69:515-20.

GÄRLING T. Children's environments, accidents and accident prevention: an introduction. In: Gärling T, Valsiner J, eds. Children within environments: toward a psychology of accident prevention. New York: Plenum Press, 1985:3-12.

GÄRLING T, GÄRLING A, MAURITZON-SANDBERG E, BJÖRNSTIG U. Child safety in the home: mothers' perception of dangers to young children. Arch Comp/ Arch Behav 1989; 5:293-304.

GLIK D, KRONENFELD J, JACKSON K. Predictors of risk perceptions of childhood injury among parents of preschoolers. Health Educ Quart 1991;18:285-301.

GLIK D, KRONENFELD J, JACKSON K. Safety behaviors among parents of preschoolers. Health Values 1993;17:18-27.

GOFIN R, PALTI H. Injury prevention practices of mothers of 0 to 2 year olds: a developmental approach. Early Child Developm Care 1991;71:117-26.

GREEN LW, KREUTER MW. Health promotion planning, an educational and environmental approach. Mayfield: Mountain View, 1991.

GUSTAFSSON LH. Childhood accidents: three epidemiological studies on the etiology. Scand J Soc Med 1977;5:5-13.

GUYER B, GALLAGHER SS, CHANG BH, et al. Prevention of childhood injuries: evaluation of the Statewide Childhood Injury Prevention Program (SCIPP). Am J Publ Health 1989;79:1521-7.

HALPERIN SF, BASS JL, MEHTA KA. Knowledge of accident prevention among parents of young children in nine Massachusetts towns. Publ Health Rep 1983;98:548-52.

JACKSON RH, WALKER JH, WYNNE NA. Circumstances of accidental poisoning in childhood. Brit Med J 1968;4:245-8.

JANZ NK, BECKER MH. The health belief model: a decade later. Health Educ Quart 1984; 11:1-47.

JORDÁN JR, VALDES-LAZO F. Education on safety and risk. In: Manciaux M, Romer CJ, eds. Accidents in childhood and adolescence: the role of research. Geneva: World Health Organization, 1991:106-20. 


\section{Chapter 4}

KELLY BK, SEIN C, McCARTHY PL. Safety education in a pediatric primary care setting. Pediatr 1987;79:818-24.

KOK G, GREEN LW. Research to support health promotion in practice: a plea for increased co-operation. Health Prom Intern 1990;5:303-8.

KOK G, VRIES H de, MUDDE AN, STRECHER VJ. Planned health education and the role of self-efficacy: Dutch research. Health Educ Res 1991;6:231-8.

KOPEC JA, ESDAILE JM. Bias in case-control studies: a review. J Epidem Comm Health $1990 ; 44: 179-86$.

LAIDMAN P. Health visiting and preventing accidents to children. London: Child accident prevention trust, 1987. Research report no. 12.

LANGLEY J, DODGE J, SILVA PA. Scalds to preschool children. New Zealand Med J 1981;93:84-7.

LANGLEY J, SILVA PA. (1982) Childhood accidents: parents' attitudes to prevention. Austral Paediatr J 1982;18:247-9.

MAISEL. G, LANGDOC BA, JENKINS MQ, AYCOCK EK. Analysis of two surveys evaluating a project to reduce accidental poisoning among children. Publ Health Rep 1967;82:55560.

MCLOUGHIN E, VINCE CJ, LEE AM, CRAWFORD JD. Project bum prevention: outcome and implications. Am J Publ Health 1982;3:241-7.

MINCHOM PE, SIBERT JR, NEWCOMBE RG, BOWLEY MA. Does health education prevent childhood accidents? Postgrad Med J 1984;60:260-2.

O'CONNOR PJ. Poisoning prevention: results of a public media campaign. Austral Paediatr J 1982;18:250-2.

PATON TJ, LEE NJ, YACOUB WR, ANGUS B. A health centre survey of childhood injury in Edmonton. Can J Publ Health 1991;82:436-7.

PETERSON L, FARMER J, MORI L. Process analysis of injury situations: a complement to epidemiological methods. J Soc Issues 1987;43:33-44.

PRIVÉ ONGEVALLEN REGISTRATIE SYSTEEM (PORS). Jaaroverzicht privé-ongevallen registratie systeem, 1985-1987. Amsterdam: Stichting Consument en Veiligheid, 1986-1988. 
RIJN OJL van, BOUTER LM, KESTER ADM, et al. Aetiology of burn injuries among children aged 0-4: results of a case control study. Burns 1991a;17:213-9.

RIJN OJL van, GROL MEC, BOUTER LM, et al. Incidence of medically treated bums in the Netherlands. Bums 1991b;17:357-62.

RIJN OJL van, MEERTENS RM, KOK GJ, BOUTER LM. Determinants of behavioural risk factors for burn injuries. Burns (1991c);17:364-70.

RIPPETOE PA, ROGERS RW. Effects of components of protection - motivation theory on adaptive and maladaptive coping with a health threat. J Personal Soc Psychol 1987;52:596604.

RIVARA FP, HOWARD D. Parental knowledge of child development and injury risks. Developm Behav Pediatr 1982;3:103-5.

ROBERTS MC, ELKINS PD, ROYAL GP. Psychological applications to the prevention of accidents and illness. In: Roberts MC, Peterson L, eds. Prevention of problems in childhood: psychological research and applications. New York: Wiley, 1984:173-99.

SANTER LJ, STOCKING CB. Safety practices and living conditions of low-income urban families. Pediatr 1991;88:1112-8.

SCHEIDT PC. Behavioral research toward prevention of childhood injury: report of a workshop sponsored by the National Institute of Child Health and Human Development, Sept. 3-5, 1986. Am J Diseases Childr 1988;142:612-7.

SCHLESINGER ER, DICKSON DG, WESTABY J, et al. A controlled study of health education in accident prevention: the Rockland County Child Injury Project. Am J Diseases Childr $1966 ; 3: 490-5$.

SCHUBERT W, AHRENHOLZ DH, SOLEM LD. Bums from hot oil and grease: a public health hazard. J Burn Care Rehab 1990;11:558-62.

SOBEL R. Traditional safety measures and accidental poisoning in childhood. Pediatr 1969; suppl.44:811-6.

THOMAS KA, HASSANEIN RS, CHRISTOPHERSEN ER. Evaluation of group well-child care for improving burn prevention practices in the home. Pediatr 1984;74:879-82.

VILARDO FJ. The role of the epidemiological model in injury control. J Saf Res 1988;19:14. 


\section{Chapter 4}

VRIES $\mathrm{H}$ de, DIJKSTRA M, KUHLMAN P. Self-efficacy: the third factor besides attitude and subjective norm as predictor of behavioral intentions. Health Educ Res 1988;3:273-82.

WEBNE S, KAPLAN BJ, SHAW M. Pediatric Bum Prevention: an evaluation of the efficacy of a strategy to reduce tap water temperature in a population at risk for scalds. J Developm Behav Pediatr 1989;10:187-91.

WEINSTEIN ND. Why it won't happen to me; perceptions of risk factors and susceptibility. Health Psychol 1984;3:431-57.

WOOLF A, LEWANDER W, FILIPPONE G, LOVEJOY F. Prevention of childhood poisoning: efficacy of an educational program carried out in an emergency clinic. Pediatr 1987;80: 359-63.

WORTEL E, OOIJENDIJK WTM. Preventie van privé-ongevallen bij kinderen: onderzoek naar preventief gedrag van ouders en gedragsdeterminanten. (Prevention of home-related accidents of children: research on parental preventive behaviour and behavioural determinants). Leiden: NIPG-TNO, 1988.

WORTEL E, GEUS GH de. Prevention of home related injuries of pre-school children: safety measures taken by mothers. Health Educ Res 1993;8:217-31. 


\section{Prevention of home-related injuries of pre-school children: safety measures taken by mothers*}

Edith Wortel and Gerard H. de Geus

\section{ABSTRACT}

Home-related injuries are a major threat to the health of pre-school children in the Netherlands. Many risk situations can only be avoided through parental safety behaviour, especially with measures taken to structure the child's environment. This study was meant to contribute to the information needed to develop a safety education programme directed at parents. Therefore, we assessed mothers' safety measures related to poisoning, burns and falls, the consistency between these measures within one type of accident, and their relation to the mothers' education. A written questionnaire was completed by 1129 mothers of pre-school children (response rate 84\%). Results suggest that many of the safety measures taken by mothers have to be judged moderately safe or unsafe and therefore correction or development of these measures is needed. Furthermore, this study suggests that safety measures belonging to one type of accident are not consistent with one another. This implies that each measure has to be advocated separately. Moreover, there was no substantial evidence for a relation between the mothers' safety measures and their education. Safety educators, therefore, do not need to differentiate between mothers with different educational levels when designing programmes.

* In: Health Education Research 1993;8(2):217-31. 


\section{INTRODUCTION}

Domestic accidents are a major threat to pre-school children in most industrialized countries. In the Netherlands these accidents are the major cause of death in the age group 1-4 years (Centraal Bureau voor de Statistiek, 1986-1988). Moreover, about 50000 children have to be treated in hospital yearly for these accidents (Privé Ongevallen Registratie Systeem, 1986-1988), i.e. 6\% of all children aged 0-4 years at the national level.

Strategies such as legislation and structural measures that require no response from the caregiver or child are recognised as the most effective (Baker, 1981). However, there is no doubt that many risk situations affecting pre-school children can only be avoided by the behaviour of their caregivers. Clearly, given the many unintentional injuries that happen to pre-school children, behavioural strategies such as safety education programmes are needed to improve parental safety behaviour as much as possible.

Effective educational programmes need thorough preparation. This means that the behaviour related to the health problem, the behaviour at risk, needs to be identified (Bouter et al., 1990). However, in the case of childhood injuries epidemiological evidence on parental safety behaviour is rarely available. In two studies on storage and accessibility of poisons in the homes of poisoned and control children no differences between the two groups were found (Baltimore and Meyer, 1968; Sobel, 1969). In a patient control study on burns of pre-school children only three behaviours were significantly related to an increased risk: an oven window which gets hot while in use, the storage of hot drinks in their original flasks and, contrary to what was expected, cooking on an electric stove (Van Rijn et al., 1991).

Thus, the epidemiological evidence for parental behaviour at risk is not yet available. This is mainly due to the use of the classical epidemiological model in which the behavioural component is overlooked (Gärling, 1985; Vilardo, 1988). Therefore, to assess parental safety behaviour needed to reduce risk for pre-school children, injury data on the host, agent and environment have to be complemented by case histories in which parental behaviour is described. For example, it is known that serious scalds 
of pre-school children are often due to coffee and tea (Klasen and Ten Duis, 1986). Not having a child on the lap while drinking tea or coffee may be one of the preventive safety measures according to information derived from case histories.

\section{Parental safety measures}

In general, parental safety behaviour can be subdivided into four behaviours: safety measures (i.e. structuring the child's environment), educating the child, supervising the child and giving first aid when an accident has happened. Figure 1 demonstrates which of these behaviours can interrupt the accident-injury process of a pre-school child at which stage.

Figure 1 Accident-injury process of pre-school children related to parental safety behaviour

ACCIDENT-INJURY PROCESS

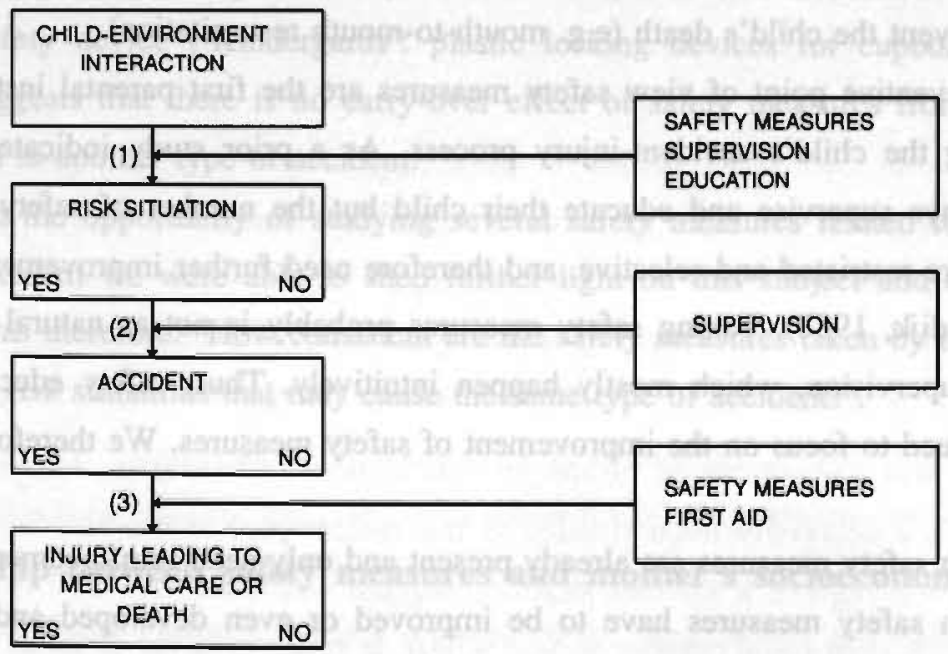

1. To prevent a child-environment interaction turning into a situation at risk, parents can take safety measures, supervise and educate their children. Although on many occasions these three forms of parental safety behaviour are necessary, 


\section{Chapter 5}

safety measures have to be taken whenever possible, because education and supervision have some major shortcomings. The effects of education in regulating the child-environment interaction are limited especially with very young children. Most of these children are not yet able to understand and calculate the risks that are threatening them, and are also easily distracted by other things that happen in their surroundings. Moreover, the effectiveness of supervision can be affected by changing circumstances, such as parental stress, illness, fatigue and sudden telephone calls. Apart from this, constant supervision is not realistic and may not be appropriate in terms of the child's psychological development.

2. Safety measures cannot always be taken or are not always sufficient to protect the child from situations at risk. Therefore, supervision is necessary to prevent a hazardous situation turning into an accident.

3. At a later stage of the accident-injury process, safety measures can limit injuries after the accident has happened (e.g. bike-helmets and protection material for sharp table comers). First aid is the last thing parents can do to restrain injury or prevent the child's death (e.g. mouth-to-mouth resuscitation).

From a preventive point of view safety measures are the first parental instrument in interrupting the child's accident-injury process. As a prior study indicated, parents nearly always supervise and educate their child but the number of safety measures they take are restricted and selective, and therefore need further improvement (Wortel and Ooijendijk, 1988). Taking safety measures probably is not as natural as education and supervision, which mostly happen intuitively. Thus, safety education programmes need to focus on the improvement of safety measures. We therefore need to know:

1. Which safety measures are already present and only need reinforcement.

2. Which safety measures have to be improved or even developed and therefore require more intensive safety education activities.

As far as we know few studies have focused on what parents of pre-school children actually do about child safety (Berfenstam and Beskow, 1982; Maisel et al., 1967; Halperin et al., 1983; Woolf et al., 1987; Gärling et al., 1989). Moreover, the results 
of these studies were not comparable. Besides, it is unknown to what extent parental safety measures are socially or culturally determined and to what extent the results of these studies are applicable to Dutch parents with pre-school children. As there were no Dutch data on this subject our first question to be answered was: 'To what extent do mothers of pre-school children take safety measures to make their homes safe in order to prevent serious injuries to their children?'. A serious injury is defined as one which requires at least a hospital visit.

\section{Consistency between safety measures}

It seems to be the case that parents are not consistent in taking safety measures for one type of accident. For instance, although parents mentioned that they keep matches/lighters out of reach, they did not use safety equipment in the kitchen to prevent burns (Wortel and Ooijendijk, 1988). A study of Dershewitz (1979) indicates that the use of one safety device (electric outlets) was not associated with using another safety device ('Kindergards': plastic locking devices for cupboards). This finding suggests that there is no carry-over effect of safety measures from one type of accident to another type of accident.

As we had the opportunity of studying several safety measures related to the same type of accident we were able to shed further light on this subject and our second question was therefore: 'How consistent are the safety measures taken by mothers for preventing risk situations that may cause the same type of accident?'.

\section{Relationship between safety measures and mother's socioeconomic status (SES)}

With respect to childhood injuries of pre-school children, although some studies have not found a relationship with parents' SES (Langley et al., 1983; Larson and Pless, 1988), more studies have indicated a negative association between childhood injuries 
and parents' social class (Beautrais et al., 1982; Mare, 1982; Wicklund et al., 1984; Nersesian et al., 1985; Wise et al., 1985; Alwash and McCarthy, 1988). It should be noted that one study even indicated a positive relation (Van Rijn et al., 1991). It would appear, therefore, that the relation between SES indicators and childhood injuries is not consistent and above all does not give concrete clues for preventive activities. In any case, from the preventive point of view, it is more fruitful to look at the relation between SES indicators and various intermediate factors that can be potentially controlled, e.g. housing conditions, use of medical services and parental safety behaviour. Assessment of this kind of relation may be helpful in order to identify groups that need more intensive guidance.

As we focused in this study on parental safety measures that may be improved by health education, we were interested in the differences in taking safety measures between mothers of different SES. Identification of this relationship implies the need for different educational activities for mothers of different SES. Therefore, the third question to be answered was: 'What is the relation between the degree to which mothers of pre-school children take safety measures and their SES?'.

\section{METHOD}

\section{Sample}

The study was carried out in Nijmegen (population 145 000) in September 1987. Nijmegen is a university town situated in the eastern part of the Netherlands. From the population register a random stratified sample was taken of 1500 families with pre-school children (total number around 4500 ). In order to have, as far as possible, a similar number of children in all age groups, the criterion chosen for stratification was the child's age. Only one child of pre-school age could be chosen per family to avoid dependent data. Furthermore, the sample only contained families of Dutch nationality. 


\section{Procedure}

A written questionnaire was developed for mothers/female carers with pre-school children. Only mothers were asked to fill in the questionnaire, because they are still the main target group of educational campaigns. The questionnaire was sent to 1500 mothers and was collected personally.

\section{Questionnaire}

The self completion questionnaire was structured and pre-coded. The variables relevant for this study were: safety measures to prevent 18 risk situations that can lead to serious injuries due to poisoning, burns and falls; mothers' formal highest level of education; and the child's age.

\section{Safety measures}

Overall, in selecting safety measures the following considerations were taken into account:

1. The safety measures had to be related to 'causal agents' for serious injuries among Dutch pre-school children. (Serious injuries are those injuries that require at least one hospital visit.) The most common poisoning agents among pre-school children are household products and medicines; less common agents include cosmetics, alcoholic drinks, smoking articles and plants (Van Vught et al., 1981; Rogmans, 1984). It seemed useful to distinguish typical do-it-yourself products like glue, oil and paint from other household products, and to consider them as a separate group. Scalds are the most common type of burns suffered by pre-school children. Agents responsible for these scalds are coffee, tea and other hot fluids (Klasen and Ten Duis, 1986). Although falls on a level surface are the most common type, there no obvious agent is involved - according to epidemiological data. The most common agent related to falls from a height is stairs (Privé Ongevallen Registratie Systeem, 1986-1988). 


\section{Chapter 5}

2. Each safety measure had to be applicable to as large a group of mothers as possible - taking account of children's age, housing and family situation.

3. The safety measures were recommended by the Dutch Consumer Safety Institute.

The selected safety measures and their precise measurement will be discussed in detail in the Results section.

\section{Mothers' educational level}

Education was selected as an indicator of mothers' SES. They were asked to state the highest level actually completed. Seven grades were presented ranging from low to high.

\section{Child's age}

Date of birth was asked.

\section{Data analysis}

In order to analyse the relation between the safety measures and mothers' education, we reduced education to three levels: low, moderate and high. Mothers with a low level of education had nine years of schooling or less, mothers with a moderate level of education had 10-14 years of schooling and mothers with a high level of education had 15 years or more.

Safety measures were analysed specifically for the child's age, and its housing and family situation. Because of the relationship between the child's developmental stage and specific accidents and injuries, an age-specific period was chosen for each safety measure (Appendix 1). The chosen lower limit starts a few months earlier than the age at which injuries most commonly occur. This is because parents have to anticipate developmental changes so that a measure is effective. Data were only analysed for mother for whom the safety measure was relevant (e.g. to keep smoking articles out of reach is only relevant in the case of smokers). 
Furthermore, in order to compare the safety measures, the scores of each safety measure were classified into safety categories. When constructing these safety categories, standard Dutch households and houses were taken into account. Where possible the safety measures were classified into safe or unsafe behaviour. However, for most safety measures, a third safety category moderately safe was needed, especially for the safety measures that were necessarily measured by two or three questions. For instance, mothers' storage behaviour related to medicines was described in accordance with three criteria: storing medicines in a high place, out of sight and locked. Fifteen different combinations of answers were possible and were placed into three categories: safe, moderately safe and unsafe. The safety classification of each measure will be presented in detail in the Results section.

\section{Consistency between safety measures within one type of accident}

To gain an insight into the consistency between safety measures within one type of accident, the behaviour of each mother was analysed as follows. A mother's behaviour was considered consistent if she was judged safe or unsafe for all the safety measures related to the accident. An inconsistent behavioural pattern was apparent if a mother was judged to be both safe and unsafe or safe together with moderately safe and unsafe on the preventive measures pertaining to a given type of accident. Her behavioural pattern was considered moderately consistent if she was judged safe together with moderately safe or unsafe together with moderately safe on the preventive measures.

\section{Statistical analysis}

In order to assess differences in taking safety measures by mothers with a low, moderate and high level of education, the chi-square test was used $(p<0.05)$. As we were primarily interested in differences between poorly and highly educated mothers, only these results will be reported here. 


\section{RESULTS}

\section{Response}

The sample group of 1500 mothers was reduced to 1345 mothers for the following reasons: more than one questionnaire was sent to a family, the questionnaire was filled in by the father, the child was mentally or physically handicapped, or the questionnaire could not be delivered. As 1129 mothers completed the questionnaire, the response rate was high: $84 \%$. This response can be considered to be representative for the research population. Reasons for non-cooperation were mostly unknown. The main reasons mentioned were 'no time' or 'no wish' to cooperate.

\section{Demographic findings}

Children of all age groups were equally represented: $20 \%$ were 0 years old, $20 \%$ were 1 year old; $20 \%$ were 2 years old, $19 \%$ were 3 years old and $21 \%$ were 4 years old; $51 \%$ were boys and $49 \%$ were girls. The mothers' level of education was distributed almost equally over the three educational levels: $29 \%$ were mothers with a low level of education, $39 \%$ of the mothers had a moderate level and $32 \%$ had a high level (missing: $n=31$ ).

\section{Safety measures}

\section{Poisoning}

We asked mothers about safety measures used to prevent poisoning from household products, do-it-yourself products, medicines, cosmetics, alcoholic drinks, smoking materials and poisonous plants.

We asked mothers if they stored all their households and do-it-yourself products at a height of at least $1.5 \mathrm{~m}$ and if they stored them in a cupboard (altematives: all prod- 
ucts, most of them, none and, in case of do-it-yourself products, also 'not applicable'). Mothers were asked if they stored medicines at a height of at least $1.5 \mathrm{~m}$ and moreover if they stored them in a locked cupboard (alternatives: all products, most of them, none).

The main safety criterion for these three groups of products was to store them in a high place (at least $1.5 \mathrm{~m}$ ). Mothers' safety measures were judged unsafe if they stored all these products lower than $1.5 \mathrm{~m}$ in spite of being locked (even if products are locked up, there is a chance that the parent does not lock the door properly). The second criterion for household and do-it-yourself products was to keep these products out of sight of their child. Therefore, mothers' behaviour was judged safe if they kept all these products in a high cupboard. For medicines the second criterion was to keep them out of sight and locked. This criterion was chosen because in practice medicine cupboards can be bought with a lock. Therefore, mothers' behaviour was judged safe if they kept all their medicines in a high locked cupboard. All other kinds of storage behaviour for the three groups of products were judged moderately safe.

Less detailed questions were asked in relation to cosmetics, alcoholic drinks and smoking articles. We asked mothers if they kept cosmetics and alcoholic drinks out of reach of their child. The alternative responses 'all products', 'most of them' and 'none' (and in the case of alcoholic drinks 'not applicable') were, respectively, judged as safe, moderately safe and unsafe behaviour. Mothers were asked if they kept their smoking articles out of reach of their child. Apart from the alternative 'not applicable', the alternatives were 'yes' and 'no': these were judged, respectively, as safe and unsafe behaviour.

Finally, we asked mothers if they possessed poisonous plants. The alternatives were 'yes', 'no' and 'do not know'; mothers who did not possess poisonous plants were judged safe whereas mothers who said they had poisonous plants or did not know if they had them were judged unsafe.

Figure 2 shows that the percentage of mothers who behave in an unsafe way varies from $5 \%$ (medicines) to $42 \%$ (smoking articles). The majority behave safely in relation to alcoholic drinks, smoking articles and poisonous plants; the minority behave 


\section{Chapter 5}

safely for the measures related to the other agents. The percentage of mothers who show moderately safe behaviour is relatively large for household products, do-ityourself products, medicines and cosmetics.

Figure 2 Safety measures taken by mothers of pre-school children to prevent poisoning of their child; classification in safely categories (results in percentages; $n=$ number of mothers; $m=$ number of missing values)

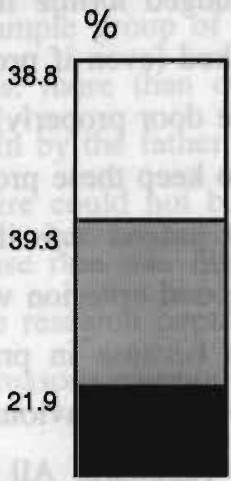

household products $(n=990)$ $(\mathrm{m}=22)$

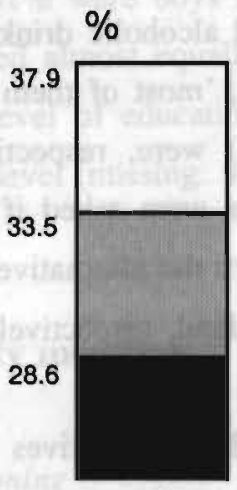

cosmetica $(n=1007)$ ( $m=5$ )
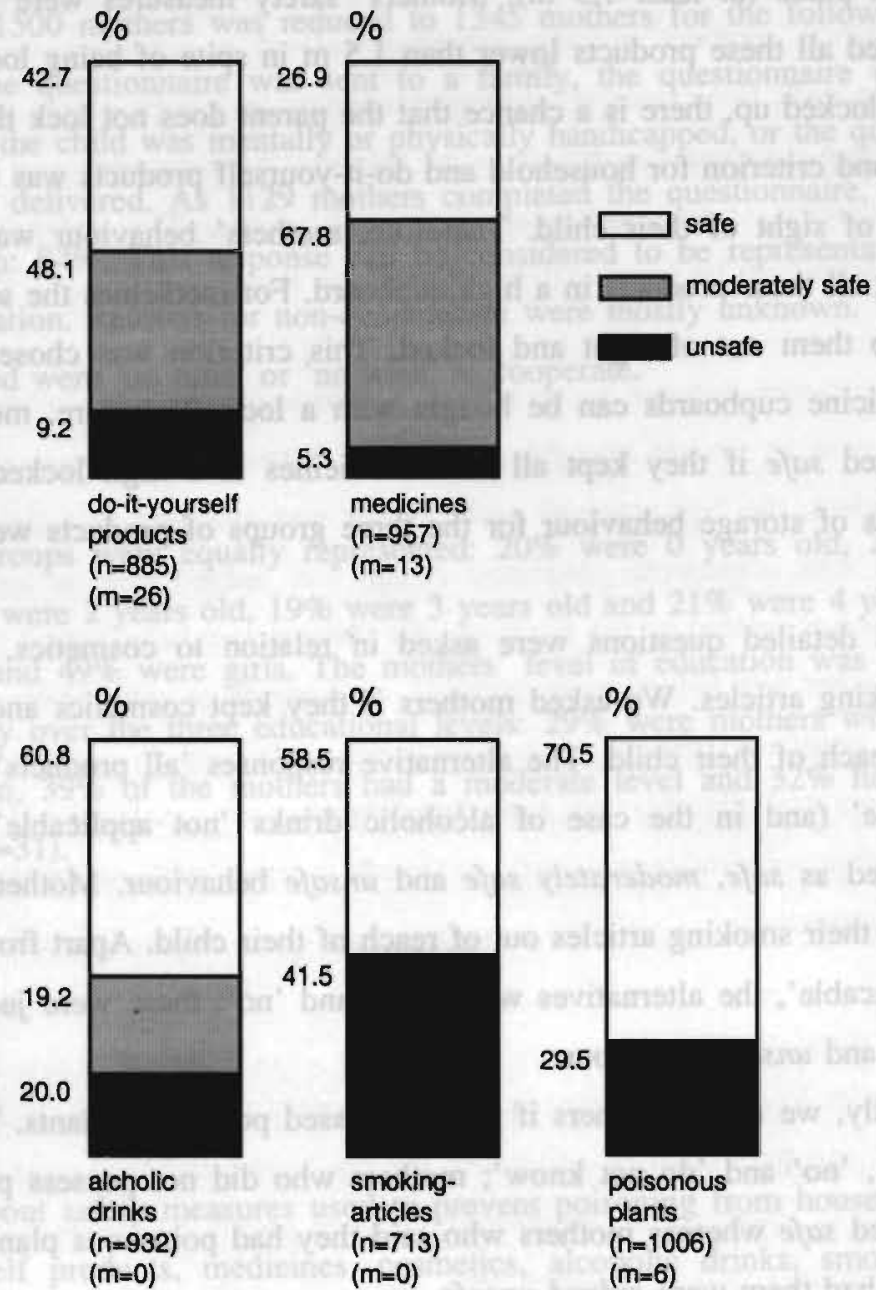
Consistency between safety measures

With respect to the seven measures to prevent poisoning, $80 \%$ of the mothers behave inconsistently; of these mothers $74 \%$ have a combination of safe, moderately safe and unsafe behaviour, whereas $6 \%$ behave in both a safe and unsafe fashion. A further $17 \%$ have a moderately consistent behavioural pattern; of these mothers $15 \%$ have a combination of safe and moderately safe behaviour.

\section{Relation with level of education}

A positive relationship is found between the mothers' level of education and keeping smoking articles out of reach $(\mathrm{p}<0.01)$ : more mothers having a low, compared with mothers having a high, level of education behave unsafely (50\% compared with $32 \%)$.

A negative relationship is found with respect to preventing poisoning through do-ityourself products, medicines and cosmetics $(\mathrm{p}<0.01)$ : more mothers with a high, compared with mothers with a low. level of education behave unsafely (10 to $8 \%, 8$ to $2 \%$ and 30 to $25 \%$ ), respectively.

\section{Burns}

We asked mothers about the safety measures they adopted to prevent burns and scalds from coffee and tea, matches and lighters, risks in the kitchen in general, and, more specifically, related to the cooker and the oven.

Mothers were asked how often they avoided taking their child on their lap while drinking (hot) tea or coffee; how often they kept the tea/coffeepot out of reach; how often they kept matches/lighters out of reach; and how often they kept their child out of the kitchen during cooking. The alternatives for these questions were 'alwaysoften', 'regularly', 'sometimes-never', and these were judged as safe, moderately safe and unsafe behaviour, respectively.

With respect to the cooker, mothers were asked if they had a safety guard around the top of the cooker (i.e. a top guard). If the oven was within reach of the child, they were asked if their oven had a glass panel that was insulated or was protected by a special screen. Furthermore, they were asked if the oven door was provided with a 
safety opening mechanism. The alternatives related to these questions were 'yes' and 'no', which were judged as safe and unsafe behaviour.

As can be seen from figure 3 the percentage of mothers who behave in an unsafe way varies from $7 \%$ (tea/coffeepot) to $93 \%$ (safety mechanism on oven door). The large majority of unsafe actions concern the safety guard around the top of the cooker, the safety glass and the safety mechanism on the oven door. However, the large majority act safely in keeping the tea/coffeepot and matches/lighters out of reach of their child.

There is more variation between mothers in not taking the child on their lap while drinking tea or coffee and keeping the child out of the kitchen during cooking. The percentage of mothers reporting moderately safe behaviour is about one third for both measures; furthermore, $40 \%$ behave unsafely with respect to keeping the child out of the kitchen during cooking.

\section{Consistency between safety measures}

With respect to the seven safety measures designed to prevent burns/scalds, $94 \%$ of the mothers behave inconsistently; of these mothers $58 \%$ have a combination of safe, moderately safe and unsafe behaviour, whereas $36 \%$ behave safely, together with unsafely.

\section{Relation with level of education}

A positive relation is found between the mothers' level of education and keeping matches/lighters out of reach $(p<0.05)$ : more mothers with a low, compared with mothers with a high, level of education behave unsafely (12 compared with $8 \%$ ).

The level of education is negatively related to having a safety mechanism and keeping the child out of the kitchen during cooking $(p<0.05)$ : more mothers with a high, compared to mothers with a low level of education behave unsafely (97 to $88 \%$ and 64 to $24 \%$, respectively). The relationship found between educational level and not taking the child on the lap while drinking tea or coffee cannot be described as a positive or negative relation: more mothers with a moderate education than mothers with a low or high level of education behave safely. 


\section{Safety measures taken by mothers:}

Figure 3 Safety measures taken by mothers of pre-school children to prevent bums/scalds of their child; classification in safety categories (results in percentages; $n=$ number of mothers; $m=$ number of missing values)

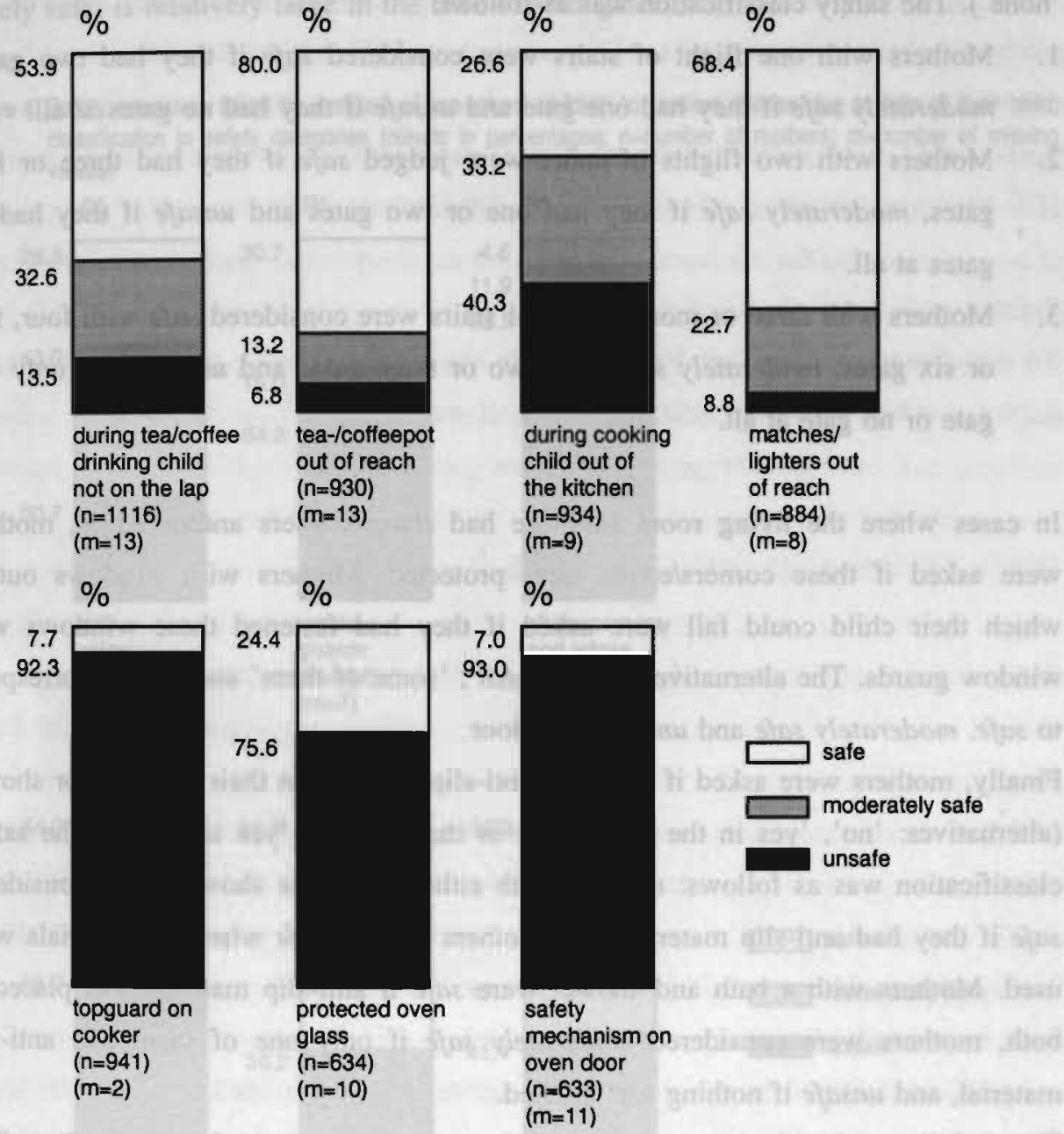

\section{Falls}

With respect to falls we asked mothers about safety measures taken for flight(s) of stairs, sharp corners, windows, and the bath and/or shower.

Mothers were first asked how many flights of stairs they had (alternatives: 'one', 'two', 'three' or 'more'). Then they were asked how many gates they had at the top 
and bottom (alternatives: 'for one flight of stairs', 'for two', 'for three or more', 'none'). The safety classification was as follows:

1. Mothers with one flight of stairs were considered safe if they had two gates, moderately safe if they had one gate and unsafe if they had no gates at all.

2. Mothers with two flights of stairs were judged safe if they had three or four gates, moderately safe if they had one or two gates and unsafe if they had no gates at all.

3. Mothers with three or more flights of stairs were considered safe with four, five or six gates, moderately safe with two or three gates and unsafe with only one gate or no gate at all.

In cases where the living room furniture had sharp cormers and/or edges, mothers were asked if these comers/edges were protected. Mothers with windows out of which their child could fall were asked if they had fastened these windows with window guards. The alternatives 'all of them', 'some of them' and 'none' correspond to safe, moderately safe and unsafe behaviour.

Finally, mothers were asked if they had anti-slip material in their bath and/or shower (altematives: 'no', 'yes in the bath', 'yes in the shower', 'yes in both'). The safety classification was as follows: mothers with either a bath or shower were considered safe if they had anti-slip materials and mothers were unsafe when no materials were used. Mothers with a bath and shower were safe if anti-slip material was placed in both, mothers were considered moderately safe if only one of them had anti-slip material, and unsafe if nothing was applied.

Figure 4 shows that the percentage of mothers who behave unsafely varies from $31 \%$ (stair gates) to $84 \%$ (protection of sharp comers). The majority behave safely with respect to one measure: applying anti-slip material in the bath. The large majority, however, act unsafely with respect to applying protective materials on sharp comers/ edges, and more than $50 \%$ behave unsafely in relation to window guards and antislip material in the shower. With regard to anti-slip material in both the bath and shower, and with regard to stair gates, the percentage of mothers who show unsafe 


\section{Safety measures taken by mothers}

behaviour is 41 and $31 \%$, respectively. Moreover, the group of mothers that is moderately safe, is relatively large in the case of stair gates.

Figure 4 Safety measures taken by mothers of pre-school children to prevent injuries due to falls of their child; classification in safety categories (results in percentages; $n=$ number of mothers; $m=n u m b e r$ of missing values)

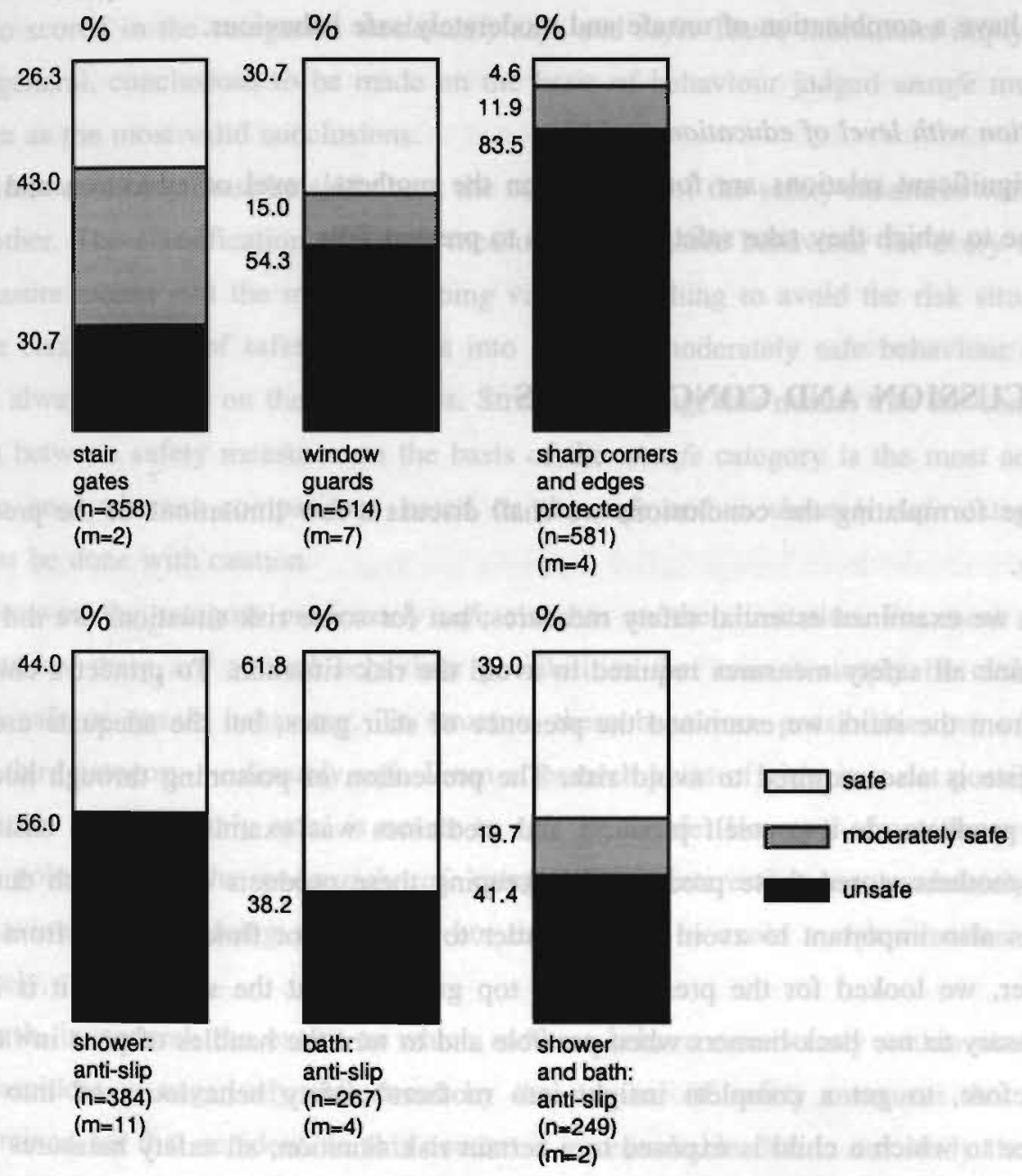




\section{Consistency between safety measures}

With respect to the four safety measures to prevent injuries due to falls, $86 \%$ of the mothers behave inconsistently; of these mothers $78 \%$ have a combination of safe, moderately safe and unsafe behaviour, whereas $8 \%$ behave in both a safe and unsafe fashion. The behavioural pattem of $12 \%$ is moderately consistent; of these mothers $10 \%$ have a combination of unsafe and moderately safe behaviour.

\section{Relation with level of education}

No significant relations are found between the mothers' level of education and the degree to which they take safety measures to prevent falls.

\section{DISCUSSION AND CONCLUSIONS}

Before formulating the conclusions we shall discuss a few limitations of the present study.

First, we examined essential safety measures, but for some risk situations we did not examine all safety measures required to avoid the risk situation. To protect a child's fall from the stairs we examined the presence of stair gates, but the adequate use of the gate is also required to avoid risk. The prevention of poisoning through household products, do-it-yourself products and medicines was examined on the basis of how mothers stored these products, but keeping these products out of reach during use is also important to avoid risk. In order to prevent hot fluids spilling from the cooker, we looked for the presence of a top guard, but at the same time it is also necessary to use back-burners when possible and to turn the handles of pans inwards. Therefore, to get a complete insight into mothers' safety behaviour and into the degree to which a child is exposed to a certain risk situation, all safety measures that are needed to prevent this risk situation have to be examined.

Second, because mothers reported their own behaviour, social desirability responses or other threats to the validity of their answers may have resulted in an over-estimate of moderately safe or safe judgement. To gain some insight into the validity of the 
mothers' self-reported behaviour, we observed the homes of 148 children whose mothers had filled in the written questionnaire. The main conclusions to be drawn were that, when a discrepancy between observed and self-reported behaviour was present, this was a negative discrepancy: the self-reported behaviour was safer than actually observed (Naber and Lampert, 1989). Clearly, this concerned the mothers who scored in the categories moderately safe and safe. These limitations imply that, in general, conclusions to be made on the basis of behaviour judged unsafe must be seen as the most valid conclusions.

Third, something must be said about the comparison of the safety measures with one another. The classification of safety measures into unsafe behaviour for every safety measure means that the mother is doing virtually nothing to avoid the risk situation. The classification of safety measures into safe and moderately safe behaviour could not always be done on the same basis. Strictly speaking, this means that the comparison between safety measures on the basis of the unsafe category is the most acceptable one, whereas comparisons based on the safe and moderately safe categories must be done with caution.

Moreover, the category moderately safe also has another limitation. For most safety measures there are several behaviour possibilities that cannot simply be classified into safe or unsafe behaviour. To structure these behaviour possibilities we created the third category moderately safe. From a research point of view it is not possible to indicate if 'moderately safe' is nearer to safe or unsafe. However, from the preventive point of view the moderately safe category is an interesting one: moderately safe behaviour implies doing something, but not enough to avoid a risk situation completely.

Fourth, in general, the extent to which mothers behave consistently within one type of accident is negatively influenced by the number of safety measures that were examined for that accident. In this context it is remarkable that in our study the percentage of mothers with an inconsistent behavioural pattern with respect to poisoning ( $80 \%$; seven safety measures) is lower than the percentage of mothers with an inconsistent behaviour related to falls ( $86 \%$; four safety measures). Therefore, conclusions based on the consistency of analysis must be considered with caution. 
Fifth, the use of education as a single indicator of SES may be criticized. Education was mainly chosen for practical reasons: income is often a sensitive topic, whereas occupation is complex to analyse. However, in general, education is frequently more strongly associated with diseases than income and occupation, probably because its association with health practices, lifestyle characteristics and adoption of new medications of procedures (Liberatos et al., 1988). Furthermore, we preferred the mothers' education instead of the fathers' education, because the mother often has the greatest impact on family health behaviour and it was they who were asked to report their safety measures.

\section{Safety measures}

Despite the above mentioned shortcomings, the results indicate that very common risk situations are partly or entirely present in the homes of many families with preschool children. Even though safety measures are available to avoid these risks, too many mothers do not adopt or only partially adopt these measures. The main conclusion is that most of the safety measures we examined to prevent a child from getting injured need further improvement. In the following section our findings will be compared, when possible, with those from other studies.

\section{Poisoning}

Overall, with respect to the prevention of poisoning, the majority of mothers have safe or moderately safe behaviour. However, the group of mothers behaving unsafely is still large for most poisonous agents: household products, alcoholic drinks, cosmetics, smoking articles and poisonous plants. This means that these products are in reach of the child and risk situations are not eliminated.

In the context of an evaluation study, Woolf et al. (1987) assessed the storage behaviour related to household products and medicines by means of a telephone interview with 262 parents with pre-school children. They found that $27 \%$ of the families kept their household products in a low place whereas $16 \%$ had their medicines in an 'ac- 


\section{Safety measures taken by mothers}

cessible' place. Our research findings give comparable results: $22 \%$ of the mothers are unsafe for household products and $9 \%$ are unsafe for medicines.

\section{Burns}

The conclusion related to safety measures to prevent burns is two-fold. On the one hand, most of the mothers behave unsafely or moderately safely with respect to risks in the kitchen: they do not keep or only sometimes keep their child out of the kitchen during cooking, they do not have a top guard on the cooker nor do they have an oven door with glass and safety mechanism; on the other hand, most mothers behave safely in relation to the other risks studied (lighters/matches, tea/coffeepot and child on the lap with coffee/tea). This means that the kitchen is a place with many opportunities for the child to get burned. Even without appropriate safety equipment on the cooker and oven, children are often allowed in the kitchen during the preparation of the meal.

However, Gärling et al. (1989) found that $57 \%$ of the mothers had a top guard, $90 \%$ had an oven door with a safety mechanism and a protective oven glass. These findings suggest that the use of the safety equipment has a strongly culturally based component. Although these safety products are available in shops, Dutch parents buy them less often than Swedish parents.

\section{Falls}

Mothers behave mainly unsafely or moderately safely with regard to preventing injuries due to falls from stairs and windows, falls against sharp corners, and falls in the shower or bath. This means that safety equipment is not used or used ineffectively.

Gärling et al. (1989) found that $92 \%$ of mothers reported that their windows were fastened, only $7 \%$ had sharp corners protected and $65 \%$ had anti-slip material in their bath. The results related to sharp corners and anti-slip in bath are comparable with our results. However, in our study only $46 \%$ have some or all of their windows fastened. 


\section{Consistency between measures within one type of accident}

Furthermore, the present study suggests that there is no consistent behavioural pattern to prevent risk situations related to one type of accident. In other words: safe behaviour to prevent a risk situation belonging to a certain type of accident (e.g. keeping away matches to prevent burns) does not imply safe behaviour for another risk situation belonging to the same type of accident (e.g. having a top guard on the cooker). Clearly further research is needed to understand why mothers behave inconsistently towards risk situations belonging to the same type of accident.

\section{Relation between SES and safety measures}

Finally, this study does not provide substantial evidence for a relationship between mothers' educational level and the degree to which they take safety measures. From the 20 safety measures examined, only eight measures show a significant relation with the level of education. When taking into account the size of the difference between poorly and highly educated mothers, only two safety measures deserve attention. More mothers with a low, compared to mothers with a high, level of education behave unsafely with respect to keeping smoking articles out of reach; the reverse is noted with respect to keeping the child out of the kitchen during cooking.

\section{IMPLICATIONS FOR PREVENTION}

In general, this study has indicated that (apart from supervising and educating their child - the things most parents already do) safety education activities need to convince mothers to take more safety measures or to adopt them more intensively. Furthermore, this study has tried to obtain an insight into the educational goals related to the adoption of preventive safety measures. If mothers take a safety measure satisfactorily, reinforcement may be given to let the mother carry on with this measure; if 
mothers only partly take a safety measure, correction is needed and if they do not take a safety measure at all, development of the measure is needed. Table 1 gives an overview of the latter two educational goals in relation to the specific safety measures.

Table 1 Presentation of the need for development and/or correction of each salety measure; the extent to which development and/or correction is needed is based on the percentage of mothers with respectively 'unsafe', and/or 'moderately safe' behaviour

\begin{tabular}{|c|c|c|c|c|}
\hline Safety measure & Unsafe & Development & Moderately saie & Correction \\
\hline \multicolumn{5}{|c|}{ Keep out of reach } \\
\hline household products & $22 \%$ & + & $39 \%$ & 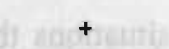 \\
\hline do-it-yourself products & $9 \%$ & ++ & $48 \%$ & + \\
\hline medicines & $5 \%$ & ++ & $68 \%$ & ++ \\
\hline cosmetics & $29 \%$ & + & $34 \%$ & + \\
\hline alcoholic drinks & $20 \%$ & -+ & $19 \%$ & + \\
\hline smoking articles & $42 \%$ & + & - & to inart \\
\hline poisonous plants & $30 \%$ & + & - & \\
\hline Child not on the lap during tea/coffee drinking & $14 \%$ & + & $33 \%$ & + \\
\hline Tea/coffeepot out of reach & $7 \%$ & + & $13 \%$ & + \\
\hline Child out of the kitchen during cooking & $40 \%$ & + & $33 \%$ & + \\
\hline Matches/lighters out of reach & $9 \%$ & -+ & $23 \%$ & + \\
\hline Top guard on cooker & $92 \%$ & +++ & - & \\
\hline Protected oven glass & $76 \%$ & +++ & - & $t$ \\
\hline Safety mechanism on oven door & $93 \%$ & $+t+$ & - & \\
\hline Stair gates & $31 \%$ & + & $43 \%$ & + \\
\hline Window guards & $54 \%$ & +t & $15 \%$ & + \\
\hline Sharp corners/edges protected & $84 \%$ & +++ & $12 \%$ & + \\
\hline Anti-slip material in shower & $56 \%$ & ++ & - & 4 \\
\hline Anti-slip material in bath & $38 \%$ & + & - & \\
\hline Anti-slip material in bath and shower & $41 \%$ & + & $20 \%$ & + \\
\hline
\end{tabular}

Percentage of mothers

$$
\begin{array}{r}
1-25 \\
25-50 \\
50-75 \\
75-100
\end{array}
$$

$$
\begin{aligned}
& \text { Development/correction } \\
& ++ \text { (moderately needed) } \\
& + \text { (needed) } \\
& ++ \text { (much needed) } \\
& +++ \text { (extremely needed) }
\end{aligned}
$$

As can be seen from table 1, educators have to develop the taking of most safety measures by a large group of parents. Educators have to be aware of the fact that, because these parents do (nearly) nothing to prevent the risk situations studied, much effort will be demanded to stimulate parents to take these measures. Moreover most safety measures also need correction. It seems likely that parents whose safety 


\section{Chaprer 5}

measures (only) need correction, are acquainted with the risk situations that may threaten their child(ren). This may give educators an instrument to bring up the subject during a conversation and to work further on the correction of these measures.

In general, safety educators need to educate parents on each safety measure separately because safety measures do not go together. Therefore, instead of stressing the need for behaviour to prevent poisoning, all separate measures have to be mentioned. This inconsistency between measures may be used as an educational method: an educator may start by discussing a safety measure parents are used to taking and then relate this measure to the safety measures they do not take in order to prevent risk situations that can lead to the same type of accident. This may be a way to let parents conclude that their own behaviour is inconsistent.

Furthermore, this study suggests that as far as reinforcement, correction or development of safety measures are concerned, educators do not need to differentiate between mothers with high and low levels of education.

Obviously, this study must be seen as a first step in developing well prepared safety education activities. To influence safety behaviour we also need to know which determinants underlie the (deficient) safety behaviour of parents, such as their knowledge on safety measures, the perceived costs and benefits involved in their taking or not taking safety measures and the social support they get from their partner. On the basis of this information the content of the safety messages can be chosen. Last, but not least, information is needed on further components of the intervention, such as the channels through which parents might be best reached, the source that has the most persuasive impact on parents and aspects of the safety message such as its comprehensiveness (McGuire, 1985).

\section{ACKNOWLEDGEMENTS}

We would like to thank Ellen Bergsma for her useful comments on earlier drafts of this paper. This work was carried out at the TNO Institute of Preventive Health Care. 


\section{REFERENCES}

ALWASH R, McCARTHY M. Accidents in the home among children under 5: ethnic differences or social disadvantage? Brit Med J 1988;296:1450-3.

BAKER SP. Childhood injuries: the community approach to prevention. J Publ Health Pol $1981 ; 3: 235-46$.

BALTIMORE CL, MEIJER RJ. A study of storage, child behavioral traits and mothers' knowledge of toxicology in 52 poisoned families and 52 comparison families. Pediatr 1968: 42:312-7.

BEAUTRAIS AL, FERGUSSON DM, SHANNON FT. Childhood accidents in New Zealand Birth cohort. Austral Paediatr J 1982;18:238-42.

BERFENSTAM R, BESKOW J. Storage of poisons in the homes of families with small children. Brit J Prev Soc Med 1962;16:123-9.

BOUTER LM, RIJN OJL van, KOK GJ. Importance of planned health education for burn injury prevention. Burns 1990;16:198-202.

CENTRAAL BUREAU VOOR DE STATISTIEK. Overledenen naar doodsoorzaak, leeftijd en geslacht in het jaar 1985-1987. Voorburg: CBS, 1986-1988. Series A1.

DERSHEWITZ RA. Will mothers use free household safety devices? Am J Diseases Child 1979;133:61-4.

GÄRLING T. Children's environments, accidents and accident prevention: an introduction. In: Gärling T, Valsiner J, eds. Children within environments; toward a psychology of accident prevention. New York: Plenum Press, 1985:3-12.

GÄRLING T, GÄRLING A, MAURITZON-SANDBERG E, BJÖRNSTIG U. Child safety in the home: mothers' perception of dangers to young children. Arch Comp/Arch Behav 1989; 5:293-304.

HALPERIN SF, BASS JL, METHA KA. Knowledge of accident prevention among parents of young children in nine Massachusetts towns. Publ Health Rep 1983;98:548-52.

KLASEN HJ, DUIS HJ ten. Changing patterns in the causes of scalds in young Dutch children. Burns 1986;12:563-6. 


\section{Chapter 5}

LANGLEY J, SILVA P, WILLIAMS S. Socio-economic status and childhood injuries. Austral Paediatr J 1983;19:237-40.

LARSON CP, PLESS B. Risk factors for injury in a 3-year-old birth cohort. Am J Diseases Child 1988;142:1052-7.

LIBERATOS P, LINK BG, KELSEY $\Omega$. The measurement of social class in epidemiology. Epidem Rev 1988;10:87-121.

MAISEL G, LANGDOC BA, JENKINS MQ, AYCOCK EK. Analysis of two surveys evaluating a project to reduce accidental poisoning among children. Publ Health Rep 1967;82:55560 .

MARE RD. Socioeconomic effects on child mortality in the United States. Am J Publ Health 1982;72:539-47.

McGUIRE WJ. Attitudes and attitude change. In: Lindzey G, Aronson E, eds. Handbook of social psychology. 3rd ed. New York: Random House, 1985:233-346.

NABER AG, LAMPERT EM. 'Het is niet altijd wat het lijkt'. Een onderzoek naar de validiteit van een vragenlijst over maatregelen ter voorkoming van privé-ongevallen van 0-4 jarigen. ('It is not always what it seems'. Research on the validity of a questionnaire concerning safety measures to prevent home related injuries of pre-school children). Leiden: NIPG-TNO, 1989:58-9.

NERSESIAN WS, PETIT MR, SHAPER R, et al. Childhood death and poverty: a study of all childhood deaths in Maine, 1976 to 1980. Pediatr 1985;75:41-50.

PRIVÉ ONGEVALLEN REGISTRATIE SYSTEEM. Jaaroverzicht privé-ongevallen registratie systeem, 1985-1987. Amsterdam: Stichting Consument en Veiligheid, 1986-1988.

RIJN OJL van, BOUTER LM, KESTER ADM, et al. Aetiology of burn injuries among children aged 0-4: results of a case control study. Bums 1991;17:213-9.

ROGMANS WHJ. Jonge kinderen en ongevalsrisico's buiten het verkeer. Leiden: Spruyt, Van Mantgem \& De Does, 1984:100-1.

SOBEL R. Traditional safety measures and accidental poisoning in childhood. Pediatr 1969; 44(suppl):811-6.

VILARDO FJ. The role of the epidemiological model in injury control. J Safety Res 1988; 19:1-4. 
VUGHT AJ van, PUTTEN MAG van, VOS de-VOS VAN STEENWIJK CCE de, ROGMANS WHJ. Epidemiologie van vergiftigingen bij kinderen. In: Benthem LHBM van, et al., eds. Preventie van vergiftigingen bij kinderen. Leiden: Spruyt, Van Mantgem \& De Does. 1981:35-48.

WICKLUND K, MOSS S, FROST F. Effects of maternal health education, age, and parity on infant accidents. Am J Publ Health 1984;74:1150-2

WISE PH, KOTELCHUCK M, WILSON ML, MILLIS M. Racial and socioeconomic disparities in childhood mortality in Boston. The New England J Med 1985;313:360-6.

WOOLF A, LEWANDER W, FILIPPONE G, LOVEJOY F. Prevention of childhood poisoning: efficacy of an educational program carried out in an emergency clinic. Pediatr 1987:80: 359-63.

WORTEL E, OOIJENDIJK WTM. Preventie van privé-ongevallen bij kinderen: onderzoek naar preventief gedrag van ouders en gedragsdeterminanten. (Prevention of home related injuries of children: research on preventive behaviour of parents and behavioural determinants). Leiden: NIPG-TNO, 1988: 63-73.

Appendix 1 Age-specilic safety measures for a child ( $n=$ number of children in the age group)

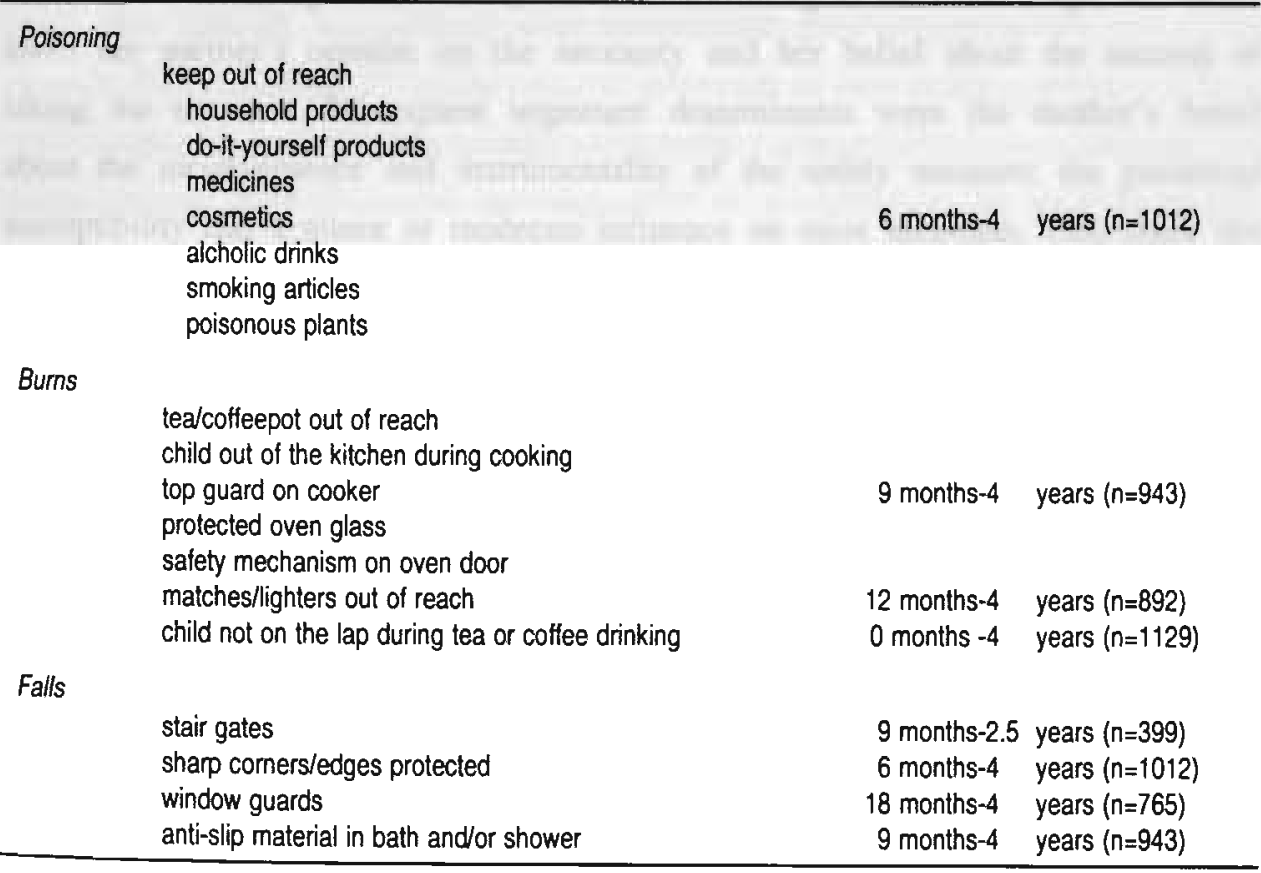




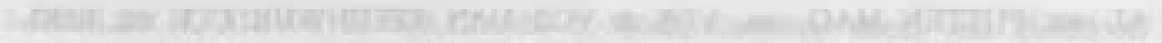

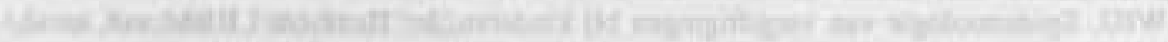

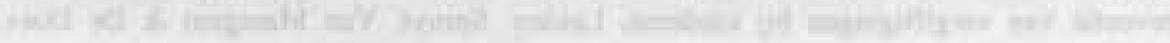

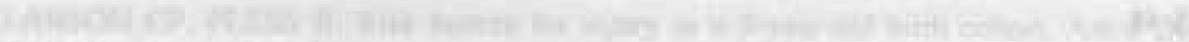

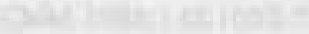

.

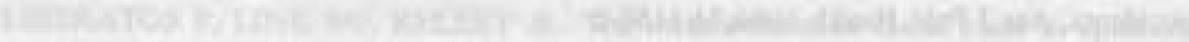
15.

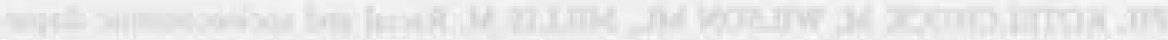

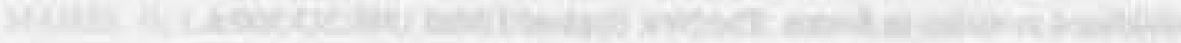

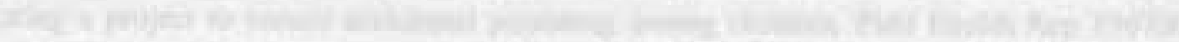

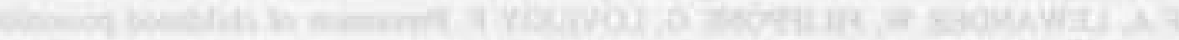

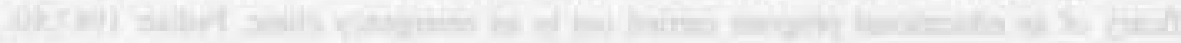

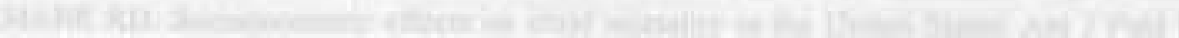

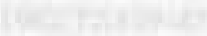

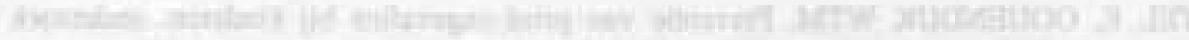
Wh

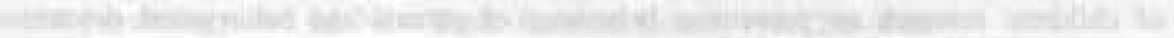

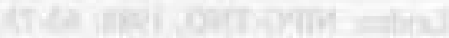

W

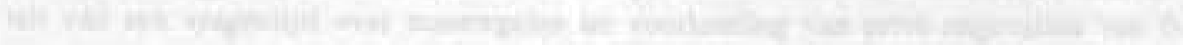

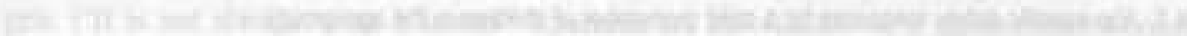

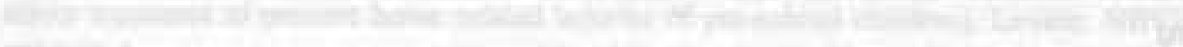

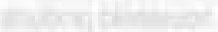

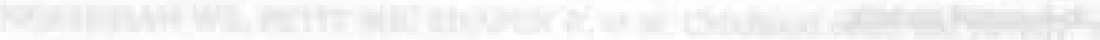

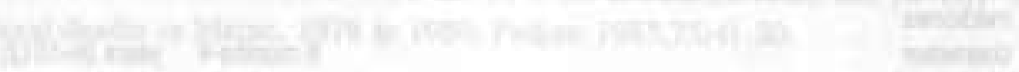

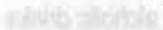

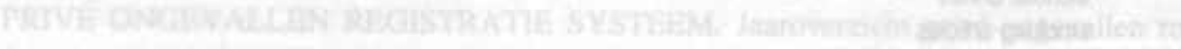

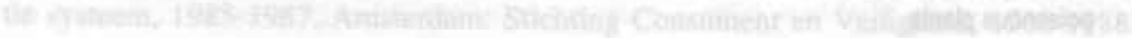

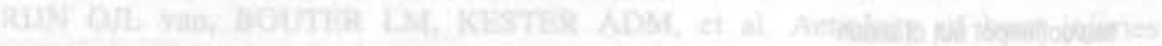

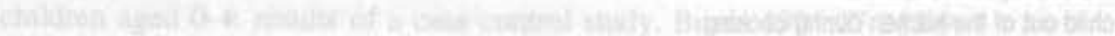

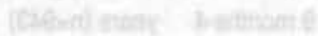

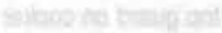

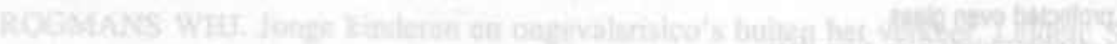

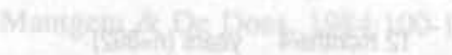

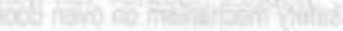

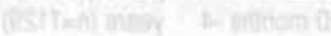

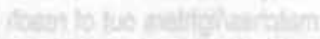

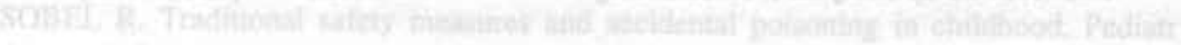

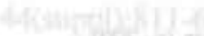

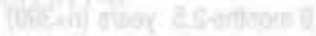

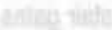

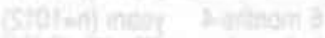

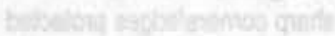

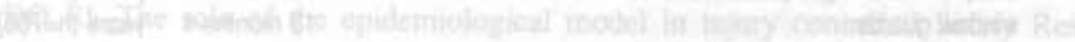

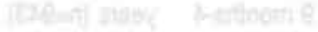

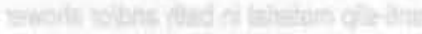




\section{Behavioural determinants of mothers' safety measures to prevent injuries of pre-school children*}

Edith Wortel, Gerard H. de Geus, Gerjo Kok

\section{ABSTRACT}

Home-related injuries are a major threat to pre-school children in the western world. In this study the behavioural determinants of 18 parental safety measures were assessed. To select behavioural determinants, the Attitude- Social influence- Selfefficacy/barriers model was used with the inclusion of variables from the Health Belief Model and the Protection Motivation Theory. A written questionnaire was completed by 1,129 Dutch mothers of pre-school children.

Most safety measures were explained (rather) well by the same set of determinants. Main determinants for adopting or not adopting a safety measure were the mother's belief in the necessity of the safety measure according to the child's age, her belief about her partner's opinion on the necessity and her belief about the success of taking the measure. Subsequent important determinants were the mother's belief about the inconvenience and instrumentality of the safety measure; the perceived susceptibility had a minor or moderate influence on most measures. This study did not indicate that more highly educated mothers were more knowledgeable about safety-related subjects. The theoretical implications of this study are discussed.

\section{INTRODUCTION}

Domestic accidents are a major threat to pre-school children in most industrialized countries. In the Netherlands these accidents are the major cause of death in the age

* Scandinavian Journal of Psychology 1995;36:??-??. 
group 1-4 years (Centraal Bureau voor de Statistiek, 1986-1988). Moreover, about 50,000 children have to be treated in a hospital yearly for these accidents (Privé Ongevallen Registratie Systeem, 1986-1988); that is 6\% of all children aged 0-4 years at the national level.

In the prevention of childhood injuries we must consider parental safety behaviour as a key factor because many risk situations that may affect pre-school children can only be avoided through their behaviour (Roberts et al., 1984). Besides supervising the child and educating the child, the taking of safety measures for structuring the child's environment is very essential. However, several studies have shown that the safety measures taken by a large group of parents tend to be selective and insufficient (Wortel and De Geus, in press). To motivate parents to adopt safety measures, knowledge of the reasons why they do not adopt safety measures is required (Kok and De Vries, 1989; Green and Kreuter, 1991). This enables safety educators to develop effective safety education activities. However, few attempts have been made to relate possible determinants to parental safety measures (most of these studies were descriptive), which makes the inferences about the relation between parental safety measures and underlying determinants rather hypothetical. Besides, even fewer used a theoretical framework to select the determinants to be studied, which suggests that the selection of determinants was arbitrary (Wortel and De Geus, in press).

The purpose of the present paper is to analyse the determinants of parental safety measures by means of a model of planned behaviour. Determinants of behaviour can be measured according to the 'Attitude - Social influence - Self-Efficacy/barriers model' (Ajzen, 1988: 'the theory of planned behaviour'; De Vries et al., 1988; Kok et al., 1991; Eagly and Chaiken, 1993: pp. 186 - 190). This model (figure 1) states that a person's behaviour is influenced by his attitude towards the behaviour, the social influence he is experiencing with respect to that behaviour, and the self-efficacy and barriers he is confronted with when performing the behaviour. External variables, such as demographic (e.g. socio-economic status), are supposed to influence behaviour via these three determinants. The actual performance of the behaviour leads to a feedback process that influences in turn the three determinants. 
The determinants may be interpreted as follows. An attitude towards the recommended behaviour is the weighting of all the beliefs (pros and cons) a person links to performing that behaviour. Social influence refers to the influence of others, directly by what others expect the person to do and indirectly by what others actually do. Self-efficacy/barriers stands for the extent to which a person thinks he/she will be able to perform the (desired) behaviour. Self-efficacy is an estimation of the ability to cope with barriers inside or outside the person.

Figure 1 Model of behavioural determinants

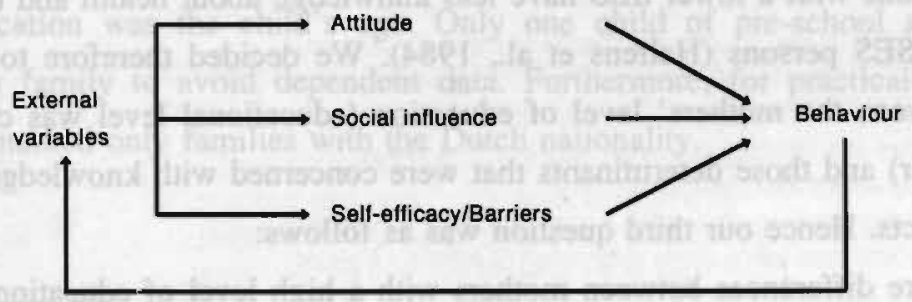

We specifically included some variables into the ASE model that may be useful in the context of determinants of parental safety behaviour. The ASE model is applicable to any kind of behaviour. As parental safety behaviour can be considered as health behaviour, we also included some variables from the Health Belief Model (Janz and Becker, 1984) and the Protection Motivation Theory (Rippetoe and Rogers, 1987). The HBM and PMT have three variables in common that affect health-related behaviour (Eagly and Chaiken, 1993: pp 440-442): 1. perceived susceptibility and 2. perceived seriousness of diseases and injuries that form the perceived threat, and 3 . response-efficacy (i.e. the extent to which a person believes the recommended behaviour can reduce the risk to be confronted). These variables can be considered as parts of the attitude (Ajzen, 1988; De Vries et al., 1988).

For this study three questions were formulated: 


\section{Chapter 6}

1. To what extent can the taking of a safety measure be explained by means of a set of determinants based on the model of planned behaviour with the inclusion of the determinants mentioned above?

2. What is the relative importance of the separate determinants on the taking or not taking of the measure and how can differences between mothers who behave safely and those who don't be interpreted?

In addition, the third question is concerned with an external variable that may be of importance in taking safety measures, namely parents' socio-economic status (SES). It may be fruitful to look at the relation between SES indicators and behavioural determinants in order to identify groups that need additional or different guidance. In general, persons with a lower SES have less knowledge about health and health risks than higher SES persons (Halfens et al., 1984). We decided therefore to assess the relation between the mothers' level of education (educational level was chosen as a SES indicator) and those determinants that were concerned with knowledge on safety related subjects. Hence our third question was as follows:

3. Are there differences between mothers with a high level of education and those with a low level of education with respect to their familiarity with safety measures, their opinion on the necessity of safety measures according to their child's age and their perception of the seriousness of risk situations their child may be confronted with?

Besides, although it is theoretically supposed that mothers' education only influences the taking of safety measures indirectly through the ASE determinants, education was also included in the analyses to check this. 


\section{METHOD}

\section{Sample}

The study was carried out in Nijmegen (population 145,000) in September 1987. Nijmegen is a university town which is situated in the eastern part of the Netherlands. From the population register a random stratified sample was taken of 1,500 families with pre-school children (total number around 4,500). In order to have, as far as possible, a similar number of children in all age groups, the criterion chosen for stratification was the child's age. Only one child of pre-school age could be chosen per family to avoid dependent data. Furthermore, for practical reasons, the sample contained only families with the Dutch nationality.

\section{Procedure}

A written questionnaire was developed for mothers/female carers with pre-school children. Mothers were asked to fill in the questionnaire, because they are still the main target group for educational campaigns and to ensure the comparability of the findings. The questionnaire was sent to 1,500 mothers and was collected personally.

\section{Questionnaire}

The self-completion questionnaire was structured and precoded. The following variables included in the questionnaire were relevant for the present study:

1. behavioural determinants to be related to safety measures;

2. safety measures to prevent 18 risk situations that can lead to serious injuries due to poisoning, burns and falls; 
3. some demographic variables.

In the questionnaire the safety measures under study were presented per type of accident first (table 1).

Table 1 Safety measures related to poisoning, bums/scalds and falls with corresponding age group*

Poisoning ( 6 months -4 years):

- storing household products in a cupboard at a height of at least $1.5 \mathrm{~m}$

- storing do-it-yourself products in a cupboard at a height of at least $1.5 \mathrm{~m}$

- storing medicines in a locked cupboard at a height of at least $1.5 \mathrm{~m}$

- keeping cosmetics out of reach

- keeping alcoholic drinks out of reach

- keeping smoking-articles out of reach

- removing poisonous plants from the house

Bums/scalds:

- not taking the child on the lap while drinking tea or coffee ( $0-4$ years)

- keeping the tea or coffee can out of reach ( 9 months - 4 years)

- keeping the child out of the kitchen during cooking ( 9 months - 4 years)

- keeping matches and lighters out of reach (12 months - 4 years)

- applying a topguard on the cooker ( 9 months -4 years)

- protecting the oven window with a safety screen ( 9 months -4 years)

- protecting the oven door with a safety mechanism ( 9 months -4 years)

Falls:

- applying a stairgate at the top and bottom of stairs ( 9 months -2.5 years)

- protecting sharp corners and edges by means of protecting material ( 6 months -4 years)

- applying window guards on windows (18 months - 4 years)

- applying anti-slip material in bath and/or shower ( 9 months -4 years)

- The corresponding age groups were not mentioned in the questionnaire.

Subsequently, the questions related to the determinants were formulated. The answer had to be given for each safety measure separately. Table 2 presents the formulation of the questions per determinant.

Thereafter mothers had to answer questions on their actual behaviour, namely the safety measures in question. This sequence (questions on determinants first) was chosen in order to minimalize rationalization while answering the questions on determinants. 
Table 2 Measurement of the determinants of the safety measures

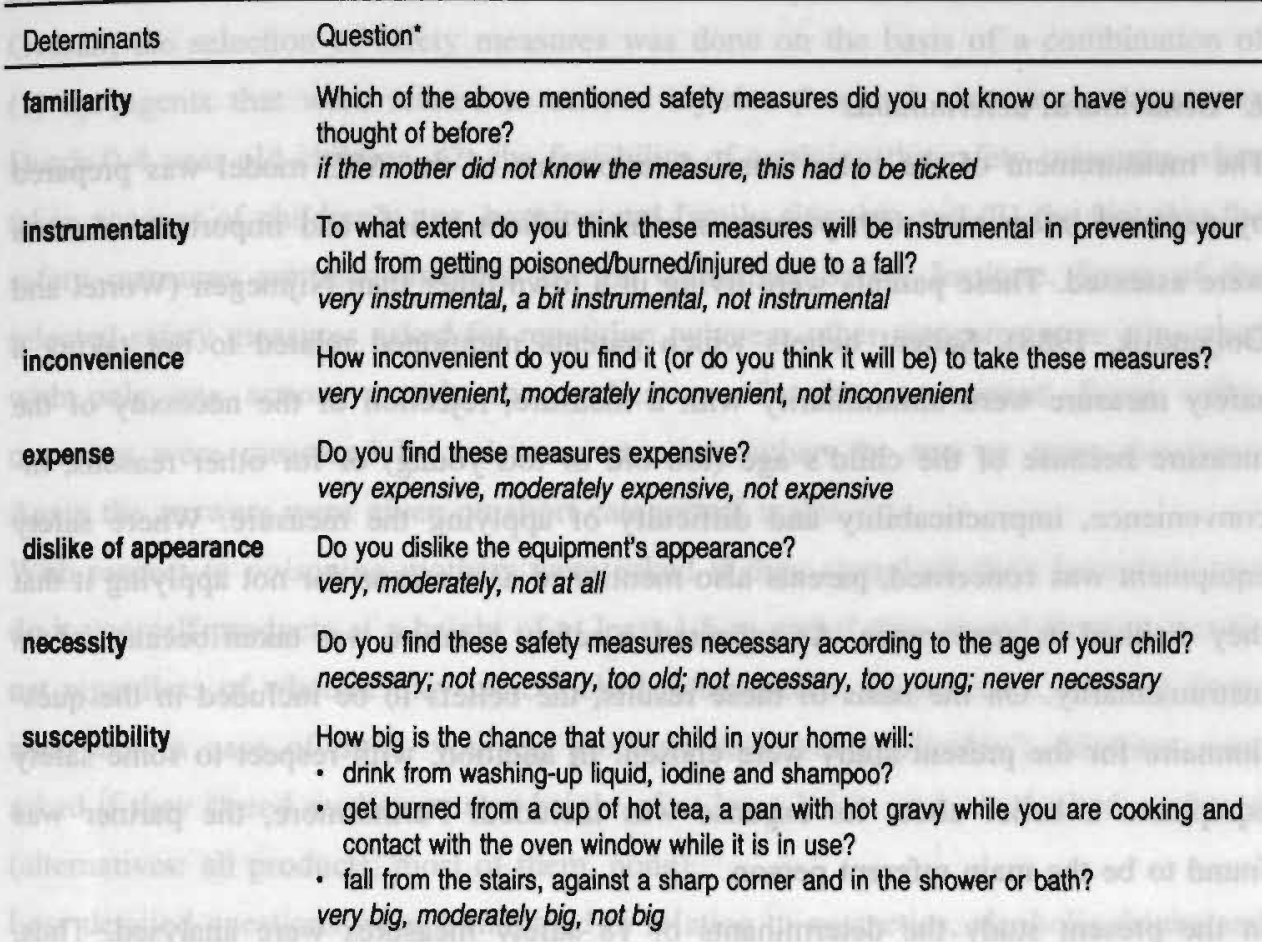

seriousness

- How poisonous do you think the following products can be for your child: washingup liquid, turpentine, iodine, shampoo, aspirin, cigarettes, gin and dieffenbachia?

very poisonous, moderately poisonous, not poisonous

- Which kind of burns/scalds do you think your child can get from: a cup of tea, a pan with hot gravy and contact with the oven window?

first degree bums, second degree bums, third degree burns

- How serious do you think the injury will be if your child falls from the stairs, against a sharp corner and in the shower or bath?

very serious, moderately serious, not serious

partner's opinion Do you think your partner finds these measures necessary for your child? certainly yes, I think so, I think not, certainly not

self-efficacy

How often do you think you will succeed in taking these measures?

always/often, regularly, sometimes/never

' All questions, except familiarity, had a category 'no idea'. 


\section{Measurements and analyses}

\section{Behavioural determinants}

The measurement of the behavioural determinants of the ASE model was prepared by personal interviews with parents in which salient beliefs and important referents were assessed. These parents were living in a town other than Nijmegen (Wortel and Ooijendijk, 1988). Salient beliefs which parents mentioned related to not taking a safety measure were unfamiliarity with a measure, rejection of the necessity of the measure because of the child's age (too old or too young) or for other reasons, inconvenience, impracticability and difficulty of applying the measure. Where safety equipment was concerned, parents also mentioned as a reason for not applying it that they disliked its appearance. As expected, a safety measure was taken because of its instrumentality. On the basis of these results, the beliefs to be included in the questionnaire for the present study were chosen. In addition, with respect to some safety equipment a belief about its expense was included. Furthermore, the partner was found to be the main referent person.

In the present study the determinants of 18 safety measures were analysed. Thus, except for questions on taking these safety measures, with respect to each safety measure questions were formulated on determinants. In order to restrict the number of questions for each safety measure a minimum number of beliefs was chosen, one normative belief and one question related to self-efficacy, in case self-efficacy was a possible determinant. Mothers were asked about their perceptions of the susceptibility and seriousness of risk situations with respect to some risk situations related to poisoning, burns and falls. Moreover, short categorical scales were used.

As the frequencies of most determinants were not equally divided over the categories, all but one of the determinants were reduced from three to two categories. The successive categories that had the lowest frequency were taken together. The categories related to the necessity of the measure were not combined because these categories were not successive. The categories of this variable were: 1. yes, necessary according to this age of the child 2. not necessary, because the child is too young, 3 . not necessary, because the child is too old, and 4 . never necessary. 


\section{Safety measures}

Overall, the selection of safety measures was done on the basis of a combination of (1) the agents that were related to serious injuries (hospital visit or death) among Dutch 0-4 year old children, (2) the feasibility of applying the safety measures when taken account of children's age, housing and family situation and (3) the fact that the safety measures are recommended by the Consumer Safety Institute. Some of the selected safety measures asked for repetition, whereas other measures were concerned with only one action, namely the application of safety equipment. Some safety measures were measured by only one question, others by two or more questions. Again the answers were given on short categorical scales.

With respect to poisoning mothers were asked if they stored all their household and do-it-yourself products at a height of at least $1.5 \mathrm{~m}$ and if they stored them in a cabinet regardless of whether they were locked (alternatives: all products, most of them, none and in case of do-it- yourself products also 'not applicable'). Mothers were asked if they stored medicines at a height of at least $1.5 \mathrm{~m}$ and in a locked cupboard (alternatives: all products, most of them, none).

Less detailed questions were formulated in relation to cosmetics, alcoholic drinks and smoking materials because it was not always clear in which places these products were stored. We asked mothers if they kept cosmetics and alcoholic drinks out of reach of their child (alternatives: all of them, most of them and none; in the case alcoholic drinks also 'not applicable'). Finally, we asked mothers if they possessed poisonous plants (alternatives: yes, no and do not know).

In regard to burns/scalds mothers were asked how often they refrained from taking their child on the lap while drinking (hot) tea or coffee, how often they kept the tealcoffee can out of reach, how often they kept matches/lighters out of reach and how often they kept their child out of the kitchen during cooking (alternatives: alwaysoften, regularly, sometimes-never). Moreover, they were asked if their cooker had a topguard. If the oven was within reach of the child they were asked whether their oven had a glass that was isolated or was protected by a special screen and whether the oven door had a safety opening mechanism (alternatives: yes or no). 
Regarding the prevention of falls mothers were first asked how many flight of stairs they had. Thereafter they were asked how many gates they had at the top and bottom of the stairs (alternatives: for one stair, two stairs, three or more stairs, none). In cases where the living room furniture had sharp corners and/or edges, mothers were asked if these corners/edges were protected. Mothers with windows out of which their child could fall were asked if they had fastened these windows with window guards (alternatives: all of them, some of them and none). Finally, mothers were asked if they had anti-slip material in their bath-tub and/or shower cabinet (alternatives: no, yes in the bath-tub, yes in the shower cabinet, yes in both).

The data of the safety measures were 'translated' into a safety qualification. This was dictated by the fact that some of the safety measures were measured by more than one question. In such cases the qualification on a safety measure comprised the different questions that were asked. The average Dutch household and houses were taken into account in formulating the safety qualifications. Where possible the safety measures taken by mothers were judged as 'safe' and 'unsafe', but for most of the measures and especially for the composed measures a third category was needed: 'rather safe'. For instance, mothers' storage behaviour related to medicines was described in accordance with three criteria: storing medicines in a high place, out of sight and locked. Fifteen different combinations of answers were possible and were placed into the three categories as mentioned above (Wortel and De Geus, 1993).

\section{Demographic variables}

Demographic variables relevant for this study were the child's age and sex, mothers' age, marital status, work outside the home and level of education. Education was selected as an indicator of mothers' SES. Mothers were asked to state the highest level of education actually completed. Seven grades were presented ranging from low to high. Subsequently these grades were reduced to three levels: low, moderate and high. Mothers with a low level of education had nine years of schooling or less, mothers with a moderate level of education had 10-14 years of schooling and mothers with a high level of education had 15 years or more. 


\section{Analyses of behavioural determinants}

The number of determinants to be related to each of the 18 safety measures varied from seven to eleven. The analyses of determinants were age specific according to the age chosen for the specific safety measure the determinants were related to (see table 1). Moreover, the analyses were done for mothers for whom the measure was relevant according to their housing and family situation. Mothers were excluded from an analysis when they skipped one of the questions or answered for one of the questions 'no idea'.

A non-linear canonical analysis was used to analyse the determinants of parental safety measures (Gifi, 1991). By means of this analysis two sets of categorical variables can be related. In the present study the first set was represented by one variable, namely the parental safety measure and was chosen as the dependent variable. The second set represented the number of determinants chosen to be related to the specific safety measure; these determinants were chosen to be the independent variables. In this way the non-linear canonical analysis can be considered as a non-linear multiple regression anaiysis.

First, the canonical correlation shows how strong the overall relation is between the set of determinants on the one hand and the parental safety measure on the other hand (tables 3, 5 and 7). Second, the canonical loads represent the independent contribution of a determinant in explaining the safety measure. The higher the canonical load the stronger the influence of the determinant in question (tables 3,5 and 7); it should be noted that no levels of significance are given with these canonical loads because this kind of analysis does not provide levels of significance. The determinants were included in the analyses without any hierarchical order. Third, by projecting the category loads we can assess which categories of behaviour (safe, moderately safe and unsafe behaviour) correspond to the categories of the determinants (tables 4 , 6 and 8). That is the sign ( + or - ) of a specific behaviour category (e.g. the category 'safe behaviour' with respect to keeping poisonous plants out of reach) corresponds to the sign of specific categories of the determinants (e.g. believing that the measure is instrumental to prevent poisoning from plants). 


\section{Chapter 6}

\section{Relation with level of education}

The chi-square test was used $(p<0.05)$ in order to assess differences between mothers with a low, moderate and high level of education in their familiarity with a safety measure, their opinion on the necessity of a safety measure according to their child's age and their perception of the seriousness of risk situations for their child. As we were primarily interested in differences between poorly and highly educated mothers, only these results will be presented here.

\section{RESULTS}

\section{Response}

The sample group of 1,500 mothers was reduced to 1,345 mothers for the following reasons: more than one questionnaire was sent to a family, the questionnaire was filled in by the father, the child was mentally or physically handicapped or the questionnaire could not be delivered. As 1,129 mothers completed the questionnaire, the response rate was $84 \%$. This response was considered representative for the research population. Reasons for non-cooperation were mostly unknown. When they were known, the main reasons mentioned were 'no time' or 'no wish' to cooperate.

\section{Demographic findings}

Children of all age groups were equally represented: $20 \%$ were 0 years old, $20 \%$ were aged 1 year, $20 \%$ were 2 years old, $19 \%$ were 3 years old and $21 \%$ were 4 years old; $51 \%$ were boys and $49 \%$ were girls.

The mothers' level of education was distributed almost equally over the three educational levels: $29 \%$ were mothers with a low level of education, $39 \%$ of the mothers had a moderate level and $32 \%$ had a high level (missing: $n=31$ ). More than $60 \%$ were 30 years or older and $88 \%$ had a partner. Thirty-five percent worked outside the home. 


\section{Determinants of safety measures to prevent poisoning}

Table 3 shows that six safety measures to prevent poisoning are moderately or rather well explained by the determinants. Because the canonical correlation with respect to medicines is low, no further results with respect to medicines will be discussed.

Table 3 Non-linear canonical analysis of determinants of safety measures to prevent poisoning

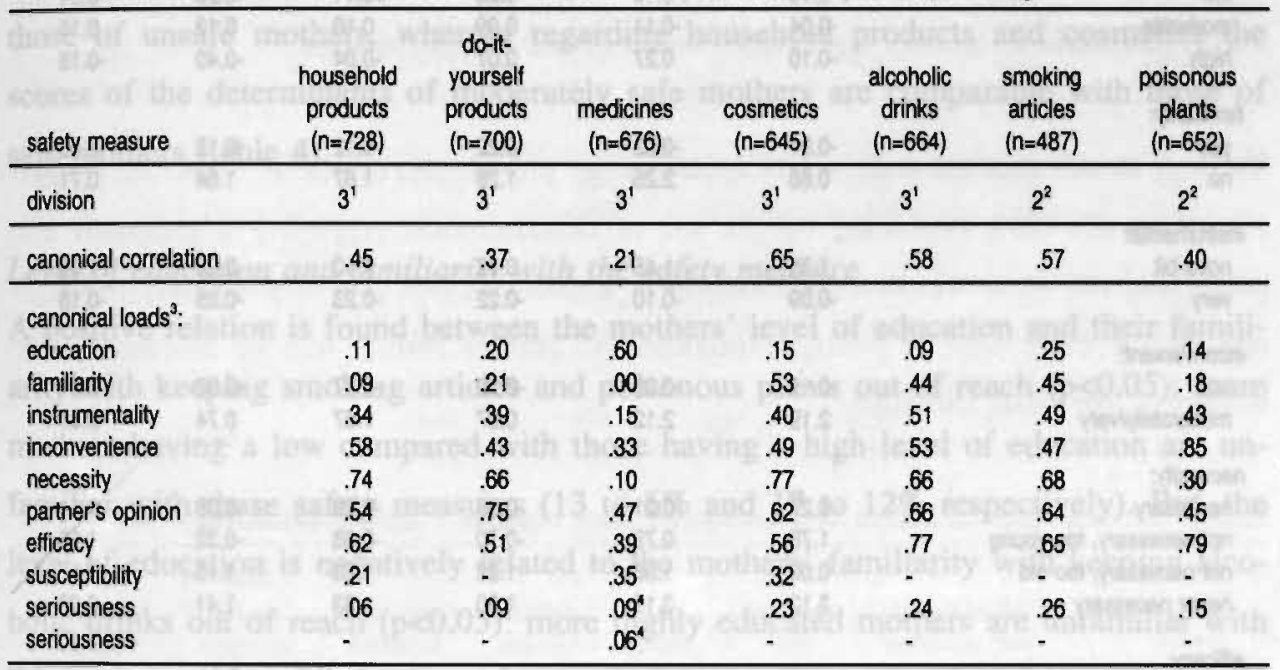

'Mothers' answers with respect to the safely measures were categorized into three categories: sale, moderately safe and unsale.

'Mothers' answers with respect to the safety measures were categorized into safe and unsafe.

3he canonical loads show the strength of the relation between the salety measure and each determinant. To interpret the direction of this relation reler to table 4 .

- With respect to medicines the perception of the seriousness of two products was asked, iodine and aspirin respectively.

For most of these six safety measures the main determinants are the belief about the necessity of taking the safety measure according to the child's age, the belief about the partners' opinion on the necessity of the safety measure and the extent to which the mother believes she will succeed in taking the safety measure. To a lesser extent taking these safety measures is influenced by beliefs about the inconvenience and the instrumentality of the measures. Familiarity only influences substantially the safety measures concerning cosmetics, alcoholic drinks and smoking articles. The perceived susceptibility, perceived seriousness and mothers' level of education have little or no impact on taking the safety measures. 


\section{Chapter 6}

Table 4 Non-linear canonical analysis for determinants of safety measures to prevent poisoning: projection of the category loads

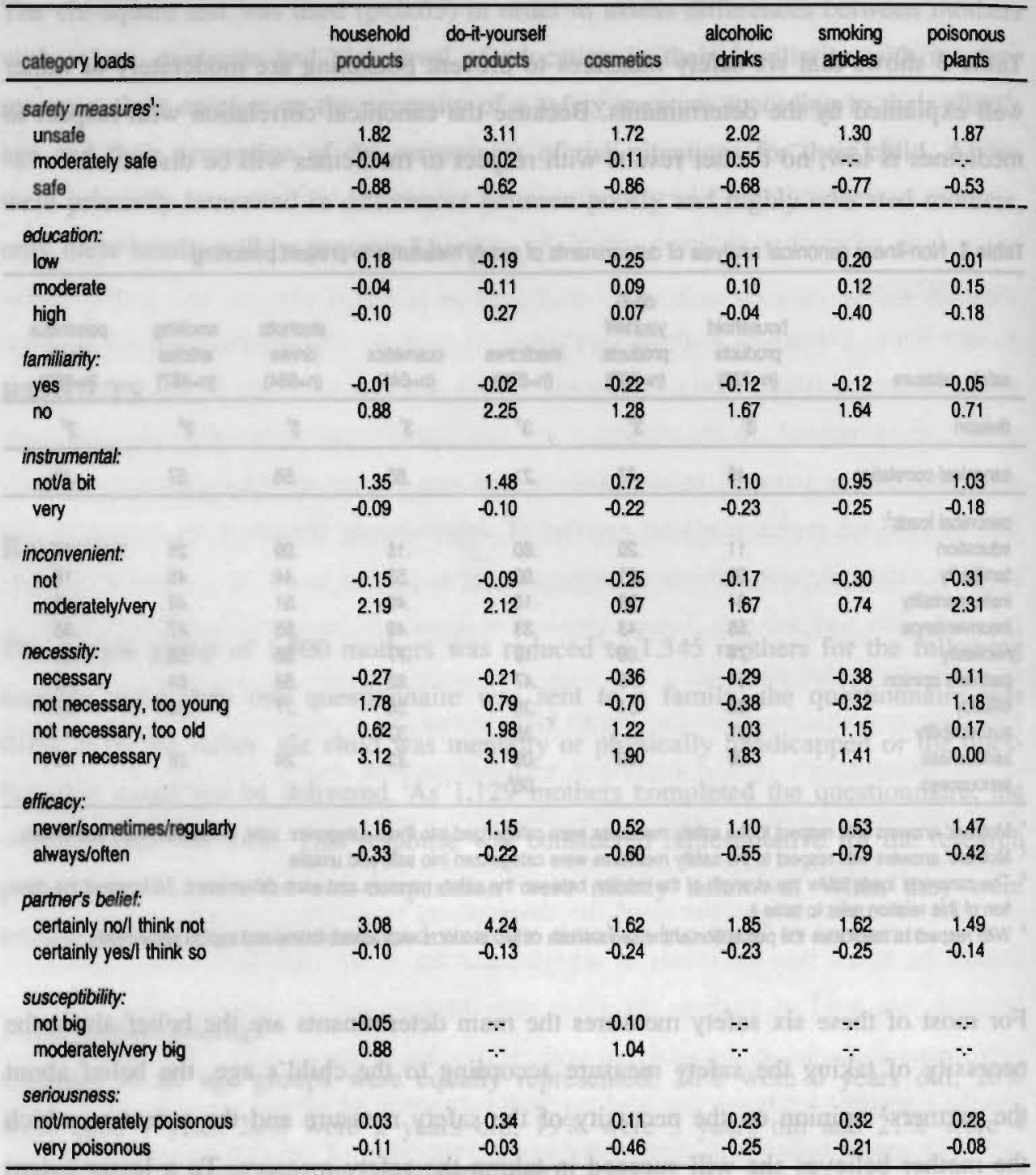

' The sign of each calegory of the safely measure corresponds to the signs of the categories of the subsequent determinants.

On the basis of the category loads (table 4) it appears that compared to safe mothers unsafe mothers more often find the measure not necessary for the child's age. More specifically, unsafe mothers more often find the measure never necessary, irrespective 
of the child's age. Moreover, unsafe mothers more often believe that they do not always/often succeed in taking the measure, that their partner (probably) does not find the measure necessary, that the measure is a bit or very inconvenient and that it is not at all or only slightly instrumental in reducing the risk situation that may confront their child.

With respect to do-it-yourself products and alcoholic drinks the scores of the determinants of mothers who were considered 'moderately safe' are comparable with those of unsafe mothers, whereas regarding household products and cosmetics the scores of the determinants of moderately safe mothers are comparable with those of safe mothers (table 4).

\section{Level of education and familiarity with the safety measure}

A positive relation is found between the mothers' level of education and their familiarity with keeping smoking articles and poisonous plants out of reach $(p<0.05)$ : more mothers having a low compared with those having a high level of education are unfamiliar with these safety measures ( 13 to $6 \%$ and 17 to $12 \%$ respectively). But, the level of education is negatively related to the mothers' familiarity with keeping alcoholic drinks out of reach $(\mathrm{p}<0.05)$ : more highly educated mothers are unfamiliar with this measure (12 to $5 \%$ for low education).

\section{Level of education and belief about the necessity of the safety measure}

A relation is found between mothers' educational level and their belief about the necessity of all safety measures to prevent poisoning ( $\mathrm{p}<0.05$ ). More 'low education' mothers compared to 'high education' mothers find it 'never necessary' to keep out of reach: household products (6 to $1 \%$ ), do-it-yourself products ( 8 to $0 \%$ ), medicines (6 to $1 \%$ ), cosmetics (14 to $5 \%$ ), smoking articles (16 to $4 \%$ ), alcoholic drinks (11 to $6 \%$ ) and poisonous plants (12 to $4 \%$ ). But, more highly educated mothers find it 'not necessary because their child is too old' to keep out of reach: cosmetics (20 to $7 \%$ ), smoking articles (17 to $7 \%$ ), alcoholic drinks (18 to 6\%) and poisonous plants (17 to $8 \%)$. 


\section{Chapter 6}

Level of education and perceived seriousness

A positive relation is only found with respect to the poisoning effects of turpentine and cigarettes $(\mathrm{p}<0.05)$ : more mothers with a 'low education' than mothers with a 'high education' believe that turpentine and cigarettes are not or rather poisonous for their child (11 to $3 \%$ and 49 to $38 \%$ respectively).

\section{Determinants of safety measures to prevent burns/scalds}

Table 5 shows that the four safety measures to prevent burns/scalds requiring repeated action are well explained by the set of determinants. Applying a topguard and protecting the oven window are moderately explained, but applying a safety mechanism on the oven door is poorly explained. No further results will be discussed with respect to the latter measure.

Table 5 Non-linear canonical analysis for determinants of safety measures to prevent bums/scalds

\begin{tabular}{|c|c|c|c|c|c|c|c|}
\hline safety measure & $\begin{array}{l}\text { not on the lap } \\
\text { with tea/coffee } \\
\text { ( } \mathrm{n}=801)\end{array}$ & $\begin{array}{c}\text { lea/coffee } \\
\text { can } \\
(n=754)\end{array}$ & $\begin{array}{c}\begin{array}{c}\text { out of } \\
\text { kitchen } \\
\text { ( } n=687)\end{array} \\
\end{array}$ & $\begin{array}{l}\text { matches/ } \\
\text { lighters } \\
(n=687)\end{array}$ & $\begin{array}{c}\text { topguard } \\
\text { on cooker } \\
(n=195)\end{array}$ & $\begin{array}{c}\text { window } \\
\text { protection } \\
(n=104)\end{array}$ & $\begin{array}{c}\text { mechanism } \\
\text { oven door } \\
(n=103)\end{array}$ \\
\hline division & $3^{1}$ & $3^{1}$ & $3^{\prime}$ & $3^{\prime}$ & $2^{2}$ & $2^{2}$ & $2^{2}$ \\
\hline $\begin{array}{l}\text { canonical } \\
\text { correlation }\end{array}$ & .76 & .79 & .81 & .78 & .36 & .45 & .28 \\
\hline \multicolumn{8}{|l|}{ canonical loads: } \\
\hline education & .04 & .00 & .39 & .17 & .42 & .35 & .59 \\
\hline familiarity & .15 & .04 & .23 & .20 & .44 & .05 & .41 \\
\hline instrumentality & .46 & .38 & .53 & .40 & .23 & .18 & .22 \\
\hline inconvenience & .60 & .35 & .73 & .58 & .58 & .22 & .34 \\
\hline necessity & .59 & .69 & .70 & .44 & .62 & .53 & .56 \\
\hline partner's opinion & .69 & .63 & .73 & .51 & .59 & .11 & .04 \\
\hline efficacy & .79 & .89 & .80 & .93 & - & - & t. \\
\hline expense & - & - & - & - & .37 & .42 & .17 \\
\hline susceptibility & .14 & - & - & - & .11 & .62 & - \\
\hline seriousness & .08 & - & -0 & - & .01 & .10 & - \\
\hline
\end{tabular}

' Mothers' answers with respect to the salety measures were categorized into three categories: safe, moderately sale and unsale.

'Mothers' answers with respect to the salety measures were categorized into sale and unsale.

3 The canonical loads show the strength of the relation between the salety measure and each determinant. To interpret the direction of this relation, refer to table 6 . 


\section{Behavioural determinants of mothers' safety measures}

Table 6 Non-linear canonical analysis for determinants of safety measures to prevent burns/scalds: projection of the category loads

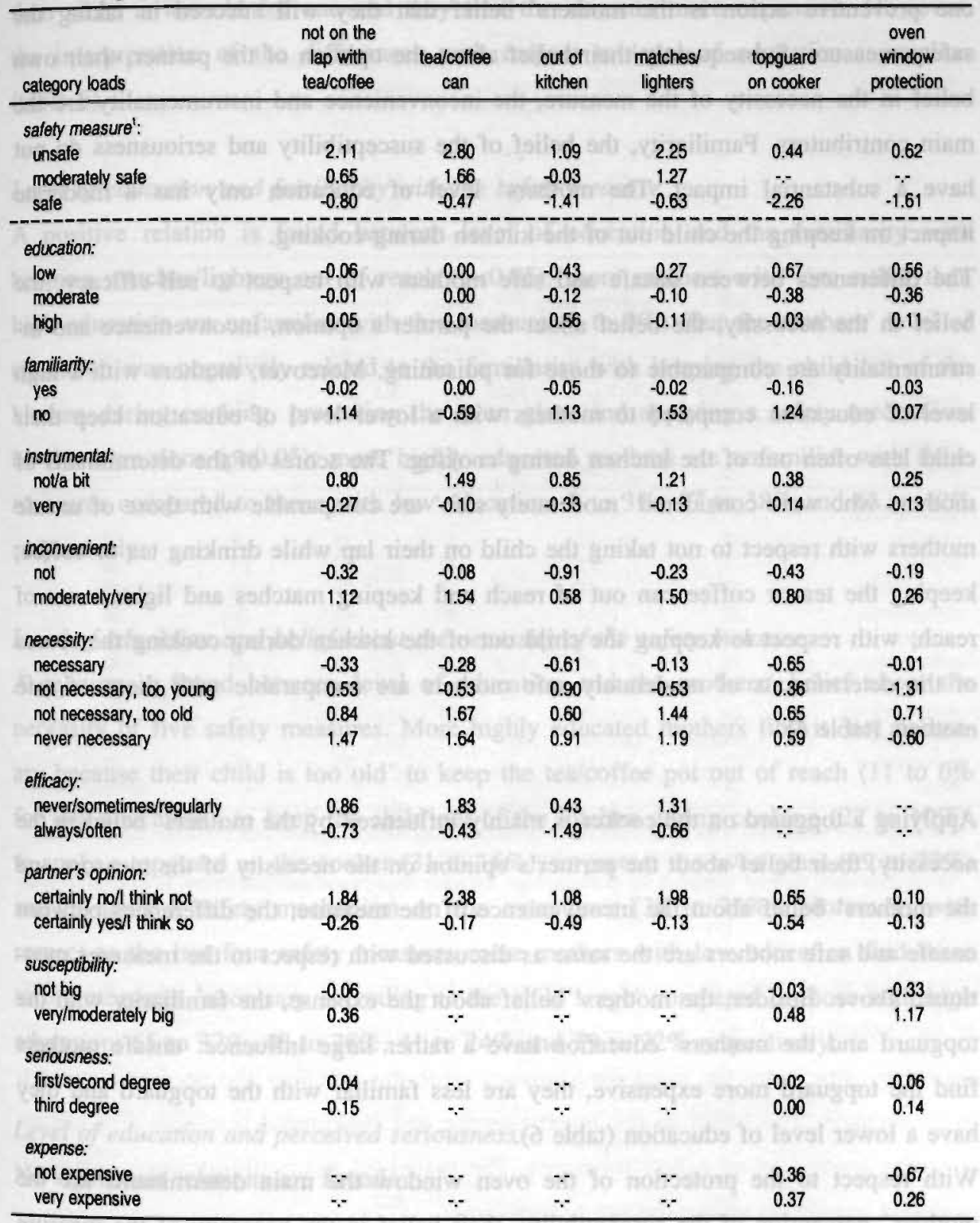

'The sign of each category of the safety measure corresponds to the signs of the categories of the subsequent determinants. 
The main determinant in explaining the four safety measures that require more than one preventive action is the mothers' belief that they will succeed in taking the safety measure. Subsequently their belief about the opinion of the partner, their own belief in the necessity of the measure, the inconvenience and instrumentality are the main contributors. Familiarity, the belief of the susceptibility and seriousness do not have a substantial impact. The mothers' level of education only has a moderate impact on keeping the child out of the kitchen during cooking.

The differences between unsafe and safe mothers with respect to self-efficacy, the belief in the necessity, the belief about the partner's opinion, inconvenience and instrumentality are comparable to those for poisoning. Moreover, mothers with a high level of education compared to mothers with a lower level of education keep their child less often out of the kitchen during cooking. The scores of the determinants of mothers who were considered 'moderately safe' are comparable with those of unsafe mothers with respect to not taking the child on their lap while drinking tea or coffee, keeping the tea or coffee can out of reach and keeping matches and lighters out of reach; with respect to keeping the child out of the kitchen during cooking the scores of the determinants of moderately safe mothers are comparable with those of safe mothers (table 6).

Applying a topguard on the cooker is mainly influenced by the mothers' belief in the necessity, their belief about the partner's opinion on the necessity of the measure and the mothers' belief about the inconvenience of the measure; the differences between unsafe and safe mothers are the same as discussed with respect to the measures mentioned above. Besides, the mothers' belief about the expense, the familiarity with the topguard and the mothers' education have a rather large influence: unsafe mothers find the topguard more expensive, they are less familiar with the topguard and they have a lower level of education (table 6).

With respect to the protection of the oven window the main determinants are the mothers' perception of the susceptibility, their belief in the necessity of the measure and to a lesser extent the belief about the expense and mothers' education. Unsafe mothers believe that their child's chance of getting burned from the oven window is 
greater, but they more often believe that an oven screen is not necessary because their child is too old for one and they find the measure more expensive. However, the interpretation of the differences with respect to level of education is unclear (table 6).

Level of education and familiarity with the safety measure

A positive relation is found between level of education and the familiarity with keeping matches/lighters out of reach $(p<0.05)$ : more mothers with low rather than high education are unfamiliar with this measure ( 3 to $0 \%$ ). But the mothers' level of education was negatively related to the familiarity with keeping the child out of the kitchen during cooking, protecting the oven glass and applying a safety mechanism on the oven door $(p<0.05)$; more highly educated mothers are unfamiliar with these measures compared to those with low education, 8 to $3 \%$; 57 to $38 \%$ and 65 to $42 \%$ respectively.

Level of education and belief about the necessity of the safety measure

A relation is found between level of education and the mothers' belief about the necessity of five safety measures. More highly educated mothers find it 'not necessary because their child is too old' to keep the tea/coffee pot out of reach (11 to 6\% for low education), to keep the child out of the kitchen during cooking (27 to $10 \%$ ), to apply a topguard on the cooker ( 31 to $16 \%$ ), to protect the oven glass ( 39 to $22 \%$ ) and to apply a safety mechanism on the oven door (38 to 22\%). Moreover, with respect to the last four safety measures more mothers with low education find these safety measures 'necessary according to the child's age' compared to those with high education: 65 to $37 \%, 48$ to $28 \%, 41$ to $24 \%$ and 39 to $22 \%$ respectively.

Level of education and perceived seriousness

No significant relations are found. 


\section{Chapter 6}

Familiarity has a moderate influence only on the application of window guards, antislip material in the shower and in the shower and bath whereas the belief about the equipment's appearance had a substantial influence only on the anti-slip material in shower and bath and on the protection material on sharp corners and edges. The belief about the expense, the perceived seriousness and mothers' level of education have little or no influence on taking the safety measures.

With respect to these determinants the differences between safe and unsafe mothers are comparable to those for poisoning and burns. With respect to the four safety measures where a moderately safe behaviour category was possible, the scores of determinants of moderately safe mothers are similar to those of safe mothers (table 8).

Level of education and familiarity with safety measures

A positive relation is found between level of education and the familiarity with protecting sharp comers and edges, and applying anti-slip material in bath and shower $(p<0.05)$; more mothers with a low level compared with those with a high level of education are unfamiliar with these safety measures (18 to $11 \%$ and 4 to $2 \%$ respectively).

Level of education and belief about the necessity of the safety measure No significant relations are found.

Level of education and perceived seriousness

No significant relations are found.

\section{CONCLUSIONS AND DISCUSSION}

In this study a set of behavioural determinants derived from the ASE model was related to the taking of 18 safety measures by mothers of pre-school children. By means of these determinants two safety measures were poorly explained, some safety 
measures were moderately explained, but most safety measures were well or rather well explained. Thus, for only some of the safety measures are determinants other than those that were examined responsible for adopting or not adopting these measures.

Moreover, the same set of determinants seems to influence different safety measures. Regardless of the number of determinants that were related to a specific safety measure, the main determinants for adopting or not adopting a safety measure were the mother's belief in the necessity of the safety measure according to the child's age and her belief about the opinion of her partner regarding the necessity. In cases where a safety measure required repeated action, a question was asked about selfefficacy: for these safety measures self-efficacy was found to be an equally important determinant as the two beliefs just mentioned. Other important determinants, although less influential, were the mother's belief about the inconvenience and instrumentality of the safety measure. The perception of the susceptibility had a minor or moderate influence on most measures. In general, the mother's familiarity with the measure, her belief about the expense, her dislike of the equipment's appearance and her perception of the seriousness of childhood injuries to be prevented by the measure had very little or no impact. Finally, the external determinant, mothers' level of education, had little or no influence on the taking of most safety measures. Clearly, this last finding accords with the theoretical assumption of the ASE model that external variables influence behaviour indirectly through the ASE determinants.

As stated in the introduction, the Health Belief Model as well as the Protection Motivation Theory suppose that the perceived susceptibility and seriousness (together they form the perceived threat) are important determinants in adopting health related behaviour. However, in the present study perceived susceptibility had a minor or moderate impact and perceived seriousness had no impact on the taking of safety measures. These findings are in line with the studies of Glik et al. (1991) and Thuen (1992), which respectively found no relation and a very weak relation between parental safety measures and the perceived threat. On the one hand this may be explained by the fact that risk perception (i.e. perceived threat) generally appears to be a necessary but not a sufficient determinant in adopting health related behaviour 
(Janz and Becker, 1984; Weinstein, 1989); on the other, measurement problems may underlie these findings.

In order to understand the contribution of influential determinants, for each safety measure a comparison was made between mothers adopting safe behaviour and those who did not; with respect to some of the safety measures mothers who were behaving 'moderately safely' also were incorporated into the comparison. It should be noted that these safety qualifications only refer to temporary status of the mother. A prior study (Wortel and De Geus, 1993) made clear that the safety measures were not interrelated, not even within one type of accident. This means that mothers who were considered safe with respect to one measure could at the same time be considered unsafe with respect to another measure. Thus, with regard to the same mother the behavioural determinants may vary across the safety measures.

In general, the interpretation was as follows:

1. mothers scored as being 'unsafe' compared to 'safe' mothers recognize less often the necessity of the recommended safety measure according to the child's age. By answering with 'the safety measure is not necessary because my child is too old' or 'the safety measure is not necessary because my child is too young' the mother seems to demonstrate a lack of knowledge about her child's development, but she also may reject the safety measure as such at this age of the child compared to other strategies like supervising and educating the child. The alternative 'the safety measure is never necessary' probably refers to a rejection of the safety measure irrespective of the child's age. Thus, the interpretation of these 'not necessary' categories is not completely clear.

Future research may improve the interpretation of this determinant by including beliefs on behaviour alternatives. Taking safety measures is one strategy to prevent a child from receiving injuries whereas supervising and educating the child are other, more self-acting strategies to accomplish this goal. Therefore, the explanatory power of the model may be better if beliefs about the necessity of supervision and education are also included into the behavioural analyses. 
2. mothers scored as being 'unsafe' compared to 'safe' mothers were less often supported by their partner's opinion about the necessity and more often thought that they would not succeed in taking the measure.

3. mothers scored as being 'unsafe' compared to 'safe' mothers found the safety measure less instrumental, more inconvenient and thought their child's chance of being confronted with risk situations at home was greater. The latter finding seems to correspond with the mothers' beliefs on the safety measure, but is in contradiction with the findings of other studies in which it was found that persons with higher objective risks seem to have lower perceived risks (Avis et al., 1989; Niknian et al., 1989; Glik et al., 1991). It seems likely that the measurement of the perceived susceptibility in our study was not valid enough. That is in measuring mothers' perception of the susceptibility that their child will be confronted with specific risk situations, no reference was made to taking or not taking the safety measure that could prevent the risk situation. When mothers with safe behaviour made their estimation of the susceptibility, they probably took into account their safety measures; this may explain why mothers behaving in an unsafe way compared to mothers showing safe behaviour think their child's susceptibility is higher.

\section{Relation with level of education}

In this study no support was found for the assumption that mothers with a high level of education compared to those with a low education may be more knowledgeable about safety- related subjects:

- No consistent relations were found between level of education and the familiarity with safety measures. Moreover, when taking account of the size of the difference between poorly and highly educated mothers, only two safety measures deserve attention. However, since mothers with a low education indicate they know these safety measures better than highly educated mothers, it may be that less well educated mothers have given social desirable answers.

- Relations between the belief about the necessity of preventive measures according to the child's age and level of education were found for poisoning and 
burns/scalds. However, the only consistent interpretation found, was that more 'high' than 'low education' mothers find safety measures 'not necessary because their child is too old'. Thus, it may be that highly educated mothers overestimate their child's development whereas less well educated mothers may have a more realistic perception of their child's capabilities. But since the interpretation of the 'not necessary' categories was not fully clear, further research is needed to draw conclusions.

- Finally, no conclusions can be drawn with respect to the relation between level of education and perceived seriousness since only two relations were found.

\section{General conclusion}

The present study has given an insight into the determinants that seem to be important in taking safety measures. However, on behalf of safety education for parents, the interpretation of the determinants needs further improvement. Therefore, future research may use a 'stage' theory instead of a 'continuum' theory. For instance, at this moment it is unclear if unsafe mothers do not (yet) adopt a specific safety measure despite perceiving the risk situation, or that they do not perceive the threat of the specific risk situation and thus are not searching for any remedy at all. The model of the Precaution Adoption Process (Weinstein and Sandman, 1992) may be helpful to gain an insight into the stage which mothers are in with regard to their preventive thinking on child safety. This model consists of the following seven stages: "unaware of the issue", "aware of the issue but not personally engaged", "engaged and deciding what to do", "planning to act but not yet having acted", "having decided not to act", "acting" and "maintenance". Moreover, in order to achieve a better insight into the role of SES in adopting safety measures, SES indicators need to be related to these stages too. When future research can provide this kind of knowledge, safety educators will probably have a more solid basis on which to develop their educational activities. 


\section{ACKNOWLEDGEMENTS}

We wish to thank Jan Radder for his assistance with the statistical analysis and Ellen Bergsma for her useful comments on earlier drafts of this paper. This work was carried out at the TNO Institute of Preventive Health Care.

\section{REFERENCES}

AJZEN I. Attitude, personality and behavior. Milton Keynes: Open University Press, 1988.

AVIS N, SMITH K, McKINLAY J. Accuracy of perceptions of heart attack risk: what influences perceptions and can they be changed? Am J Publ Health 1989;79:1608-12.

CENTRAAL BUREAU VOOR DE STATISTIEK. Overledenen naar doodsoorzaak, leeftijd en geslacht in het jaar 1985-1987. Voorburg: CBS, 1986-1988. (Series A1)

EAGLY AH, CHAIKEN S. The psychology of attitudes. Fort Worth, TX: Harcourt Brace Jovanovich, 1993.

GIFI A. Non-linear multivariate analysis. New York: Wiley, 1991.

GLIK D, KRONENFELD J, JACKSON K. Predictor of risk perceptions of childhood injury among parents of preschoolers. Health Educ Quart 1991;18:285-301.

GREEN LW, KREUTER MW. Health promotion planning, an educational and environmental approach. Mountain View: Mayfield, 1991.

HALFENS R, DROP MJ, PHILIPSEN H. Leefwijzen en subjectieve gezondheid van een panel uit de Nederlandse bevolking. Maastricht: Rijksuniversiteit Limburg, 1984.

JANZ NK, BECKER MH. The health belief model: a decade later. Health Educ Quart 1984; 11:1-47.

KOK GJ, VRIES H de. Primary prevention of cancers: the need for health education and intersectoral health promotion. In: Heller T, Davey B, Bailey L, eds. Reducing the risks of cancers. London: Hoddor and Stoughton, 1989:99-111. 


\section{Chapter 6}

KOK G, VRIES H de, MUDDE AN, STRECHER VJ. Planned health education and the role of self-efficacy: Dutch research. Health Educ Res 1991;6:231-8.

NIKNIAN M, McKINLAY SM, RAKOWSKI W, CARLETON RA. A comparison of perceived and objective CVD risk in a general population. Am J Publ Health 1989;79:1653-4.

PRIVÉ ONGEVALLEN REGISTRATIE SYSTEEM (PORS). Jaaroverzicht Privé-Ongevallen Registratie Systeem, 1985-1987. Amsterdam: Stichting Consument en Veiligheid, 1986-1988.

RIPPETOE PA, ROGERS RW. Effects of components of protection motivation: theory on adaptive and maladaptive coping with a health threat. J Personal Soc Psychol 1987;52:596604.

ROBERTS MC, ELKINS PD, ROYAL GP. Psychological applications to the prevention of accidents and illness. In: Roberts MC, Peterson L, eds. Prevention of problems in childhood: psychological research and applications. New York: Wiley, 1984:173-93.

THUEN F. Preventing childhood accidents in the home: parental behavior to reduce household hazards. Scand J Psychol 1992;33:370-7.

VRIES H de, DIJKSTRA M, KUHLMAN P. Self-efficacy: the third factor besides attitude and subjective norm as a predictor of behavioral intentions. Health Educ Res 1988;3:273-82.

WEINSTEIN ND. Perceptions of personal susceptibility to harm. In: Mays VM, et al., eds. Primary prevention of AIDS: psychological approaches. Newbury Park: Sage publications, 1989. Volume XIII:142-67.

WEINSTEIN ND, SANDMAN PM. A model of the precaution adoption process: evidence from home radon testing. Health Psychol 1992;11:170-80.

WORTEL E, OOIJENDIJK WTM. Preventie van privé-ongevallen bij kinderen: onderzock naar preventief gedrag van ouders en gedragsdeterminanten. (Prevention of home-related accidents of children: research on parental preventive behaviour and behavioural determinants). Leiden: NIPG-TNO, 1988.

WORTEL E, GEUS GH de. Prevention of home related injuries of pre-school children: safety measures taken by mothers. Health Educ Res 1993;8:217-31.

WORTEL E, GEUS GH de, KOK G, WOERKUM C van. Injury control in pre-school children: a review of parental safety measures and the behavioural determinants. Health Educ Res 1994:9,201-13. 


\section{General discussion and conclusions}

\section{INTRODUCTION}

Work to prevent accidents and injuries is often divided into three main approaches (Laidman, 1993): primary prevention to stop accidents happening, secondary prevention to reduce the severity of the injury sustained as a result of an accident and tertiary prevention to improve treatment of injuries to ensure good recovery. The five studies carried out in the context of this dissertation can mainly be characterized as behavioural research on the primary prevention of childhood injuries. More specifically, these studies were meant to contribute to the effectiveness of safety education directed at parents in order to prevent home-related injuries of pre-school children.

The first study (chapter 2) describes the development, implementation and effects of a community campaign on child safety where safety education was the main prevention strategy; the second study (chapter 3 ) focuses on a part of this campaign, namely the role of volunteers as safety educators.

The third, fourth and fifth studies of this thesis were carried out more or less simultaneously to the evaluation of the campaign. From the viewpoint of effective health education planning these studies should have been carried out before the start of the campaign (Green and Kreuter, 1991), but for practical reasons we were not able to do so. Nevertheless, the results of these last three studies may contribute to the empirical basis needed for effective child safety programmes in the future. More specifically, the third study (chapter 4) concerns a review of literature on parental safety measures (behavioural diagnosis) and behavioural determinants (educational diagnosis). Subsequently, the fourth study (chapter 5) provides information on 18 parental safety measures among 1,129 Dutch mothers of pre-school children in order to prevent poisoning, burns/scalds and falls. Based on the same group of mothers, the fifth study (chapter 6) presents the behavioural determinants underlying the taking of these safety measures. 
In this chapter the major findings of these studies will be discussed. Since in all of these studies mothers' SES was studied, the results related to SES will be discussed together in a separate section. Next, some methodological issues will be discussed and the implications for future research. Finally, recommendations will be formulated for the content of safety education directed at parents of pre-school children, for professionals as safety educators, for a community campaign on child safety and the role of volunteers in such a campaign.

\section{EVALUATION OF A COMMUNITY CAMPAIGN ON CHILD SAFETY}

The first study (chapter 2) was meant to provide an insight into the results of a oneyear community campaign on child safety. The Consumer Safety Institute (CSI) was the initiator of the campaign that was carried out in Nijmegen. The goal of this campaign was twofold: to reduce children's home-related injuries by $20 \%$ through safety education directed at parents and to stimulate cooperation between local organizations to create permanent attention for child safety in the community.

In order to involve local organizations a committee was installed in which representatives of local (operating) organizations participated together with a consultant of the CSI and a researcher of the TNO Institute of Preventive Health Care. This committee was responsible for the development and implementation of safety education activitics in the community. In the development of safety education activities planning principles for effective education were taken into account as far as was possible. To evaluate the campaign the TNO Institute carried out an effect and process evaluation. The effectiveness of the campaign on parental knowledge, their beliefs and the taking of safety measures was studied by means of a pre-test-post-test control design with four separate groups. Data were gathered by means of a self-completion questionnaire to be filled in by Dutch mothers of pre-school children. The questionnaire was collected personally by means of research assistants which provided high response rates in all four research groups (79\% or higher). Logistic regression analysis was used to analyse the effects. The regression coefficient was expressed in an Odds 
Ratio (confidence interval $95 \%$ ) because all variables were measured at a categorical level.

The process evaluation was meant to provide an insight into the development and implementation of the campaign. Therefore, a mix of data collection methods was used, like short semi-structured telephone interviews, written questionnaires, selfreports, minutes and observations of meetings. Data were gathered throughout the project.

The community campaign demonstrated only few effects on parents' safety knowledge, their beliefs and the adoption of safety measures. However, these effects could also be expected on the basis of chance due to multiple testing and therefore can be ignored. The main reason for the lack of effects on parental safety behaviour was that the majority of parents received little or no information via interpersonal channels which is supposed to be a necessary condition for realising behaviour changes (Rogers, 1983; Bettinghaus, 1986). Besides, those parents exposed to interpersonal safety education (18\%) were biased towards the relatively highly educated.

The process evaluation made clear that the low exposure and participation of parents were due to an implementation failure (Orlandi et al., 1990): the limited activities of professional intermediaries in combination with the short implementation period (less than 1 year). Professional intermediaries did not integrate safety education in their regular contact with parents and organized only a few safety group sessions. In turn, these poor efforts are related to the functioning of the linkage system: in other words, the committee that was responsible for the activities of intermediaries did not operate well. This is related to the cooperation between the CSI and local organizations.

First, the CSI had no detailed strategy in order to cooperate with local organizations. No plan was available in which the time investment and responsibilities of the local organizations were assigned resulting in a low level of participation in the committee by representatives of local organizations. Second, at the start of the campaign the CSI had no training programmes and only a few educational tools/materials available for professional intermediaries. Therefore, in combination with the limited manpower, all kinds of materials were not ready at the start of the implementation period. Consequently, professional intermediaries were too little prepared and equipped in 


\section{Chapter 7}

order to give high quality safety education to parents. Third, intermediaries' activities were also hampered by structural factors in their organization. Some intermediaries were motivated but experienced barriers like the limited time available for safety education; others considered safety education not as a part of their task which is probably related to their job description. Thus, the local organizations created no structural basis for their personnel to stimulate them undertake safety education activities.

When it became clear that professional intermediaries would not be able to reach most parents in the community, the CSI decided to bring volunteers into the campaign in order to try to reach the campaign goal. However, due to the short implementation period the small number of volunteers recruited was not able to reach most parents in the community with safety education activities and those parents reached were relatively highly educated.

On the whole, it turned out that the committee's activities on behalf of intermediaries, both professionals and volunteers, were mainly developed and carried out by the CSI. Since the participating organizations were not mainly responsible for the campaign activities, maintenance of safety education activities after the end of the campaign was not created.

In sum, the community campaign showed no behavioural effects (knowledge, beliefs, safety measures) due to an implementation failure of the campaign: too few parents were reached with interpersonal safety education due to the poor activities of professional intermediaries in combination with the limited campaign period. The organizing committee experienced difficulties in the diffusion of high standard safety education activities at the community level. This was mainly due to the inadequate preparation and planning of the campaign by the CSI which made the CSI not only the initiator of the campaign but also the main executor. 


\section{VOLUNTEERS AS SAFETY EDUCATORS IN A COMMUNITY CAM- PAIGN ON CHILD SAFETY}

In this study a detailed insight was provided into the role of volunteers as safety educators in the community campaign described in the previous section. Since the change of parental safety behaviour was a main goal of the campaign, it was intended to reach parents of pre-school children via both mass media and interpersonal channels. Volunteers were recruited and trained because professional intermediaries were not able to reach most parents in the community with (extensive) safety education. (The advantages of working with volunteers as paraprofessionals were recognized, but these were not the main reason to use volunteers in the campaign). Although the 'Voluntary Safety Educators Project' (VSEP) had the approval of local organizations participating in the campaign, the consultant of the Consumer Safety Institute (CSI) was mainly responsible for the development and implementation of the VSEP.

In order to evaluate the VSEP a mix of data collection methods were used, such as a report by the CSI consultant, a written questionnaire for volunteers, telephone interviews with volunteers, their administration on parents' participation and a written questionnaire for participating parents.

Group sessions were chosen as the educational method since this could minimize the number of volunteers needed. Volunteers had to follow a 3-day training course in conducting safety group sessions and needed to have pre-school children themselves to be credible and attractive in the eyes of parents. Moreover, they had to be willing to organize 25 group sessions. After making the criteria for selection less strict 20 volunteers could be trained. Most volunteers were women, more than half of them had children of pre-school age and all volunteers had a secondary or higher level of education. After training most volunteers reported they were able to invite parents and the majority found themselves capable of educating parents on different aspects of child safety, but half of them indicated they had too few skills to lead a group session. Nearly all volunteers were satisfied with the communication aids. 
In fact 15 volunteers started work and organized 139 safety group sessions. Most volunteers had positive work experiences, but shortcomings mentioned were the difficulties in leading a group session, too much time needed to organize a group session, too little guidance from the CSI consultant and loss of motivation because parents who had promised to participate did not turn up. From the 4,500 families with pre-school children in Nijmegen more than 2800 parents were invited to participate of whom 713 actually participated. The participation rate at the community level was $16 \%$ whereas the participation rate in response to the volunteers' invitation was $25 \%$.

Parents who participated completed a written questionnaire (response $89 \%$ ). Most parents were women $(84 \%)$ with secondary or higher education $(83 \%)$ : compared to a representative group of mothers the participating mothers had significantly more often secondary or higher education. Participating parents gave the VSEP a positive appraisal (volunteer and group process) and reported positive effects on their knowledge and behaviour related to child safety. Moreover, nearly $50 \%$ of all parents had only one child: these parents reported stronger effects than parents with more children $(\mathrm{p}<0.05)$.

A considerable number of parents received safety education through interpersonal channels due to volunteers. But volunteers were not able to educate parents of most families in the community. One reason for this result was that the small number of volunteers that worked for the VSEP were unable to invite parents in all families during the one-year period of the campaign. Another reason was that participating parents were biased towards the relatively higher educated parents. This was probably related to the fact that mothers with a lower level of education are less involved in the subject as such, may differ too much from the educational level of volunteers and do not feel comfortable in safety group sessions. A pre-test of the VSEP might have revealed these factors.

In sum, volunteers were main educators in a community campaign on child safety. Participating parents gave the VSEP a positive appraisal and reported an improvement on their knowledge and behaviour. However, participating parents were relatively highly educated. 


\section{REVIEW OF PARENTAL SAFETY MEASURES AND THE BEHAV- IOURAL DETERMINANTS}

The effectiveness of health education programmes is determined by the quality of the planning of the programme (Mullen et al., 1985; Kok, 1992). The previous sections have demonstrated that the failure of the community campaign on child safety in Nijmegen can be characterized as an implementation failure: only a relatively small part of the target group was reached with interpersonal safety education due to the poor activities of professional intermediaries in combination with the limited campaign period. However, essential elements in the planning process of health education programmes are not only related to the implementation of the intervention, but also to the quality of the programme itself. Among other things, programmes that are not based on empirical information on the behaviour involved in the health problem and the underlying behavioural determinants in advance are less effective (Green and Kreuter, 1991). Since the content of the safety education in the campaign in Nijmegen was mainly based on a small, explorative pilot study, to some extent this campaign also may have suffered from 'programme failure'.

In order to get a more general indication of the possibility that previous safety education programmes had for grounding their activities in a thorough empirical basis, a review study was carried out on parental safety measures and the underlying behavioural determinants.

The review of studies on parental safety behaviour was undertaken on the basis of a model. In this model a distinction is made between three forms of parental behaviour that can prevent a child from having an accident: parents can supervise their child, educate their child to recognize and handle dangerous situations and take safety measures to make the child's environment safe. From the viewpoint of injury prevention taking safety measures is very important. First, safety measures remove often the source of accidents and second because supervision and education have some shortcomings that do not always make them effective in regulating the childenvironment interaction. For instance, constant supervision is not feasible and educa- 
tion of the very young is not possible. Therefore, safety educators need to know which parental safety measures have to be changed.

The review demonstrated that information for setting priorities for safety measures to be addressed in safety education is scarcely available. First, too little epidemiological research has been carried out to ascertain the relationship between childhood injuries and the omission of safety measures. This may be attributed to the predominant use of the classical epidemiological model that describes the etiology of childhood injuries by means of the host, agent and environment. In this model the behavioural component is overlooked. Second, too few studies assessed the prevalence of different parental safety measures in a population and moreover, their results were hard to compare. Although these studies did not provide a basis for setting priorities, it was clear that the safety measures taken by many parents are selective and insufficient. In fact, these studies provided empirical evidence for the need to promote the taking of safety measures as a strategy alongside supervision and education.

Furthermore, the review study showed that there is little literature available on the behavioural determinants underlying the adoption of safety measures. Only a few attempts have been made to study these determinants. Moreover, even fewer studies used a model of planned behaviour in which different determinants are related to the behaviour under study.

In order to provide an insight into the contribution of the individual studies reviewed, their findings were ordered according to a model of psycho-social determinants of behaviour, the Attitude-Social influence-Self-efficacy/barriers model (Ajzen, 1988; De Vries et al., 1988; Kok et al., 1991). The ASE model states that behaviour is influenced by three kind of determinants: a person's attitude towards the behaviour, the social influence a person experiences from other persons and the extent to which a person feels he/she will be able to perform the behaviour. As parental safety behaviour can be considered as health behaviour, we specifically included some variables from the Health Belief Model (HBM; Janz and Becker, 1984) and the Protection Motivation Theory (PMT; Rippetoe and Rogers, 1987). These variables were the 'threat' a person experiences of the injury and the 'response-efficacy', the extent to which a person believes the recommended behaviour can reduce the risk to be con- 
fronted. These variables can be considered as parts of the attitude (Ajzen, 1988; De Vries et al., 1988).

The review indicated (1) that the threat parents experience of childhood injuries seems to be insufficiently present; (2) that, in general, there is a lack of evidence as to whether parents consider their own behaviour as a remedy to avoid childhood injuries in contrast to their opinion that accidents just happen, and as to the extent to which they find different forms of safety behaviour instrumental in preventing injuries; (3) that although some studies gave an indication of parents' beliefs, normative beliefs and estimations of self-efficacy that may influence the adoption of specific safety measures, none of the studies have provided an insight into the relative importance of these determinants in the adoption of safety measures. Thus, causal relations were not presented.

In sum, the review showed that a thorough knowledge of the parental safety measures that need to be changed and the determinants of taking such safety measures is not available. Hence for the development of previous safety education programmes no solid basis was apparent. Therefore, those past programmes that did not show effects, among others, may a priori have suffered from 'programme failure'.

\section{PARENTAL SAFETY MEASURES}

The questionnaire study on mothers' safety measures (chapter 5) was meant to contribute to setting priorities in recommending safety measures to parents. This study assessed the prevalence of 18 parental safety measures to prevent poisoning, burns/scalds and falls.

Overall, the selection of safety measures was done on the basis of a combination of agents that were related to serious injuries (hospital visit or death) among Dutch 0-4 year old children, a large possibility to apply the safety measures when taking account of children's age, housing and family situation, and the fact that the safety measures are recommended by the Consumer Safety Institute. As the response to the 


\section{Chapter 7}

questionnaire was high (84\%) the results were representative for Dutch mothers with pre-school children.

In relation to the prevention of poisoning, the group of mothers behaving in an unsafe way is still large for most poisoning agents: household products, alcoholic drinks, cosmetics, smoking-articles and poisonous plants. This means that these products are within the child's reach and risk situations are not eliminated.

With regard to the prevention of burns/scalds in the kitchen most mothers behaved unsafely or rather safely: they did not keep the child out of the kitchen during cooking, they did not have a topguard on the cooker nor did they have an oven door with protected glass nor an ovendoor with a safety mechanism. On the other hand most mothers behaved safely with regard to the other risks studied, lighters/matches in reach, tea/coffee can within reach and child on the lap while drinking coffee/tea.

Mothers have mainly unsafe or rather safe behaviour in order to prevent injuries due to falls from stairs, windows, against sharp comers and anti-slip in the shower cabinet or bath-tub. This means that safety equipment is not applied or applied deficiently.

Compared to the results of international studies, it appeared that some safety measures have a strong cultural element. In some countries specific safety measures seem to be more common in households with pre-school children than in the Netherlands, e.g. in Sweden the use of safety equipment in the kitchen is much more common. Finally, this study showed that in the safety measures related to one type of accident (e.g. poisoning) no consistency was apparent, which implied that safety measures between accidents would also show inconsistency. This result not only accords with another study on parental safety measures (Dershewitz, 1979), but also with studies in which the correlation of different health-related behaviours (smoking, fat dieting etc.) was studied (Calnan, 1985; Calnan and Rutter, 1986; Van Assema et al., 1993).

In sum, this study showed that very common risk situations related to poisoning, burns/scalds and falls were partly or entirely present in the homes of many preschool children. Therefore, most of the safety measures examined needed further improvement. 


\section{BEHAVIOURAL DETERMINANTS OF PARENTAL SAFETY} MEASURES

This study (chapter 6) provided information on the behavioural determinants of 18 safety measures to prevent poisoning, burns/scalds and falls. The measurement of determinants was done via the same written questionnaire used for the measurement of the safety measures and was based on the same research group.

For the operationalization of the determinants the ASE model was used with inclusion of variables from the Health Belief Model (HBM) and the Protection Motivation Theory (PMT, see also the section on the review study). A non-linear canonical analysis (a kind of non-linear multiple regression analysis) was used to analyse the determinants of the safety measures because the determinants were measured by means of short categorical scales.

The study showed that most of the safety measures were well or rather well explained. Moreover, the same set of determinants seems to influence different safety measures.

Regardless of the number of determinants that were related to a specific safety measure, the main determinants for adopting or not adopting a safety measure were the mother's belief in the necessity of the safety measure according to the child's age and her belief about the opinion of her partner regarding the necessity. In cases where a safety measure required repeated action, a question was asked about selfefficacy: for these safety measures self-efficacy was found to be an equally important determinant as the two beliefs just mentioned. Other important determinants, although less influential, were the mother's belief about the inconvenience and instrumentality of the safety measure. The perception of the susceptibility had a minor or moderate influence on most measures. Determinants that had little or no impact were the mother's familiarity with the measure, her belief about the expense, her dislike of the equipment's appearance and her perception of the seriousness of childhood injuries to be prevented. Finally, mothers' level of education had little or no influence on the taking of most safety measures, which accords with the theoreti- 
cal assumption of the ASE model that external variables influence behaviour indirectly through the ASE determinants.

Hence, contrary to what might be expected according to the HBM and the PMT, the perceived susceptibility and seriousness of risk situations seem to have little influence on the taking of safety measures. This may be due to the fact that, in general, these determinants appear to be necessary but not sufficient determinants in adopting health-related behaviour (Janz and Becker, 1984; Weinstein, 1989), but on the other hand, measurement problems may be responsible for these results.

The interpretation of influential determinants was as follows: 'unsafe' mothers compared to 'safe' mothers recognize less often the necessity of the recommended safety measure according to the child's age, they were less often supported by their partner's opinion on the necessity of the safety measure, and they thought more often that they would not succeed in taking the measure. Moreover, unsafe mothers found the measure less instrumental and more inconvenient, and thought their child's chance of being confronted with risk situations at home was greater. The latter result is in contradiction with the findings of other studies in which it was found that persons with higher objective risks seem to have lower perceived risks (Avis et al., 1989; Niknian et al., 1989; Glik et al., 1991). Therefore, it seems likely that the measurement of the perceived susceptibility in our study was not valid. In this measurement no reference was made to taking a safety measure that may prevent the risk situation.

Furthermore, a limitation of the study was that the parents' belief regarding the necessity of the safety measure according to the child's age was not easily interpretable; it was unclear whether mothers did not recognize the necessity of the safety measure according to their child's age, or whether they preferred alternative safety behaviour (supervision, education) instead.

In sum, the study showed which behavioural determinants seem to be important in taking safety measures. However, for safety education for parents, the interpretation of the determinants needs further improvement. 


\section{THE ROLE OF SES}

In the empirical studies carried out in this thesis mothers' level of education was chosen as a SES indicator. The evaluation of the campaign indicated that mothers with a high level of education were relatively more exposed to interpersonal campaign activities than less well educated mothers. Since most interpersonal safety education was given via volunteers who had secondary or higher education, this seems to accord with the principle that paraprofessionals may be more easily accepted by their peers. Other factors that may be related to the lower participation of parents with a lower level of education are that these mothers seem to be less involved in child safety (Laidman, 1987) and/or that the educational method, safety group sessions, may not fit into their lifestyle.

In the review study no conclusions could be made on the relation between SES indicators on the one hand and safety measures and behavioural determinants on the other because the studies reviewed provided too little evidence for making inferences. Our empirical study on parental safety measures did not provide substantial evidence for a relation between mothers' educational level and the degree to which they take safety measures. Moreover, in the study on behavioural determinants no support was found for the assumption that mothers with a high level of education compared to those with a low education may be more knowledgeable about safety-related subjects. In sum, there was no substantial evidence for a relation between mothers' SES and their actual taking of safety measures and their behavioural determinants. But, mothers' SES was related to exposure to safety education messages: compared to mothers with a higher level of education, those with a low education were less exposed to safety education through interpersonal channels.

\section{METHODOLOGICAL AND THEORETICAL ISSUES}

In evaluating the community campaign (chapter 2 ) we tried to provide an insight into the causal chain from the development and implementation of the community cam- 


\section{Chapter 7}

paign to the expected outcomes. Therefore, not only the effects on parental knowledge, beliefs and the taking of safety measures were evaluated, but detailed information was also provided about the components of the campaign by means of process evaluation. The results of the process evaluation appeared to be valuable for interpreting the lack of effects at a behavioural level. However, in carrying out this process evaluation we experienced difficulties especially with respect to the involvement of local organizations, in particular their cooperation with the CSI. On the one hand these difficulties stem from the fact that in general the methods involved in process evaluation are less well defined (Nutbeam et al., 1992), while on the other no detailed campaign goals were formulated on this subject. Obviously, this made it difficult to formulate research goals. Notwithstanding these problems, we may assume from the process evaluation that the lack of effects was due to an implementation failure. Thus, it was unlikely that methodological problems were responsible for the no-effect conclusions. Nevertheless, we were confronted with some methodological shortcomings of the effect evaluation.

Woerden had to be chosen as a control community because of the assessment of changes in the incidence of injuries, a goal of the effect evaluation that was not the focus of this thesis. In the hospital in Woerden the registration of the incidence of childhood injuries took place in the same period as in the hospitals in Nijmegen. A major shortcoming of this control community was the small population of families with pre-school children. In the case where it would have been realistic to expect changes at the community level, these effects could have stayed undetected because of the small number of mothers in the research groups of the control community. Another problem in relation to the effect analysis was that some of the behavioural determinants showed high baseline scores at the pre-test (e.g. the familiarity with some safety measures was very high). Therefore, should the campaign have been influential, these determinants could not have changed any further. On the other hand most of the mothers' safety measures had the opportunity to change, but did not.

In studying safety measures and their behavioural determinants some specific problems related to injury prevention must be addressed. Difficulties experienced in studying parental safety measures were that there are so many safety measures to be 
studied. Within different types of accidents there are many risk situations that often may be prevented by means of more than one safety measure. Therefore, it is nearly impossible for research to study all relevant safety measures regarding injury prevention of pre-school children. However, the possibility to study a selection of safety measures and to consider these safety measures as representative for other measures does not seem feasible since there are indications that safety measures are not interrelated, even not within the same type of accident. Moreover, there is no consensus with respect to the formulation of safety measures ('what is safe?') nor with respect to the developmental period in which the measures should be taken, which makes it difficult for research to operationalize and analyse safety measures. Thus, in order to yield more comparability of studies, future research has to provide a detailed insight into the operationalization and analysis of the safety measures.

Moreover, because mothers reported their own behaviour, social desirability or other threats to the validity of their answers may have happened and may have induced an invalid 'rather safe' or 'safe' judgement. In order to validate the safety measures in our study an observation study was carried out. Observations were made in the houses of 148 mothers who belonged to the research group at the post-test in Nijmegen. Indeed, negative discrepancies were assessed with respect to the 'rather safe' and 'safe' categories (Naber and Lampert, 1989). In addition, it was indicated that the reason for these discrepancies was more due to difficulties parents had in judging their own behaviour than to social desirability. Obviously, conclusions to be made on the basis of 'unsafe' qualified behaviour must be seen as the most valid.

In assessing the behavioural determinants of parental safety measures we used the ASE model with some variables of the HBM and the PMT. In this respect this study may be considered as one of the first attempts to examine behavioural determinants of parental safety measures by means of a social-psychological model of determinants. Although this model may be helpful to achieve a comprehensive impression of the determinants that may influence parental safety measures, the operationalization of the model generally requires many items. Hence, in combination with the high number (18) of safety measures to be studied, too many items would be needed. We tried to deal with this problem by leaving out the 'evaluation of beliefs' and the 
'motivation to comply'. Moreover, we selected a minimum of items, for instance one normative belief was selected in which the partner was the reference person and with respect to only some of the safety measures beliefs on the susceptibility and seriousness of risk situations were measured. Finally, the items were measured by short categorical scales which required a non-linear regression analysis for relating the determinants to safety measures. This method does not provide levels of significance, a feature that is not common in research on behavioural determinants. Although the set of selected items explained the adoption of most of the safety measures well or rather well, we experienced difficulties in the interpretation of some of these items which provided too few clues for safety education.

First, it appeared that unsafe mothers as opposed to safe mothers found their child's chance of being confronted with risk situations at home greater. This finding seems to correspond with the mother's belief on the safety measure, but is in contradiction with the findings of other studies in which it was found that persons with higher objective risks seem to have lower perceived risks (Avis et al., 1989; Niknian et al., 1989; Glik et al., 1991). Probably this finding is the result of an invalid measurement of the susceptibility. When measuring the susceptibility of a child being confronted with a certain risk situation, no reference was made to taking the safety measures that may prevent the risk situation. When mothers with safe behaviour made their estimation of the susceptibility, they probably took into account their safety measures; this may explain why mothers behaving in an unsafe way compared to mothers behaving in a safe way, think their child's susceptibility is higher. In general, according to the HBM the perceived susceptibility should be measured while referring to not adopting the recommended health behaviour. In addition, since specific risk situations are closely related to the child's developmental stage, the measurement of the perceived susceptibility may be further improved by the inclusion of parents' understanding of child development.

Second, another interpretation problem was related to the mothers' belief about the necessity of a safety measure according to the child's age. Mothers who did not acknowledge the necessity of a safety could choose from three altematives: 'not necessary because my child is too young', 'not necessary because the child is too 
old' and 'not necessary at all'. Even when the mother gave an answer that was related to the child's age, it is not clear if the mother rejects the safety measure because she prefers behaviour alternatives instead, namely supervision and/or education. Future research may improve the interpretation of this determinant by including also beliefs on the necessity of supervision and education in order to prevent the same risk situation.

In general, the interpretation of a stage theory instead of a continuum theory like the ASE model may improve the interpretation of the determinants of safety measures even further. At present it is unclear whether unsafe mothers do not (yet) adopt a specific safety measure despite perceiving the risk situation or whether they do not perceive the threat of the risk situation and do not search for a coping strategy anyhow. The model of the Precaution Adoption Process (Weinstein and Sandman, 1992) may be helpful in gaining an insight into the stage parents are in with regard to their preventive thinking. These stages vary from "unaware of the issue" to "maintenance of behaviour".

In addition, a stage theory may spread light on those determinants that must be considered as necessary but not sufficient determinants in influencing parental safety measures, namely the perceived seriousness and the familiarity with safety measures. In our study these determinants did not have a considerable influence next to other determinants. But, for instance, it seems likely that parents have to know how serious specific risk situations may be for their child before they will take actions to prevent these situations arising. By means of a stage theory it will be clearer how these determinants influence parents in which stage in their preventive thinking. For instance, we may be able to assume that parents are unaware of the disastrous effects of coffee and tea since most scalds of pre-school children are due these liquids (Klasen and Ten Duis, 1986). Dishwater detergents and other household products that may cause chemical burns seem to be unknown to parents since they form the largest group of very poisonous agents among children aged 0-4 years (SIG, 1988). A stage theory may reveal in which stage parents are knowledgeable about serious hazards and risk situations. 


\section{Chapter 7}

Finally, in studying the role of SES, mothers' level of education was chosen as a single indicator mainly for practical reasons. Income often is a sensitive topic whereas occupation is complex to analyse. But, in general, education compared to income and occupation is frequently more strongly associated with diseases, which is probably due to its correlation with health practices, lifestyle characteristics and adoption of new medications or procedures (Liberatos et al., 1988). Moreover, recently Winkleby et al. (1992) showed that the relationship between several SES measures and risk factors is strongest and most consistent for education.

\section{IMPLICATIONS FOR SAFETY EDUCATION DIRECTED AT PAR- ENTS}

\section{Content of safety education}

Although a thorough knowledge on the behavioural and educational diagnosis is not available, some implications can already be given regarding the content of safety education messages.

In trying to convince parents to comply with recommended safety measures the first step is to make them aware of the child safety problem so that they will feel the need to cope with the problem. This means that parents have to perceive the threat of childhood injuries; this threat is built up of their perceived susceptibility and seriousness of risk situations pre-school children may be confronted with. In order to give an idea of the child's susceptibility, it has to be explained how the child's developmental process makes each child vulnerable to the specific risk situations. Explaining this to parents may mitigate parental unrealistic optimism (Weinstein, 1984), a belief that an accident will not happen to their child(ren).

Moreover, the most serious type of hazards that may affect children of pre-school age have to be addressed. Parents need to know that many risk situations may have only mild consequences or no consequences at all for their children, but also can badly injure their child or even lead to the child's death. Naturally, to enhance parents' perception of the threat is only allowed when safety measures are available 
to reduce this threat. Only in this way may 'danger control' instead of 'fear control' be realized (Leventhal, 1984).

More or less simultaneously to influencing the perception of the threat which may create a need in parents to cope with the child safety problem, parents have to be convinced of the idea that most accidents are preventable and that their own behaviour is crucial in the process that may lead to an accident. The taking of safety measures must be advocated as an effective strategy in combination with supervision and education of the child. Therefore, the pros of safety measures and the cons of supervision and education have to be addressed. In addition to the child's safety, another advantage of taking safety measures is the peace of mind the parent will get when the child is moving in a safe home environment.

Until now, it has been difficult to set priorities in regard to safety measures that need more or less attention because we have indications that most safety measures need improvement (see chapter 5). This may be due to the fact that, compared to supervision and education that might be seen as rather self-acting behaviour, taking safety measures is more likely to be preceded by a decision making process. Moreover, parents need to be educated on each safety measure separately because there are indications that safety measures do not go together. Thus, instead of stressing the need for safety measures to prevent poisoning, separate safety measures like keeping household products and cosmetics out of reach have to be addressed. The best way to limit the number of safety measures to be advocated is to discuss only those measures that are relevant to the child's developmental stage.

In order to convince parents to take specific safety measures the need for specific safety measures according to risk situations apparent at the child's developmental stage must be discussed. The educator has to create a positive trade-off between the reduction in injury risk and the costs of taking the safety measure. In general, at least parents have to be convinced of the instrumentality of the safety measure in reducing the risk situation and that they will be able to succeed in taking the safety measure. With respect to the latter, we may note that once the taking of safety measures has become habitual, the easier it is to succeed in taking the measure (Van Rijn, 1991). 
Education on child safety by professional intermediaries

Professional intermediaries who have regular contact with parents of pre-school children have an important role in providing safety education to parents. However, it must be recognized that their time is limited because they are responsible for information on the child's health that is also related to other problems than safety. However, professionals are able to reach the majority of parents in the community and therefore are a main chain in providing the community with safety education. In order for professional intermediaries to give safety education to parents first, their organizations need to create a structural basis for giving safety education (see chapter 2). This means that professionals need the time to be trained and guided, but they also need the time in their daily work to attend to child safety. Moreover, the organization has to formulate safety education as a part of their job description. In addition, to give safety education to parents professionals need the tools to be provided by the CSI. A distinction can be made between tools meant for individual safety education at the parents' home and at the child health centre.

Child safety in and around the home lends itself very well to an individual method of education by means of home visits (Laidman, 1987). Therefore, the professional (district nurse or maternity nurse) needs a checklist by means of which risk situations can be systematically observed and discussed. When parents complete the checklist themselves, parents' involvement in assessing hazards may be enhanced. A clear advantage of home visits compared to education at the child health centre is that the problem of child safety will be made visible to the parent in their own home and therefore may make the problem more recognizable. Moreover, the educator may give advice that is well suited to the parents' housing situation. In order to restrict the number of home visits, it is advisable to select families with first-born children since they seem to learn more from safety education and seem to be more willing to comply with advice (see chapter 3 ).

For safety education at the child health centre, district nurses need, in addition to the so-called 'safety cards', a method to bring up the subject of child safety which seems to be a task for the CSI. Kelly et al. (1987) developed a method that consists of an age-appropriate questionnaire to be completed by the parent and the educator. The 
parents' responses to the questionnaire serve as a basis for a dialogue. By means of this strategy active participation of the parent is stimulated which is useful in assessing parents' knowledge on child development safety in combination with risk situations present in their homes.

The use of the checklists mentioned above have to pre-tested on a small scale. By means of the experiences of professionals these checklists may be improved. Irrespective of the place where education will be given, professionals need to be trained and guided thoroughly in giving safety education to parents and in using the educational tools.

It is questionable whether professionals have to be motivated to conduct group sessions on child safety. The organizing of group sessions in general seems to put heavy demands on professionals and takes a lot of time (see chapter 2). This creates extra barriers for them to educate parents on safety. Moreover, when taking into account the parents who visited safety group sessions conducted by volunteers, professionals also may be confronted with this self-selecting phenomena. Therefore, if priorities are to be set in educating parents on child safety, individual education seems to be preferable.

\section{Dutch community campaigns on child safety}

To enhance the success of a Dutch community campaign on child safety it would be advisable for the CSI to change their role when participating in a community campaign. Their role as a resource system must be followed more strictly in the sense that they have to provide resources to local organizations, like injury data, educational materials and trainings for intermediaries. Moreover, the CSI has to fit in with the needs of a community campaign, e.g. with respect to the need to start a campaign on child safety.

In general, all key participants in a community campaign have to agree on the goals to be reached. This may create commitment in reaching these goals and to induce a sense of 'community ownership'. The latter may enhance the chance that the campaign activities will be maintained in the community (Bracht and Tsouros, 1990; Orlandi et al., 1990). 
The higher the campaign goals - for instance changing parental safety behaviour, the more time is needed for a thorough development of high standard activities of which pre-tests of activities have to be a necessary part. Moreover, the need of an adequate implementation period is stressed. To observe measurable effects at the community level enough parents have to come into contact with both mass media messages and interpersonal education activities.

Besides professionals, volunteers may be important in providing the community with safety education because they may substitute and/or complement the educational efforts of professional intermediaries. Obviously, the need for volunteers depends on the organization of child health care in a local community. However, the role of volunteers has to be thoroughly prepared, among other things, by means of pre-tests. Since safety group sessions have disadvantages for volunteers to educate parents, home visits may be a more suitable because they require probably fewer skills from volunteers. Consequently, it may be easier to recruit volunteers from all segments of the community and participation of a representative group of parents in the community will be promoted.

Furthermore, we like to focus on two other aspects that may further improve the impact of child safety education in a community campaign. A community campaign often uses a multi-media approach (Kok and De Vries, 1989). In general, mass media may have the function of enhancing awareness of the problem by giving information on the magnitude of the problem (susceptibility and seriousness). With respect to child safety this is very essential because there are indications that the threat parents experience of childhood injuries seems to be insufficiently present (Wortel et al, in press). In this way mass media can be used to support interpersonal activities.

Finally, a multifaceted approach in which other strategies strengthen the influence of safety education may be more powerful. As in some other community campaigns on child safety (Spiegel and Lindaman, 1977; Gallagher et al., 1985) it would be better to use a combination of strategies, like education together with the distribution and installation of safety devices in the home. For instance, safety equipment may be more available for parents when local shops sell safety products and when local health centres set up a loan scheme. 


\section{REFERENCES}

AJZEN I. Attitude, personality and behavior. Milton Keynes: Open University Press, 1988.

ASSEMA P van, PIETERSE M, KOK G, et al. The determinants of four cancer-related risk behaviours. Health Educ Res 1993;8:461-73.

AVIS N, SMITH K, McKINLAY J. Accuracy of perceptions of heart attack risk: what influences perceptions and can they be changed? Am J Publ Health 1989;79:1608-12.

BETTINGHAUS EP. Health promotion and the knowledge-attitude-behavior continuum. Prev Med 1986;15:475-91.

BRACHT N, TSOUROS A. Principles and strategies of effective community participation. Health Prom Int 1990;5:199-207.

CALNAN M. Pattems in preventive behavior: a study of women in middle age. Soc Sci Med $1985 ; 20 ; 263-8$.

CALNAN M, RUTTER DR. Preventive health practices and their relationship with sociodemographic characteristics. Health Educ Res 1986;1:247-53.

DERSHEWITZ RA. Will mothers use free household safety devices? Am J Diseases Child 1979;133:61-4.

GALLAGHER SS, HUNTER P, GUYER B. A home injury prevention program for children. Pediatr Clin North Am 1985;32:95-112.

GLIK D, KRONENFELD J, JACKSON K. Predictors of risk perceptions of childhood injury among parents of preschoolers. Health Educ Quart 1991;18:285-301.

GREEN LW, KREUTER MW. Health promotion planning, an educational and environmental approach. Mayfield: Mountain View, 1991.

JANZ NK, BECKER MH. The health belief model: a decade later. Health Educ Quart 1984; $11: 1-47$.

KELLY BK, SEIN C, McCARTHY PL. Safety education in a pediatric primary care setting. Pediatr 1987;79:818-24.

KLASEN HJ, DUIS HJ ten. Changing patterns in the causes of scalds in young Dutch children. Burns 1986;12:563-6. 


\section{Chapter 7}

KOK G. Quality of planning as a device determinant of health education effectiveness. Hygie 1992;11:5-8.

KOK G, VRIES H de. Primary prevention of cancers: the need for health education and intersectoral health promotion. In: Heller T, Davey B, Bailey L, eds. Reducing the risk of cancers. London: Hodder and Stoughton, 1989:99-111.

KOK G, VRIES H de, MUDDE AN, STRECHER VJ. Planned health education and the role of self-efficacy: Dutch research. Health Educ Res 1991;6:231-8.

LAIDMAN P. Child safety activities: a guide to their planning. London: CAPT-ECOSA, 1993.

LAIDMAN P. Health visiting and preventing accidents to children. London: Child accident prevention trust, 1987. Research report no.12.

LEVENTHAL H. Findings and theory in the study of fear communications. In: Berkowitz L, ed. Advances in experimental social psychology. Vol. 5. New York: Academic Press, 1984.

LIBERATOS P, LINK BG, KELSEY JL. The measurement of social class in epidemiology. Epidem Rev 1988;10:87-121.

MULLEN PD, GREEN LW, PERSINGER GS. Clinical trials of patient education for chronic conditions: a comparative meta-analysis of intervention types. Prev Med 1985;14:753-81.

NABER AG, LAMPERT EM. 'Het is niet altijd wat het lijkt'. Een onderzoek naar de validiteit van een vragenlijst over maatregelen ter voorkoming van privé-ongevallen van $0-4$ jarigen. ('It is not always what it seems'. Research on the validity of a questionnaire conceming safety measures to prevent home related injuries of pre-school children). Leiden: NIPG-TNO. 1989:58-9.

NIKNIAN M, MCKINLAY SM, RAKOWSKI W, CARLETON RA. A comparison of perceived and objective CVD risk in a general population. Am J Publ Health 1989;79:1653-4.

NUTBEAM D, SMITH C, CATFORD J. Evaluation in health education: a review of progress. possibilities, and problems. J Epidem Comm Health 1990;44:83-9.

ORLANDI MA, LANDERS C, WESTON R, HALEY N. Diffusion of health promotion innovations. In: Glanz K, Lewis FM, Rimer B, eds. Health behavior and health education: theory, research and practice. San Francisco: Jossey-Bass, 1990:288-313. 


\section{General discussion and conclusions}

RIJN OJL van, MEERTENS RM, KOK GJ, BOUTER LM. Determinants of behavioural risk factors for burn injuries. Burns (1991);17:364-70.

RIPPETOE PA, ROGERS RW. Effects of components of protection - motivation theory on adaptive and maladaptive coping with a health threat. J Personal Soc Psychol 1987;52:596604.

ROGERS EM. Diffusion of innovations. New York: The Free Press, 1983.

SIG Zorginformatie. Landelijke medische registratie. Utrecht: SIG, 1982-1988.

SPIEGEL CN, LINDAMAN FC. Children can't fly: a program to prevent childhood morbidity and mortality from window falls. Am J Publ Health 1977;12:1143-7.

VRIES $H$ de, DIJKSTRA M, KUHLMAN P. Self-efficacy: the third factor besides attitude and subjective norm as predictor of behavioral intentions. Health Educ Res 1988;3:273-82.

WEINSTEIN ND. Perceptions of personal susceptibility to harm. In: Mays VM, et al., eds. Primary prevention of AIDS: psychological approaches. Newbury Park: Sage publications, 1989. Volume XIII:142-67.

WEINSTEIN ND. Why it won't happen to me; perceptions of risk factors and susceptibility. Health Psychol 1984;3:431-57.

WEINSTEIN ND, SANDMAN PM. A model of the precaution adoption process: evidence from home radon testing. Health Psychol 1992;11:170-80.

WINKLEBY MA, JATULIS DE, FRANK E, FORTMANN SP. Socioeconomic status and health: how education, income, and occupation contribute to risk factors for cardiovascular disease. Am J Publ Health 1992;82:816-20. 


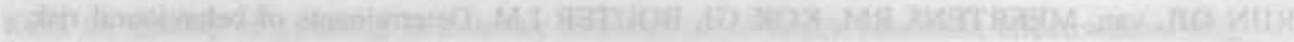

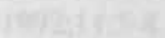

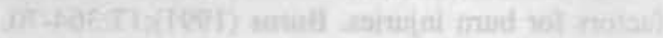

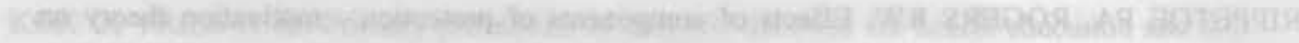

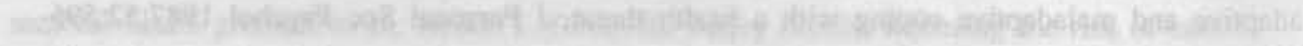

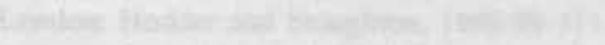

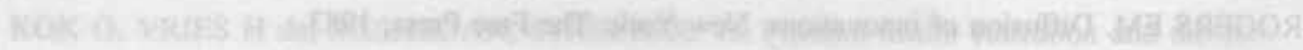

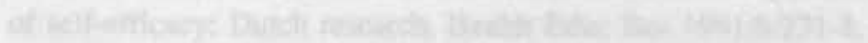

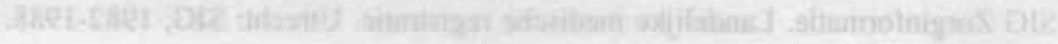

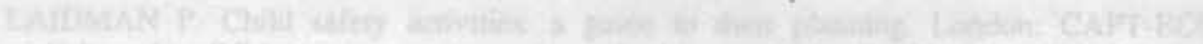

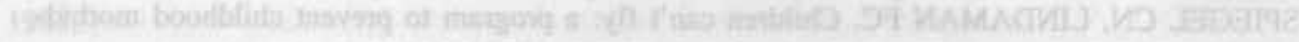

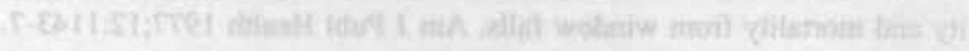

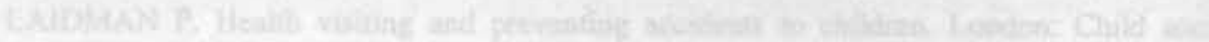

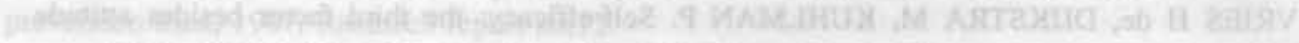

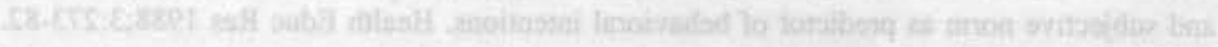

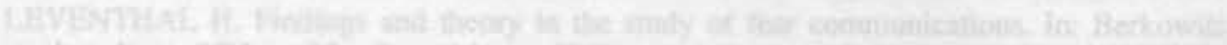

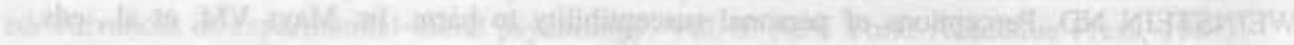

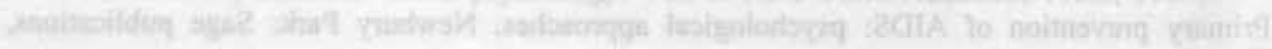

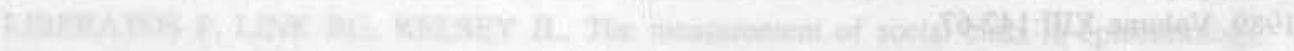

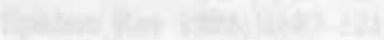

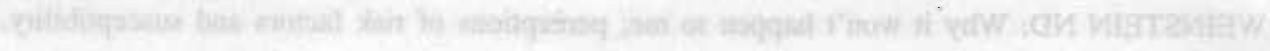

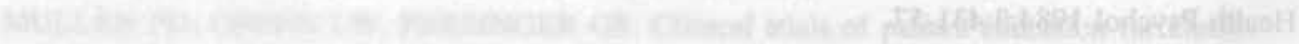

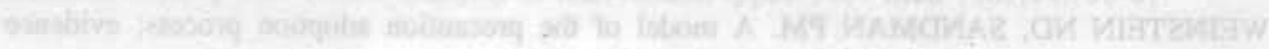

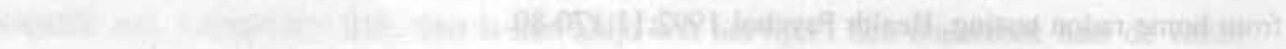

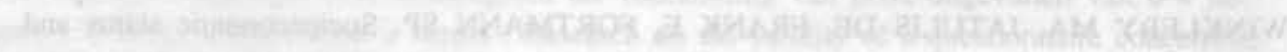

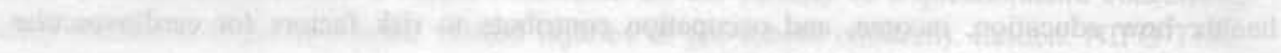

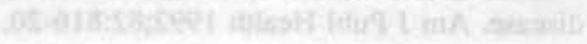

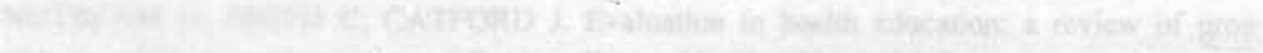

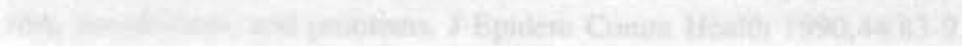

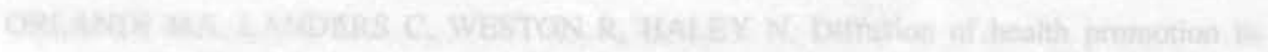

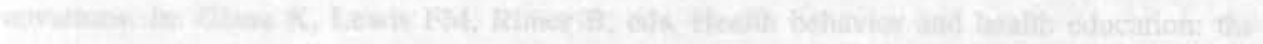

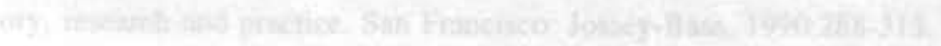




\section{Summary}

Home-related injuries are a major threat to the health of pre-school children in most of the industrialized world. Safety education directed at parents of pre-school children is a main strategy in order to prevent these accidents. The five studies in this dissertation are meant to contribute to the effectiveness of safety education directed at parents.

Chapter 1 presents the background to the studies. The studies are part of a research project that was carried out from 1986 to 1991 by the TNO Institute of Preventive Health Care. The initiative for the research project was a community campaign on child safety that was held in Nijmegen. The Consumer Safety Institute (CSI) and the Ministry of Welfare and Social Affairs decided to start this campaign to reduce childhood injuries by $20 \%$. The TNO Institute evaluated the campaign. More or less simultaneously to the evaluation, three other studies were carried out that can be characterized as studies needed for the development of safety education activities. (For practical reasons we were not able to carry out these studies before the development of the campaign in Nijmegen). A review study was conducted to gain insight into the empirical information available on the parental safety measures to be changed and the underlying behavioural determinants. In addition, two empirical studies were carried out on parental safety measures to prevent poisoning, bums/ scalds and falls and the underlying behavioural determinants of these safety measures respectively.

Chapter 2 presents the results of the effect and process evaluation on the community campaign on child safety in Nijmegen. The CSI installed a committee in which representatives of local (operating) organizations cooperated together with the CSI and the TNO Institute. The committee's task was to see that safety education reached parents in the community through mass media channels as well as via interpersonal channels through professionals who have regular contact with parents of pre-school children. The community campaign showed no effects on parental safety knowledge, beliefs and safety measures. The process evaluation indicated that this was due to an 'implementation failure': too few parents were reached with interpersonal safety education (18\%) which was related to the poor activities of professional inter- 


\section{Summary}

mediaries in combination with the short campaign period. Those parents reached were mainly educated by volunteers who were brought into the campaign when it appeared that professionals would not be able to reach most families with intensive education. Overall, the organizing committee experienced difficulties in the diffusion of high standard safety education at the community level. This can be related to the inadequate preparation and planning of the campaign by the CSI, which resulted in the CSI being not only the initiator of the campaign but also the main executor.

Chapter 3 discusses the role of volunteers as safety educators in the community campaign in Nijmegen. Volunteers invited parents to participate in safety group sessions. Far more parents received interpersonal safety education than would have been the case if the volunteers had not been brought into the campaign. Moreover, these parents gave a positive appraisal of the volunteers' activities and reported an improvement on their knowledge and behaviour. However, the objective to educate parents in most families in the community was not achieved. Too few volunteers worked during the campaign period to reach most parents in the community. Moreover, participating parents were relatively highly educated. This might be due to fact that lower SES parents are less involved in child safety as such, that the volunteers were too different from lower SES parents and/or that group sessions may not fit into these parents' lifestyle.

Chapter 4 provides the current state of knowledge on the parental safety measures to be changed and the underlying behavioural determinants. Among other things, this kind of knowledge is supposed to be necessary in order to develop effective safety education. The review demonstrated that a thorough knowledge about these subjects was not available. Hence on the development of previous safety education programmes no solid basis was apparent. Therefore, those past programmes that did not show behavioural effects may have suffered from 'programme failure' in advance.

In chapter 5 the results on the taking of 18 parental safety measures to prevent poisoning, burns/scalds and falls of mothers with pre-school children were presented. It appeared that many safety measures taken by mothers have to be judged moderately safe or unsafe. The study showed that there is no consistency between safety measures and that some safety measures seem to have a strong cultural element since 
these safety measures are more often applied in other countries. Furthermore, there was no substantial evidence for a relation between mothers' safety measures and their education.

Chapter 6 reports on the behavioural determinants of the 18 safety measures mentioned above. To operationalize the determinants the Attitude- Social influence-Efficacy/barriers model (ASE model) was used with the inclusion of variables from the Health Belief Model and the Protection Motivation Theory. Most safety measures were explained (rather) well by the same set of determinants. Main determinants for adopting or not adopting a safety measure were the mothers' belief in the necessity of the safety measure according to the child's age and her belief about the opinion of her partner on the necessity. Self-efficacy, where relevant, appeared to have an equal impact. Other important determinants were the mother's belief about the inconvenience and instrumentality of the safety measure; perceived susceptibility had a minor or moderate influence on most safety measures. This study did not indicate that more highly educated mothers were more knowledgeable about safety-related subjects. A limitation of the study was related to interpretation problems of one of the main determinants, the belief about the necessity to take the safety measure according to the child's age. This was probably due to the fact that we did not incorporate beliefs about alternative safety behaviours. Moreover, this may be the result of the use of the ASE model instead of a model that entails stages of preventive thinking of the target group.

In the chapter 7 the major outcomes of the studies are reviewed and, overall, the results with respect to mothers' SES have been discussed. Moreover, methodological issues are outlined. The main problems in carrying out the evaluation of the campaign were related to the process evaluation: with respect to the involvement of organizations no detailed goals were formulated and, more generally, the methods involved in process evaluation are less well defined. With respect to the studying of safety measures in particular the lack on consensus about the operationalization and analysis of safety measures was experienced as a barrier. Finally, recommendations were given for practice. The taking of safety measures in combination with supervising and educating the child in particular has to be advocated to parents. 


\section{Summary}

Professional workers in the field of child health need proper tools, training and guidance, but also support from their organizations. In setting up a community campaign the CSI has to be the provider of resources to the community, while local organizations have to initiate and carry out the campaign. 


\section{Samenvatting}

Ongevallen in de privé-sfeer vormen een belangrijke bedreiging voor de gezondheid van kinderen in de leeftijd van 0-4 jaar. Veiligheidsvoorlichting gericht op ouders van deze kinderen is een belangrijke strategie om deze ongevallen te voorkomen. De vijf studies die deel uitmaken van dit proefschrift zijn bedoeld om een bijdrage te leveren aan de effectiviteit van veiligheidsvoorlichting aan ouders.

In hoofdstuk 1 wordt de achtergrond van de studies toegelicht. De studies maken deel uit van een onderzoeksproject dat is uitgevoerd van 1986 tot 1991 door het Nederlands Instituut voor Preventieve Gezondheidszorg TNO (NIPG-TNO)*. De aanleiding voor het onderzoeksproject was een lokale veiligheidscampagne uitgevoerd in Nijmegen. De Stichting Consument en Veiligheid (SCV) en het Ministerie van Welzijn, Volksgezondheid en Cultuur (WVC) besloten om deze campagne te starten met het doel ongevallen van kinderen te reduceren met $20 \%$. Het NIPG-TNO evalueerde de campagne. Min of meer tegelijkertijd met de evaluatie zijn drie andere studies uitgevoerd, welke zijn te typeren als studies die nodig zijn voor de ontwikkeling van effectieve veiligheidsvoorlichting (om praktische redenen waren we niet in staat om deze studies voorafgaand aan de Nijmeegse campagne uit te voeren). Een overzichtsstudie had tot doel inzicht te verkrijgen in de empirische kennis met betrekking tot veiligheidsmaatregelen die ouders van 0-4 jarigen treffen en de gedragsdeterminanten die aan die maatregelen ten grondslag liggen. Daamaast zijn twee empirische studies uitgevoerd met betrekking tot maatregelen die ouders treffen om vergiftiging, verbranding en vallen te voorkomen en de gedragsdeterminanten van die maatregelen.

In hoofdstuk 2 wordt ingegaan op de resultaten van de effect- en procesevaluatie van een lokale veiligheidscampagne die is gehouden in Nijmegen. De SCV heeft een commissie opgericht, waarin vertegenwoordigers van lokale en lokaal opererende organisaties samenwerkten met de SCV en TNO. De commissie had de taak om ouders in de gemeente te bereiken met veiligheidsvoorlichting zowel via massamediale kana-

* Met ingang van 1 januari 1994 is de naam van het NIPG-TNO veranderd in TNO Preventie en Gezondheid (TNO-PG). 


\section{Samenvatting}

len als via interpersoonlijke kanalen door professionals die regelmatig contact hebben met ouders van 0-4 jarigen. De lokale campagne had geen effecten op de kennis van ouders, noch op hun opvattingen en veiligheidsmaatregelen. De procesevaluatie heeft aangegeven dat dit te maken had met een 'implementatie-fout': te weinig ouders zijn bereikt met veiligheidsvoorlichting via interpersoonlijke kanalen (18\%) hetgeen samenhing met de beperkte activiteiten van professionele intermediairs en met de korte campagneduur. De ouders die wel zijn bereikt, zijn vooral voorgelicht door vrijwilligers die onderdeel zijn uit gaan maken van de campagne toen bleek dat professionals niet in staat zouden zijn om de meeste families met intensieve voorlichting te bereiken. Al met al heeft de organiserende commissie problemen ervaren in het verspreiden van kwalitatief goede veiligheidsvoorlichting op gemeentelijk niveau. Dit kan weer in verband worden gebracht met een onvoldoende voorbereiding en planning van de campagne door de SCV hetgeen ertoe leidde dat de SCV niet alleen de initiator van de campagne was, maar ook de belangrijkste uitvoerder.

In hoofdstuk 3 wordt de rol van vrijwilligers als veiligheidsvoorlichters in de campagne in Nijmegen besproken. Deze vrijwilligers hebben ouders uitgenodigd te participeren in een groepsbijeenkomst. Veel meer ouders zijn met interpersoonlijke veiligheidsvoorlichting bereikt dan wanneer vrijwilligers niet in de campagne waren ingezet. Bovendien hebben deze ouders de activiteiten van de vrijwilligers positief gewaardeerd en gaven zij aan dat hun kennis en gedrag was verbeterd. Echter, het doel om ouders van de meeste families in de gemeente voorlichting te geven is niet gerealiseerd. Te weinig vrijwilligers hebben gedurende de campagne gewerkt om de meeste ouders te bereiken. Daar komt bij dat de meeste ouders die wel bereikt zijn relatief hoger opgeleid waren. Dit hangt waarschijnlijk samen met het feit dat lager opgeleide ouders minder geïnvolveerd zijn in het onderwerp 'kinderveiligheid', dat de opleiding van de vrijwilligers te veel verschilde van lager opgeleide ouders en/of dat groepsbijeenkomsten minder goed passen in de leefstijl van lager opgeleide ouders.

In hoofdstuk 4 wordt een overzicht gegeven van de huidige kennis over veiligheidsmaatregelen die ouders treffen en de gedragsdeterminanten die daarbij van invloed zijn. Dergelijke kennis wordt, onder andere, noodzakelijk geacht om effectieve veiligheidsvoorlichting te ontwikkelen. De overzichtsstudie heeft laten zien dat gedegen 
kennis over deze onderwerpen niet voorhanden was. Dus ten tijde van de ontwikkeling van eerdere veiligheidsprogramma's was geen solide basis aanwezig. Dit maakt het aannemelijk dat eerdere programma's die geen effecten hebben laten zien op onder meer gedrag van ouders, a priori hebben geleden aan een zogenaamde 'programma-fout'.

In hoofdstuk 5 worden de resultaten beschreven met betrekking tot 18 veiligheidsmaatregelen die moeders van 0-4 jarigen treffen ter preventie van vergiftiging, verbranding en vallen. Het bleek dat de meeste veiligheidsmaatregelen die moeders nemen, beoordeeld moeten worden als 'tamelijk veilig' of 'onveilig'. De studie heeft laten zien dat er tussen de veiligheidsmaatregelen geen consistentie is en dat sommige maatregelen sterk cultureel bepaald lijken te zijn, omdat ze in andere landen vaker worden getroffen. Verder bleek er geen substantieel bewijs te zijn voor een relatie tussen het treffen van veiligheidsmaatregelen en de opleiding van de moeders.

In hoofdstuk 6 wordt ingegaan op de gedragsdeterminanten van de 18 veiligheidsmaatregelen die onderzocht zijn in het vorige hoofdstuk. De operationalisatie van de determinanten is gedaan met behulp van het Attitude-Sociale invloed-Eigen effectiviteit model (ASE model) met daarin opgenomen variabelen uit het 'Health Belief Model' en de Protectie Motivatie Theorie. De meeste maatregelen zijn (tamelijk) goed verklaard met behulp van dezelfde set van determinanten. Belangrijke determinanten bij het wel of niet treffen van een veiligheidsmaatregel waren de moeder's opvatting over de noodzaak van de maatregel gezien de leeftijd van het kind en haar opvatting over de mening van haar partner over de noodzaak van de maatregel. Daar waar dat relevant was, bleek de 'eigen-effectiviteit' een even grote invloed te hebben. Andere belangrijke determinanten waren de moeder's opvatting over het ongemak en de effectiviteit van de maatregel; de waargenomen kans had een kleine of matige invloed op het treffen van de maatregelen. Deze studie heeft niet kunnen aantonen dat hoger opgeleide ouders meer kennis hadden over aan veiligheid gerelateerde kennis. Een beperking van de studie was met name het interpretatieprobleem dat optrad bij één van de belangrijkste determinanten, de opvatting over de noodzaak van de maatregel gezien de leeftijd van het kind. Dit had waarschijnlijk te maken met het feit dat we geen opvattingen hebben gemeten over alternatief veiligheidsgedrag. Bovendien, is 


\section{Samenvatting}

dit mogelijk het. gevolg van het gebruik van het ASE model in plaats van een model dat stadia van preventief denken van de doelgroep weergeeft.

In hoofdstuk 7 is een overzicht gegeven van de belangrijkste bevindingen van de studies. De resultaten met betrekking tot de sociaal-economische status van moeders die in de afzonderlijke studies aan bod zijn gekomen, zijn apart besproken. Daarnaast zijn methodologische problemen in kaart gebracht. Belangrijke problemen in het uitvoeren van de evaluatie van de campagne hadden betrekking op de procesevaluatie: er waren geen gedetailleerde doelen geformuleerd met betrekking tot het involveren van organisaties, en meer in het algemeen, zijn de methoden die gebruikt worden bij een procesevaluatie minder goed beschreven. Met betrekking tot het bestuderen van veiligheidsmaatregelen bleek met name het gebrek aan consensus over de operationalisatie en analyse van die maatregelen een lastige zaak. Tenslotte zijn aanbevelingen gedaan voor de praktijk. Het treffen van veiligheidsmaatregelen samen met toezicht houden en het kind opvoeden zou ouders vooral aanbevolen moeten worden. Professionals die regelmatig contact hebben met ouders van 0-4 jarigen hebben geschikte middelen, training en begeleiding nodig, maar ook ondersteuning vanuit hun organisatie. Tenslotte zou de SCV bij het opzetten van een lokale veiligheidscampagne haar kennis en middelen beschikbaar moeten stellen aan de gemeente, terwijl lokale organisaties het initiatief voor de campagne moeten nemen en de campagne moeten uitvoeren. 


\section{Dankwoord}

Na gedane arbeid is het goed even stil te staan bij degenen die hun steentje hieraan hebben bijgedragen.

Veel dank ben ik verschuldigd aan Gerard de Geus (Stichting Consument en Veiligheid) die mij zowel tijdens het onderzoekstraject als bij het schrijven van de artikelen steun geboden heeft. De samenwerking met hem gaf mij vaak de inspiratie en het enthousiasme om aan het proefschrift te werken.

Hein de Vries (vakgroep GVO, RL) dank ik voor zijn goede adviezen vanaf de beginfase, zijn actieve betrokkenheid bij het laatste artikel (zijn behendige streepvaardigheid was heel bruikbaar), voor zijn morele steun en handige tips.

Van de promotores dank ik Gerjo Kok voor zijn pragmatische instelling en grote bereikbaarheid via de telefoon (misschien ga ik die korte telefoontjes wel missen) en Cees van Woerkum ben ik erkentelijk voor zijn verfrissende commentaar dat het onderzoek toch in een heel ander daglicht kon stellen.

In het kader van het uitvoeren van het onderzoeksproject gaat mijn dank uit naar Wil Ooijendijk (TNO-PG) voor zijn constructieve samenwerking en naar Jan Radder (TNO-PG) voor zijn geduldige advisering bij de statistische analyses. Ans Naber en Marlies Lampert, destijds stagiaires bij de LU Wageningen, hebben een waardevolle bijdrage geleverd door het consciëntieus uitvoeren van de observatiestudie.

Ten behoeve van de procesevaluatie was de samenwerking met Louisa Bosker (Stichting Consument en Veiligheid) heel vruchtbaar; bovendien vormde zij mijn schakel naar de praktijk, een groot goed voor de toegepast onderzoeker!

José van Helden komt dank toe voor haar enthousiaste projectassistentie en secretariële ondersteuning, Henny Knijnenburg voor haar punctuele secretariële inzet, Ellen Bergsma en Bob Wilkinson voor de nodige correcties van het Engels, Lidy-Marie Ouwehand voor haar ondersteuning bij de literatuurstudie en ten slotte Winnie Schats en Henk Koffijberg (Stichting Consument en Veiligheid) voor hun veelvuldige en snelle toelevering van de benodigde kinderveiligheidsliteratuur gedurende al die jaren (ik heb begrepen dat ik de grootste externe afnemer was).

Mijn werkgever, TNO-PG, dank ik voor het scheppen van de structurele voorwaarden die het schrijven van een proefschrift mede mogelijk maken. Met name mijn 
afdelingshoofden, Harry van de Water en Jan Dul, hebben zich hiervoor sterk gemaakt.

Verder dank ik mijn vrienden en collega's voor de blijvende interesse voor 'hoever het er nu mee stond'.

Ten slotte dan het thuisfront. Het feit dat Theo zelf blootgesteld is geweest aan promotieperikelen werkte in mijn voordeel: minder goede stemmingen kregen weinig negatieve aandacht en aan ruimte om te gaan werken was, hoewel niet altijd tot mijn genoegen, geen gebrek! En .... hoewel zij zich daar nog niet van bewust is, is mijn dochter Feliek de ultieme motor geweest in de slotfase. Door haar werd mijn motto: 'geen getreuzel meer achter die pc, maar van de zomer met Feliek op de fiets!' 


\section{Curriculum Vitae}

Edith Wortel werd op 2 januari 1960 in Leeuwarden geboren. In 1978 behaalde zij haar diploma aan het Stedelijk Gymnasium te Leeuwarden. In 1979 begon zij de studie Psychologie aan de Rijksuniversiteit Groningen en sloot deze studie af in 1986 met als specialisatie Sociale Psychologie.

Vanaf april 1986 is zij werkzaam als wetenschappelijk medewerker bij TNO Preventie en Gezondheid (voorheen Nederlands Instituut voor Praeventieve Gezondheidszorg TNO, NIPG-TNO). Binnen dit instituut werkte zij tot en met 1990 in de sector Basisgezondheidszorg en Epidemiologie. In die periode is het onderzoek verricht ten behoeve van dit proefschrift. Sinds januari 1991 werkt zij in de sector Houdings- en Bewegingsonderzoek, divisie Arbeid en Gezondheid, waar zij zich vooral bezighoudt met veranderingskundige projecten in bedrijven en organisaties ter verbetering van de arbeidsomstandigheden. 